\title{
Large ants are not easy - the taxonomy of Dinoponera Roger (Hymenoptera: Formicidae: Ponerinae)
}

\author{
Amanda Martins DIAS ${ }^{\oplus_{1, *}}$ \& John Edwin LATTKE ${ }^{\oplus_{2}}$ \\ ${ }^{1,2}$ Universidade Federal do Paraná, Departamento de Zoologia, Curitiba, Paraná, Brazil. \\ *Corresponding author: amandamdbio@gmail.com \\ ${ }^{2}$ Email: lattke@ufpr.br \\ ${ }^{1}$ urn:lsid:zoobank.org:author:D8E29645-E8DC-419D-ADFB-7ECA76541FCD \\ ${ }^{2}$ urn:1sid:zoobank.org:author:7AE0D94C-619B-4E77-B16F-3F18731EE390
}

\begin{abstract}
The taxonomy of the giant ants of the genus Dinoponera is revised based on female and male morphology. Eight species are recognized. Dinoponera nicinha sp. nov., from Amazonas and Rondônia, Brazil, is described and D. grandis (Guérin-Méneville, 1838) is revived. The species D. australis Emery, 1901 and D. snellingi Lenhart, Dash \& Mackay, 2013, plus the subspecies D. australis bucki Borgmeier, 1937 and D. australis nigricolor Borgmeier, 1937 are synonymized under D. grandis sp. rev. An unnamed and unidentified male is reported. In general, male morphology has greater and more discrete variation than in females, but they are scarce in museum collections. Species distributions are updated and illustrated, the genus ranging from southern Colombia to northern Argentina, with no reliable records from the Guiana Shield and all nominal species occurring in Brazil. Intraspecific variation and natural history are discussed. New illustrated identification keys are provided for both sexes. Future studies should address the collection of fresh specimens for molecular work and to assess the conservation status of several species and populations.
\end{abstract}

Keywords. Cryptic species, gamergate, predatory ants, South America, threatened ants.

Dias A.M. \& Lattke J.E. 2021. Large ants are not easy - the taxonomy of Dinoponera Roger (Hymenoptera: Formicidae: Ponerinae). European Journal of Taxonomy 784: 1-66. https://doi.org/10.5852/ejt.2021.784.1603

\section{Introduction}

Ants of the ponerine ant genus Dinoponera Roger, 1861 may have a body length exceeding $3.5 \mathrm{~cm}$, making them the genus with the largest known ant workers. They are exclusively South American, with their center of diversity in Brazil, the only country where all described species can be found. Dinoponera was described by J. Roger (1861) to include Ponera gigantea Perty, 1833 and Ponera grandis GuérinMéneville, 1838, the latter being considered a junior synonym by Roger. According to the principle of taxonomic priority, Dinoponera gigantea was defined as the valid name of the species (Bequaert 1926). Since then, several authors have used variations in size, integument brightness, petiole shape and male color to name such forms as subspecies and varieties of D. gigantea (Emery 1901; Santschi 1921, 1928; 
Borgmeier 1937). Borgmeier (1937) raised one variety to species, D. australis Emery, 1901, on account of male morphological differences.

The first taxonomic revision of Dinoponera was carried out by Kempf (1971). He elevated several subspecies and varieties previously described by Emery (1901) and Santschi (1921) to species, providing detailed descriptions and increasing the number of species from two to seven. One of the species he described, D. opaca Kempf, 1971, was later synonymized by Kempf (1975) himself. The taxonomy of the group remained untouched until Lenhart et al. (2013) revised the genus. These authors described two new species as well as the male of one known species. Schmidt (2013) found the genus to be the sister group to Pachycondyla Smith, 1858 using molecular data. Schmidt \& Shattuck (2014) provided a morphological and natural history synopsis of the genus. Tozetto \& Lattke (2020) described, imaged and analyzed the genitals of several species of Dinoponera in a comparative study.

Despite these studies, significant problems still overshadow the taxonomy of Dinoponera. Despite their spectacular large size, a trait that would conceivably make them attractive to even general insect collectors, there are surprisingly few specimens of these ants in collections. This relative dearth of specimens negatively affects both our knowledge regarding their distribution and about the intraand interspecific variability of the species. Another problem concerns the species only known by one sex, such as D. hispida Lenhart, Dash \& Mackay, 2013, D. mutica Emery, 1901 (only females) and D. snellingi Lenhart, Dash \& Mackay, 2013 (only males). Here we revise the species of Dinoponera, using the largest amount yet studied of females and males, mostly from Brazilian institutional collections. We describe a new species, revive one name and synonymize two species and two subspecies. We also redescribe the known species, discuss their morphological variability and natural history, and provide distribution maps and images for all species. We also provide new identification keys for females and males that take intraspecific variability into account.

\section{Material and methods}

\section{Repositories}

We examined 1145 specimens of Dinoponera from the following institutions:

$\begin{aligned} \text { CASC = } & \text { California Academy of Sciences, San Francisco, California, USA } \\ \text { CPDC }= & \text { Centro de Pesquisas do Cacau, Comissão Executiva do Plano de Lavoura Cacaueira, } \\ & \text { Ilhéus, Bahia, Brazil } \\ \text { DZUP }= & \text { Departamento de Zoologia da Universidade Federal do Paraná, Coleção Entomológica } \\ & \text { Padre Jesus Santiago Moure, Universidade Federal do Paraná, Curitiba, Paraná, Brazil } \\ \text { ICNC } & \text { Instituto de Ciencias Naturales, Universidad Nacional de Colombia, Bogotá DC, Colombia } \\ \text { INPA = } & \text { Instituto Nacional de Pesquisas da Amazônia, Manaus, Amazonas, Brazil } \\ \text { MCSN = } & \text { Museo Civico di Storia Naturale "Giacomo Doria", Genoa, Italy (one type examined by } \\ & \text { images available at www.antweb.org) } \\ \text { MCZC = } & \text { Museum of Comparative Zoology, Harvard University, Cambridge, Massachusetts, USA } \\ \text { MNHNP = } & \text { Museo Nacional de Historia Natural del Paraguay, San Lorenzo, Asunción, Paraguay } \\ \text { MPEG = } & \text { Museu Paraense Emílio Goeldi, Belém, Pará, Brazil } \\ \text { MZSP = } & \text { Museu de Zoologia da Universidade de São Paulo, São Paulo, Brazil } \\ \text { UEG = } & \text { Laboratório de Pesquisa Ecológica e Educação Científica, Universidade Estadual de } \\ & \text { Goiás, Anápolis, Goiás, Brazil } \\ \text { UEMS = } & \text { Laboratório de Ecologia Comportamental, Universidade Estadual do Mato Grosso do Sul, } \\ & \text { Dourados, Mato Grosso do Sul, Brazil } \\ \text { UFES }= & \text { Laboratório de Biodiversidade de Insetos (LABI), Universidade Federal do Espírito Santo, } \\ & \text { Vitória, Espírito Santo, Brazil }\end{aligned}$




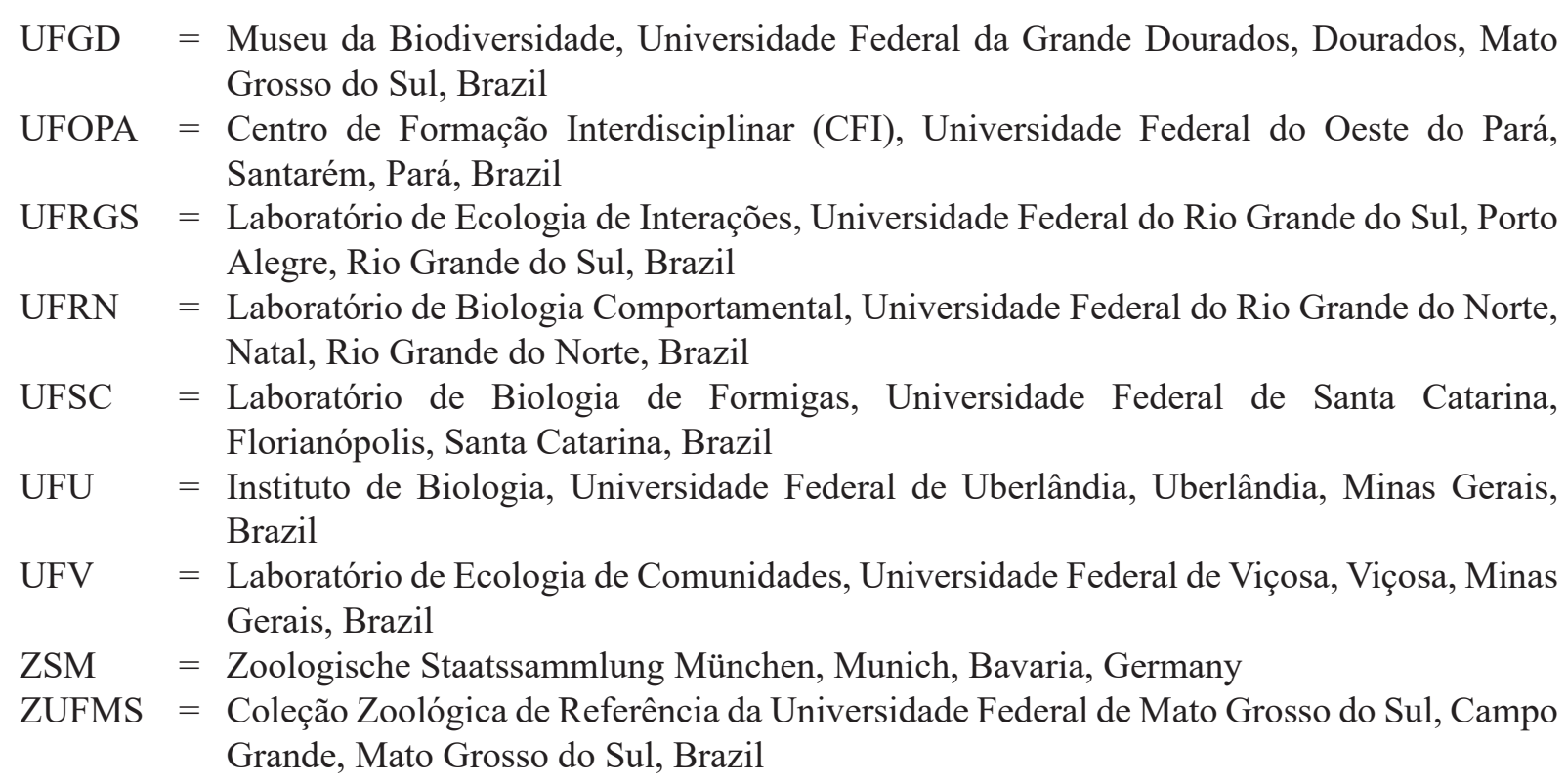

All legible label data was transcribed for the 'Material examined' section of each species account. Quotes of label text that could not easily be made to conform to the presentation format of the journal are provided within citation marks. In the case of two or more sequential series of specimens sharing some data, the term 'same locality as for preceding' was used when just locality data is shared, and the term 'same collection data as for preceding' was used when more information is shared. Different pieces of information were transcribed normally after these terms, if applicable. The symbol $\zeta$ is used to indicate females (workers) and $\widehat{\partial}$ for males.

\section{Morphology}

All female specimens, regardless of reproductive status, are referred to as females. Terms used for external morphology follow Bolton (1994), Keller (2011) and Boudinot (2015). Surface sculpturing follows Harris (1979) and hair position follows Wilson (1955). Male genitalia follow Boudinot (2013) and Tozetto \& Lattke (2020). The male genital capsule was extracted from all possible specimens, except when it already lacked genitalia or gaster. Most of the dissections were done previously by Tozetto \& Lattke (2020) and additional dissections followed their procedures.

Characters that are shared throughout the genus are not repeated in each species description. For the head the term "internal" is used for structures closest to the median longitudinal cephalic axis and "external" for structures closest to the lateral cephalic margin.

Cold light sources are recommended for examining these ants and optics with at least $32 \times$ magnification and an ocular micrometer. Dried specimens of Dinoponera frequently have layers and deposits of fat on their bodies that obscure the observation of finer sculptural features. The careful use of a fine brush moistened with alcohol may help to dislodge or partially dissolve some of these deposits.

\section{Measurements}

Measurements were taken using a Zeiss Stemi DV4 stereoscope with a micrometer in a $10 \times$ ocular lens. All measurements are expressed in $\mathrm{mm}$. Among the criteria used for selecting specimens for measuring we considered those representing the largest and smallest intraspecific variance. The number of measured specimens is placed between parentheses at the beginning of each 'measurements' section in the species accounts. The dimensions of type specimens, when measured, are given separately from those of other specimens. Most measurements, indices and their acronyms are based on Lattke (2011), Lenhart et al. (2013) and Escárraga et al. (2017), and are listed below (Figs 1-2). Each measurement is followed by 
'male' and/or 'female', indicating the sex measured. A spreadsheet with all measurements and indices for each measured specimen is available at www.zenodo.org (https://doi.org/10.5281/zenodo.5168830).

ASL $=$ Abdominal sternites III and IV, length. In lateral view, a longitudinal line from the anteriormost point of abdominal sternite III to the distal edge of abdominal sternum IV. Male.

ATS = Abdominal tergites III and IV, size. In lateral view, a diagonal line from the anteriormost point of abdominal sternite III to the posteriormost point of abdominal tergite IV. Female.

$\mathrm{EL} \quad=$ Eye length. In full-face view, maximum length from anterior to posterior margin of compound eye. Male.

$\mathrm{HBL}=$ Hind basitarsus length. Maximum length of hind basitarsus in lateral view. Female.

$\mathrm{HFL}=$ Hind femur length. Maximum length of hind femur in lateral view, from the end articulation with the trochanter to the apex of the articulation with the tibiae. Female and male.

$\mathrm{HL}=$ Head length. In full-face view, a median line traced on the head from the mid-point of the anterior clypeal margin to the posterior head margin. Female and male.

$\mathrm{HW}=$ Head width. Maximum width of head in full-face view. Female.

HW1 = Head width. Maximum width of the head in full-face view, including the compound eyes. Male.

LOD = Lateral ocellus diameter. Maximum diameter of lateral ocellus with head positioned such that the anterior and posterior margins of the lateral ocellus are in the same focal plane. Male.

$\mathrm{MDL}=$ Mandible length. In full-face view, a straight line distance from the mandibular apex to the external margin of the articulation with the clypeus. Female and male.

MOD $=$ Median ocellus diameter. Maximum diameter of median ocellus with head positioned such that the anterior and posterior margins of the median ocellus are in the same focal plane. Male.

MSL = Mesosoma length. In profile, a diagonal line from the middle point between the anterior and dorsal faces of the pronotum to the posteroventral metapleural corner. Female and male.

$\mathrm{PH}=$ Petiole height. Maximum height of petiole in profile, tracing a transverse line between the dorsal and ventral margins (with sternum). Female and male.

$\mathrm{PL} \quad=$ Petiole length. In profile, maximum longitudinal length between the anterior and posterior margins of the petiolar node. Female.

PL1 = Petiole length. Length of petiole in profile from the inflection point of the petiolar presclerites to the most posterior point of the sclerite. Male.

$\mathrm{PW}=$ Petiole width. Maximum width of petiole in dorsal view tracing a transverse line between the lateral margins. Female and male.

$\mathrm{SL}=$ Scape length. Maximum length of first antennomere along its anterior surface without the bulbus and radicular constriction. Female and male.

$\mathrm{BL}=$ Body length. Sum of MDL, HL, MSL, PL and ATS. Female.

BL1 = Body length. Sum of MDL, HL, MSL, PL1 and ASL. Male.

Indices:

$\mathrm{CI}=$ Cephalic index: HW/HL. Female.

CI1 = Cephalic index: HW1/HL. Male.

DPI $=$ Dorsal petiole index: PW/PL. Female.

SEI $=$ Scape-eye index: EL/SL. Male.

SI = Scape index: SL/HW. Female.

SI1 = Scape index: SL/HW1. Male.

\section{Images and maps}

Ant images were obtained using a Zeiss Stereo Discovery V20 stereo microscope with a Zeiss Axiocam 305 color video camera. Due to the enormous size of these ants, separate pictures were taken of the anterior and posterior regions of the body for the lateral and dorsal views. Image stacks were combined 


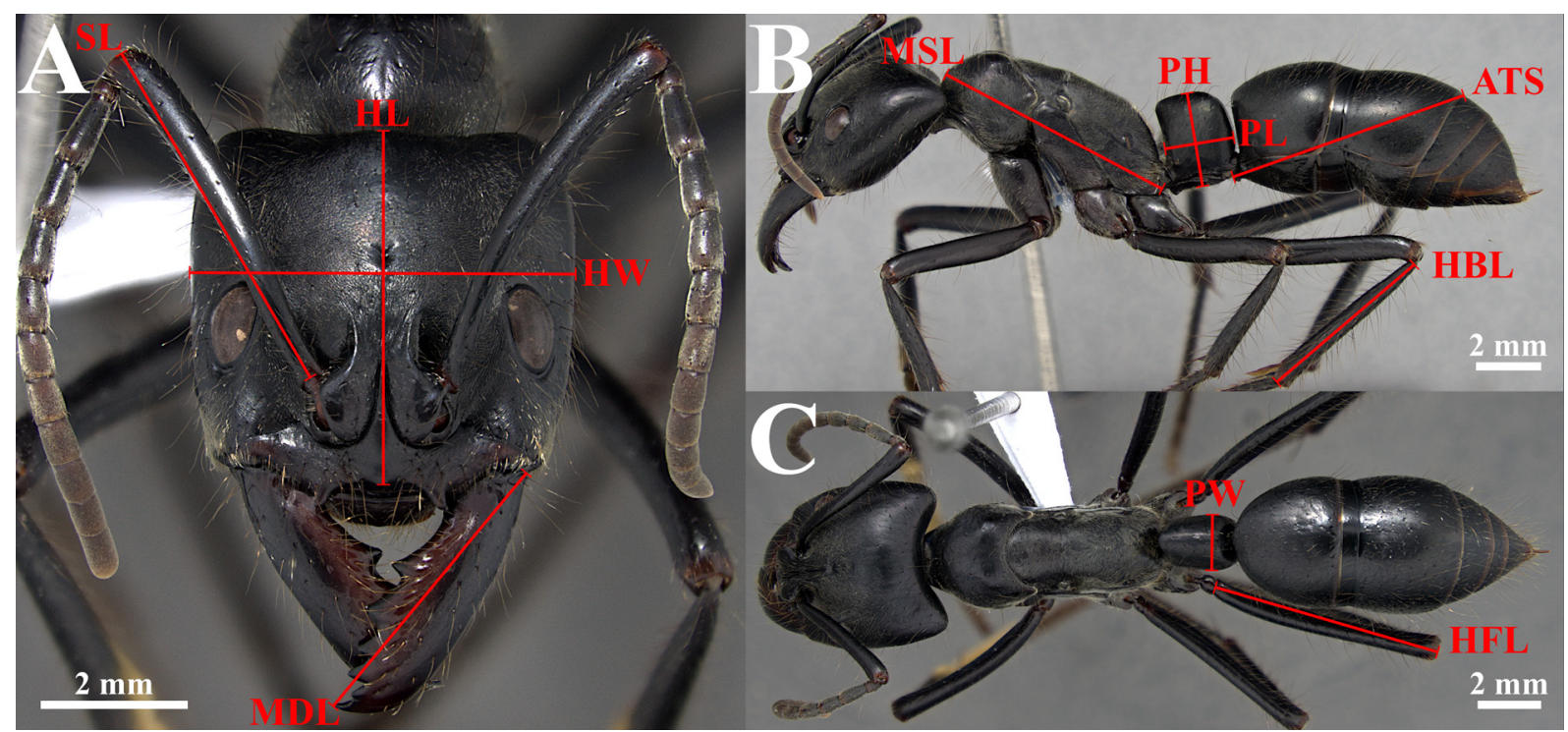

Fig. 1. Measurements of Dinoponera quadriceps Kempf, 1971, ఫ (DZUP 549811). A. Full-face view. B. Full body in lateral view. C. Full body in dorsal view.

with Zerene Stacker ver. 1.04. Images of the anterior and posterior body regions were stitched with Photoshop CC 14. All images were edited using GIMP ver. 2.10.8.

One specimen of each sex and species was photographed. Additionally, the lectotype and two paralectotypes of Ponera gigantea, and the lectotypes of Dinoponera australis bucki and D. australis nigricolor were also imaged and are available at www.antweb.org (ZSM HYM-25181, ZSM HYM25182, ZSM HYM-25183, MZSP 65800, and MZSP 65801, respectively).

Distribution maps were created using QGis ver. 3.16.0 and are based on the locality data for examined specimens only. In the case of specimens with no coordinates the specimen was georeferenced using the central point of the smallest locality on the label using Google Earth.

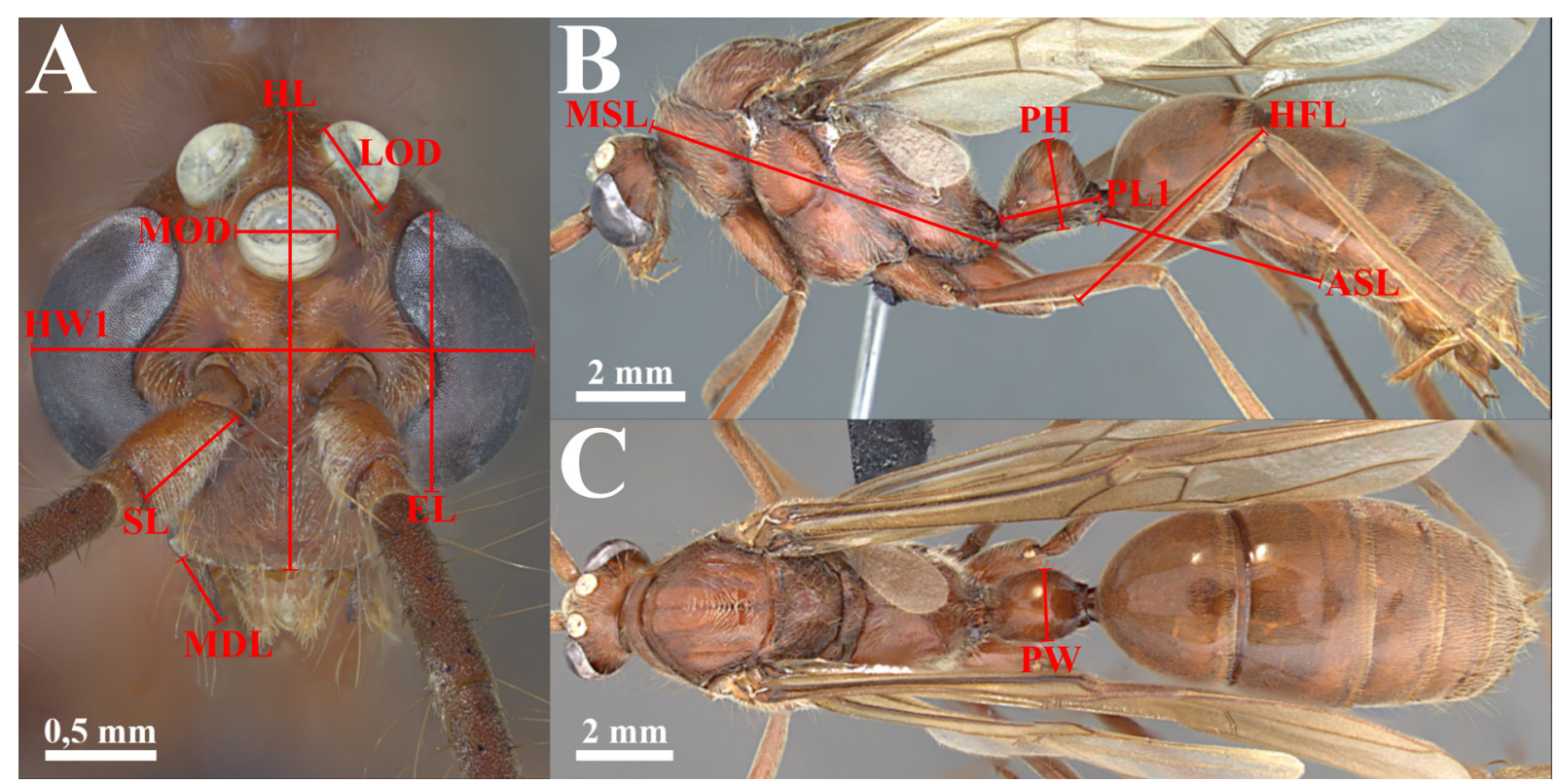

Fig. 2. Measurements of Dinoponera quadriceps Kempf, 1971, $\widehat{o}$ (DZUP 549804). A. Full-face view. B. Full body in lateral view. C. Full body in dorsal view. 


\title{
Results
}

\author{
Class Insecta Linnaeus, 1758 \\ Order Hymenoptera Linnaeus, 1758 \\ Family Formicidae Latreille, 1809 \\ Subfamily Ponerinae Lepeletier de Saint-Fargeau, 1835
}

Genus Dinoponera Roger, 1861

Dinoponera Roger, 1861: 37 (type species: Ponera gigantea Perty, 1833).

\section{Diagnosis}

Female

Mandible subtriangular. Anterior clypeal margin with lateral tooth along same longitudinal axis as antennal insertion. Head width greater than $4 \mathrm{~mm}$. Pygidium and hypopygium each with lateral row of stout setae. Body length (BL) longer than $22 \mathrm{~mm}$.

\section{Male}

Head width, including compound eyes, greater than $2.1 \mathrm{~mm}$. Abdominal pretergite IV with stridulatory file. Meso- and metatibiae each with two pectinate spurs at apex. Easily diagnosed among Ponerinae by the large size (BL1>12 mm).

\section{Redescription}

\section{Female}

Measurements. Body length greater than $22 \mathrm{~mm}$. Head width greater than $4 \mathrm{~mm}$.

HEAD. In full-face view sub-rectangular, posterior margin concave, lateral margins subparallel, broadly convex. Anterior clypeal margin in frontal view with lateral tooth along same longitudinal axis as antennal insertion; clypeal disc with longitudinal raised area that narrows posteriorly between frontal lobes. Clypeal disc generally microareolate, laterally smooth to striate; anterior margin with hairs as long as or longer than clypeal tooth; external side of tooth usually with row of short hairs. Anterior tentorial pit region with oblique striae. Frontal lobe covers most of antennal insertion, anteriorly distinctly elevated above surrounding cuticle, internal margin forms fine longitudinal strip below frontal lobe surface; anterior region usually areolate, posterior constriction longitudinally striate. Malar area with varying amounts of longitudinal to oblique striae; if present, striae may reach all of anterior ocular margin and extend to gena, rarely surpassing posterior ocular margin. Gena may be smooth and shining to microareolate and opaque; pilosity variable. Anterior gena with or without longitudinal striae and variable appressed pubescence. Eye elliptical to broadly convex, placed on anterior half of head, occupying less than one-fourth of lateral cephalic margin, not reaching lateral cephalic margin in fullface view; circumocular sulcus present. Appressed pubescence present between eye and frontal lobe, extending posteriorly to frons. Frons smooth and shining to microareolate and opaque; insertion of hairs scalloped, posteriorly fading (particularly noticeable in $D$. hispida); pilosity variable; pubescence usually very sparse on median portion and densest laterally. Longitudinal median sulcus extends from between frontal lobes to frons, ending in tiny depression. Occipital corner strongly microareolate and opaque to smooth and shining (with no visible microsculpture with up to $32 \times$ magnification). Antenna with 12 segments. Scape extends beyond posterior margin of head; length usually longer than head width; smooth or microareolate; pilosity variable. First six funicular segments usually widening towards apex; funiculus with sparse hairs longer than scape diameter usually on first segments, rarely on four to five most apical segments; funicular segments densely covered by appressed and very short pubescence. Ventral surface smooth and shining to weakly microareolate or strigulate and opaque; strigulae absent 
to covering all surface or just anterior half; pilosity variable; hypostomal tooth usually longitudinally striate. Labrum smooth or weakly transversely striate-punctate; median longitudinal sulcus present or absent. Mandible subtriangular; usually with seven teeth; basal tooth separated from other teeth by diastema; dorsum weakly longitudinally striate only at inner base or along masticatory margin; long hairs present along masticatory margin; integument widely impressed at hair insertions. Mandible ventrally curved in lateral view. Mandible in ventral view with shallow longitudinal basal sulcus that gradually fades apicad; sulcus and row of long, flexuous hairs parallel masticatory margin. Discal area of stipes depressed, usually smooth, sometimes weakly rugulose; usually two long and flexible hairs visible at base. Submentum with weak sulcus at base; discal protuberance present; usually no microsculpturing visible. Palpal formula 4,4.

Mesosoma. In lateral view, dorsal margin slightly divided by promesonotal junction; pronotum slightly higher than rest of mesosoma. Dorsal margin of pronotum in lateral view convex. Pronotum with lateral dorsoposterior swelling of variable convexity; smooth and shining to opaque and microareolate and/or rugulose; lateral surface densely covered by appressed to decumbent pubescence. Anteroventral corner of pronotum rounded, angled or toothed. Propleuron densely punctulate and pubescent. Prosternal process longer than wide. Mesonotal and propodeal dorsal margins in lateral view continuous and widely convex, metanotal groove slightly impressed. Mesopleuron and mesosternum separated by welldeveloped carina. Anepisternum usually with mesopleural pit next to mesometapleural suture and to metathoracic spiracle. Mesometapleural suture straight and well developed. Metanotal spiracular sclerite ovoid. Dorsal and declivitous propodeal margins in lateral view rounded and continuous; propodeal spiracle opening vertical to oblique and slit-shaped; spiracle at same level as surrounding propodeal surface; metapleural-propodeal suture well-marked and straight, or weak and sinuous. Mesometapleuron and lateral surface of propodeum punctulate; appressed pubescence variable in length and density. Mesonotum and propodeal dorsum usually densely covered with punctulae bearing medially converging pubescence. Mesosoma usually with numerous long hairs, distance between each hair usually less than half length. Coxae, femora and tibiae microareolate or smooth, with long hairs throughout each surface, separated from each other by distance less than half its length. Protibial apex with robust seta and well-developed pectinate spur, spur lamellate on inner base. Protibia with pubescence concentrated on opposing side of robust seta. Meso- and metatibia each with row of robust setae around entire apex, each apex with simple spur and pectinate spur; pubescence more concentrated on opposite surface of pectinate spur. Posterior surface of probasitarsus with basal concavity containing row of dark brown setae and parallel row of fine, light brown hairs; surface covered by thick yellow hairs. Tarsi with dark brown setae concentrated ventrally on apex of each tarsomere. Tarsal claws bidentate, arolium absent.

Metasoma. Petiolar node in lateral view usually robust and sub-rectangular; taller than long; lateral surface smooth and shining to microareolate and opaque; anterior margin with short, whitish decumbent hairs. Node longer than broad in dorsal view, narrower than either propodeum or abdominal tergite III; lateral margins subparallel to anterodorsally converging, always with rounded corners; integument shining or opaque. Hairs present in variable density. Posterior surface usually with shallow longitudinal sulcus. Petiolar sternite height in lateral view always higher anteriorly than posteriorly; subpetiolar process anteroventrally projecting; anterior apex rounded or longitudinally carinate. Anterior margin of abdominal tergite III in lateral view broadly convex and vertical; dorsal margin broadly convex; prora discrete and slightly concave ventrally. Gastral spiracles rounded. Abdominal tergite III in dorsal view smooth and shining to microareolate and opaque, with hairs of variable length and density; pubescence either present on entire surface or concentrated only laterally. Abdominal pretergite IV with fine transverse striae, stridulatory file of variable size (usually well-developed in D. lucida Emery, 1901 and D. longipes Emery, 1901). Pygidium and hypopygidium each with lateral row of stout setae. Apex of hypopygium ending in two robust triangular spines which are usually covered dorsally by pygidium.

COLOR. Integument black. 


\section{Male}

Measurements. Body length (BL1) greater than $12 \mathrm{~mm}$. Head width greater than $2.1 \mathrm{~mm}$.

HEAD. In full-face view ovoid, wider than long. Anterior margin of clypeus with a transverse lamella, concave; surface of clypeal disc with slight swelling. Anterior tentorial pit large. Epistomal sulcus usually broadly convex. Supraclypeal area flat and triangular-shaped, located between antennal sockets. Distance between antennal sockets less than their maximum diameter. Torular arch simple, exposing antennal condyles. Frontal carina reduced to a short median longitudinal swelling between posterior margins of antennal sockets. Eye large and convex, occupying entire lateral cephalic margin; inner margin emarginate at height of antennal socket. Median and lateral ocellus present; lateral ocellus surpassing posterior head margin in full-face view, except in some specimens of $D$. grandis. Posterior margin of head convex. Head punctulate and slightly microareolate, varying from shining to silky sheen; with decumbent to suberect yellowish pubescence; variable density of hairs. Antenna with 13 segments; filiform. Scape wider than all other segments; at least two times as long as pedicel; length approximately half that of third antennal segment. Antenna with appressed pubescence; hairs, if present, only on funiculus. Ventral surface of head varies from microareolate and subopaque to smooth and shining. Mandible reduced, edentate, spoon-shaped in lateral view; weakly punctulate and shiny. Labrum reduced, narrower than labium; anterior margin concave, rarely rounded in D. quadriceps Kempf, 1971. Palpal formula 4,3, sometimes 5,3.

Mesosoma. Pronotum in dorsal view narrow, with concave posterior margin; posterolateral corner acute and bulging. Mesoscutum in dorsal view rounded; with anteromedian longitudinal carina and lateral parapsidal line; notaulus present or absent; in lateral view with convex dorsal margin. Mesopleural sulcus oblique and well-developed; mesopleural pit easily distinguible, opening anteroventrally. Spiracular sclerite approximately rounded, opening posterodorsally. Scutoscutellar sulcus easily distinguible and usually scrobiculate. Mesoscutellum in dorsal view with concave anterior margin and straight to convex posterior margin, usually with lateral strigulae; dorsal margin in lateral view strongly convex. Metanotum usually with silky sheen, narrow and sub-rectangular in dorsal view, convex in lateral view; metanotal disc slightly rugulose, laterally strigulate. Metapleuron with oblique median depression at posterior metapleural pit; metapleural pit opening usually facing anteroventrally, except in some specimens of $D$. grandis and D. lucida. Metapleuron with anteroventral carina that extends briefly posterodorsally. Metapleural-propodeal suture forms carina that fades dorsally to propodeal spiracle, becoming broad, sometimes scrobiculate, sulcus. Anterior margin of propodeum in dorsal view with median notch; dorsal and declivitous margins of propodeum slightly discontinuous, sometimes separated by weak carina; propodeal spiracle slit-shaped. Mesosoma varies from microareolate and subopaque to smooth and shining, becoming coarsely punctate on declivitous surface of propodeum, except in D. grandis; usually with decumbent pubescence; long hairs present or absent. Legs very slightly microareolate and shining; densely pubescent; long hairs present or absent. Protibial apex sometimes with one stout seta; protibial spur well-developed and pectinate with lamellate inner base. Meso- and metatibiae each with two pectinate spurs at apex: one well-developed and the other less developed. Posterior surface of probasitarsus with basal concavity containing row of short setae. Tarsi with decumbent setae, usually more concentrated on apex of each tarsomere; claws bidentate; arolium well-developed. Wings covered by short pubescence. Forewing with pterostigma and following longitudinal veins: $\mathrm{C}, \mathrm{Sc}+\mathrm{R}, \mathrm{R}, \mathrm{Rs}+\mathrm{M}$, $\mathrm{M}, \mathrm{M}+\mathrm{Cu}, \mathrm{Cu}$ and $\mathrm{A}$; crossveins $2 \mathrm{r}-\mathrm{rs}, 2 \mathrm{rs}-\mathrm{m}, 1 \mathrm{~m}-\mathrm{cu}$ and cu-a present. Hindwing with following longitudinal veins: $\mathrm{R}+\mathrm{Rs}, \mathrm{Rs}, \mathrm{M}+\mathrm{Cu}, \mathrm{M}, \mathrm{Cu}$ and $\mathrm{A}$; crossveins $1 \mathrm{rs}-\mathrm{m}$ and cu-a present.

Metasoma. Petiolar node in lateral view with rounded dorsal margin, anterior and posterior margins forming a continuous curve, usually with posterior hump; spiracle oval to rounded. Petiolar sternum continuous, lacking well-developed subpetiolar process, usually longitudinally carinate. In dorsal view longer than wide with rounded corners. Sculpturing varies from microareolate and subopaque to smooth and shining; pubescence and pilosity of variable density. Anterior margin of abdominal tergite 
III in lateral view broadly convex and curving posterad. Gastral spiracles oval to rounded. Abdominal pretergite IV with stridulatory file. Well-marked constriction between abdominal segments III and IV; abdominal tergite VIII (pygidium) triangular to spiniform. Cercus apically dilated, with long hairs; hypopygium elongate, posterior margin concave to straight. Sculpturing varies from microareolate and subopaque to smooth and shining; pubescence and pilosity of variable density.

Genitalia. Basal ring in dorsal view trapezoid, with lateral margins converging anteriorly; dorsoanterior margin thicker, forming lateral loop and median invagination; each loop surrounds a fenestra. Basal ring in lateral view with dorsal margin varying from straight to very concave, some species having anterior lobe; anteroventral process varying from rounded to subquadrate to subtriangular. Parameres notably divided in two regions: gonocoxite anteriorly and gonostylus posteriorly; gonostylus varying from broad and rounded to narrow and sharp. Cuspis volsellaris in lateral view finger-like and ventrally torulose, size variable; digitus volsellaris widening posteriorly, ventral margin varying from broadly to strongly concave; posterior region torulose. Penisvalva highly variable among species, with ventral margin serrated.

CoLOR. Integument in shades of brown, with legs usually lighter.

\section{Remarks}

This genus is rarely mistaken with any other due to its enormous size. Dinoponera shares some synapomorphies with Pachycondyla Smith, 1858, the most notable being the presence of a row of stout setae on the hypopygium on each side of the sting (Schmidt \& Shattuck 2014). However, females of Pachycondyla have no tooth on the anterior margin of the clypeus and rarely exceed $2 \mathrm{~cm}$ in body length. Neither females nor males of Pachycondyla have a stridulatory file on abdominal pretergite IV, a character present in both sexes of Dinoponera. A possible karyotypic apomorphy of Dinoponera is the presence of a pair of pseudo-acrocentric chromosomes, observed in D. grandis, D. gigantea, D. lucida and D. quadriceps (Santos et al. 2012).

\section{Biology}

Nests are always constructed in the soil, usually close to the base of trees or in areas shaded by vegetation (Araujo et al. 1990; Morgan 1993; Paiva \& Brandão 1995; Fourcassié et al. 1999; Fourcassié \& Oliveira 2002; Peixoto et al. 2010). Each nest may have one to thirty entrances, and some may be polydomic (Morgan 1993; Paiva \& Brandão 1995; Fourcassié \& Oliveira 2002). The entrances may contain branches and loose soil, forming mounds in D. longipes (Morgan 1993; Fourcassié et al. 1999; Peixoto et al. 2010). Nest depth varies from 10 to $143 \mathrm{~cm}$, with species from more arid environments, such as D. quadriceps and D. grandis, usually having deeper nests. Nests are distributed in patches, and the spatial arrangement within each patch may be random or influenced by intraspecific territorial competition (Araujo et al. 1990; Paiva \& Brandão 1995; Fourcassié \& Oliveira 2002; Vasconcellos et al. 2004). Local density of nests can vary from 15 to 180 per hectare (Vasconcellos et al. 2004; Tillberg et al. 2014). In D. longipes, Morgan (1993) estimated an average distance of $35 \mathrm{~m}$ between nests.

The average number of workers per colony varies from 13 to 78, and can reach more than 140 in D. quadriceps (Paiva \& Brandão 1995; Monnin \& Peeters 1998; Monnin et al. 2003). Division of labour occurs mainly because of age polyethism, with the oldest workers responsible for activities outside the nest (Peixoto et al. 2008). Foraging is always solitary, regardless of resource size (Araújo \& Rodrigues 2006; Azevedo et al. 2014). Their diet is omnivorous, with a preference for angiosperm seeds and living or dead invertebrates (Fourcassié \& Oliveira 2002; Araújo \& Rodrigues 2006; Peixoto et al. 2010; Tillberg et al. 2014). Each worker maintains fidelity to a foraging route, with only slight deviations while searching for food (Fourcassié et al. 1999; Fourcassié \& Oliveira 2002; Vasconcellos et al. 2004; Tillberg et al. 2014). Studies suggest that spatial orientation occurs mainly through large-scale visual cues (Fourcassié et al. 1999; Araújo \& Rodrigues 2006; Tillberg et al. 2014). 
In Dinoponera there has been loss of the queen; consequentially, reproduction is carried out by workers called gamergates (Haskins \& Zahl 1971; Peeters \& Crewe 1984; Araujo et al. 1990; Peeters 1991; Peixoto et al. 2008). All workers have reproductive potential, but a hierarchical system of dominance guarantees that the colonies are usually monogynous (Monnin \& Peeters 1999; Monnin et al. 2003; Peixoto et al. 2008). Each colony has a cadre of workers of elevated hierarchical status that usually compete with each other for the reproductive role. These workers are often referred to as alpha, beta, gamma, and delta, being defined by the frequency and intensity of specific behaviours (Monnin \& Peeters 1999; Peixoto et al. 2008). The gamergate is the alpha, the highest status in the colony (Monnin \& Peeters 1999). Agonistic interactions performed by workers of higher status usually are blocking, gaster rubbing and gaster curling (Monnin \& Peeters 1999; Peixoto et al. 2008). When beta, gamma or delta workers lay unfertilized eggs, the gamergate often recognizes them and destroys them by oophagy (Monnin \& Peeters 1997). Dominance hierarchy is also determined by age (Araujo et al. 1990), as usually only young workers have high level positions (Monnin \& Peeters 1999). As workers age their ovaries atrophy and they lose their reproductive capacity (Araujo et al. 1990). Thus, a newly emerged worker has a good chance to become a beta and possibly an alpha (Araujo et al. 1990; Monnin \& Peeters 1999). Gamergates, however, may be relatively old, which suggests that fertilization is an important factor that prevents ovary atrophy (Araujo et al. 1990).

Reproduction occurs when a virgin alpha leaves the nest at night and waits for a male to fertilize it (Monnin \& Peeters 1998). Male attraction probably occurs through pheromones produced only by alpha females (Monnin \& Peeters 1998). After mating, the male genitalia remain attached to the gamergate, ensuring monandry (Monnin \& Peeters 1998). A newly fertilized alpha can replace a dead gamergate or found a new colony by fission (Monnin \& Peeters 1998). Fission can be gradual, as demonstrated for D. quadriceps and D. lucida (Peixoto et al. 2010; Medeiros \& Araújo 2014). Initially the new gamergate and other workers can migrate to a nearby nest and remain in contact with the parental nest. After this polydomous stage, that may continue for months, the two colonies gradually become independent from each other (Peixoto et al. 2010; Medeiros \& Araújo 2014).

Several invertebrates can inhabit Dinoponera nests. The most common taxa are Termitidae, Gastropoda, Corinnidae, Zygentoma, Tenebrionidae, Histeridae, Phoridae, and Isopoda (Paiva \& Brandão 1995; Vasconcellos et al. 2004). Ants of the genus Pheidole Westwood, 1839 are often found in nests of several species of Dinoponera (Paiva \& Brandão 1995; Vasconcellos et al. 2004; Peixoto et al. 2010).

\section{Distribution}

Dinoponera has been recorded in most Brazilian states except Amapá, Roraima and Rio de Janeiro. The genus also occurs in other countries of South America, such as Colombia, Ecuador, Peru, Bolivia, Paraguay and Argentina (Kempf 1971; Lenhart et al. 2013). Lenhart et al. (2013) recorded the genus in Guiana, but this single record may be a labeling error, since no other records have been reported throughout the region between the Rio Negro in the Amazon and the Bartica district of Guiana.

\section{Taxonomic synopsis}

D. gigantea (Perty, 1833)

D. grandis (Guérin-Menéville, 1838) revived species

$=D$. australis Emery, 1901 syn. nov.

=D. australis brevis Borgmeier, 1937

=D. australis bucki Borgmeier, 1937 syn. nov.

$=D$. australis nigricolor Borgmeier, 1937 syn. nov.

$=D$. snellingi Lenhart, Dash \& Mackay, 2013 syn. nov.

D. hispida Lenhart, Dash \& Mackay, 2013

D. longipes Emery, 1901

D. lucida Emery, 1901 
D. mutica Emery, 1901

D. nicinha sp. nov.

D. quadriceps Kempf, 1971

=D. opaca Kempf, 1971

\section{Key to females of Dinoponera Roger, 1861}

1. Integument mostly smooth and shining; microsculpturing not visible on first gastric tergite (best seen at $32 \times$ magnification) (Fig. 3A)

- Integument mostly microareolate and opaque; microsculpturing always visible on first gastric tergite (best seen at $32 \times$ magnification) (Fig. 3B)

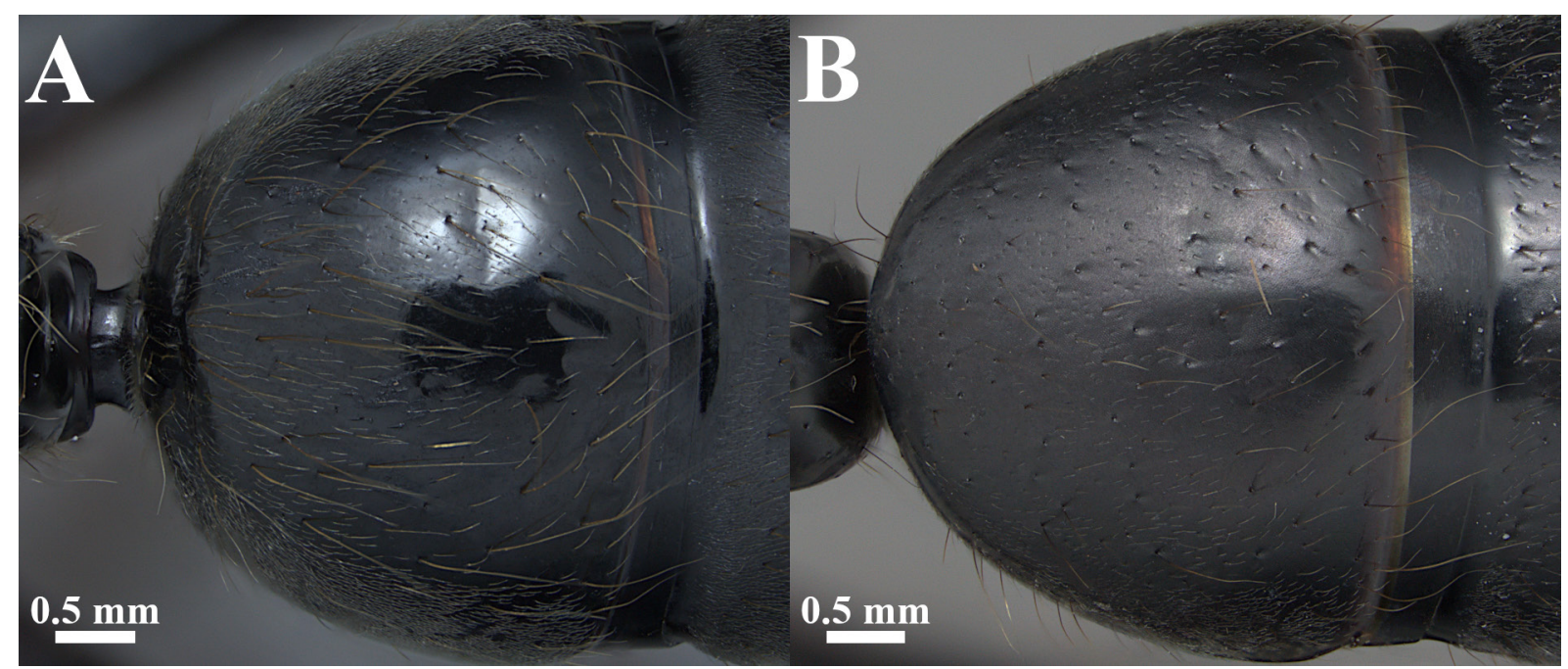

Fig. 3. Detail of first gastric tergite microsculpturing. A. Dinoponera mutica Emery, 1901. B. D. quadriceps Kempf, 1971.

2. Petiolar node in lateral view with the anterodorsal angle at a level clearly lower than the posterodorsal angle (Fig. 4A). Anteroventral corner of pronotum in lateral view with a tooth or forming an acute angle

D. lucida Emery, 1901 (east of Brazil)

- Petiolar node in lateral view with the anterodorsal angle higher, at the same level as or slightly lower than the posterodorsal angle (Fig. 4B). Anteroventral corner of pronotum in lateral view without a tooth, forming obtuse angle at most

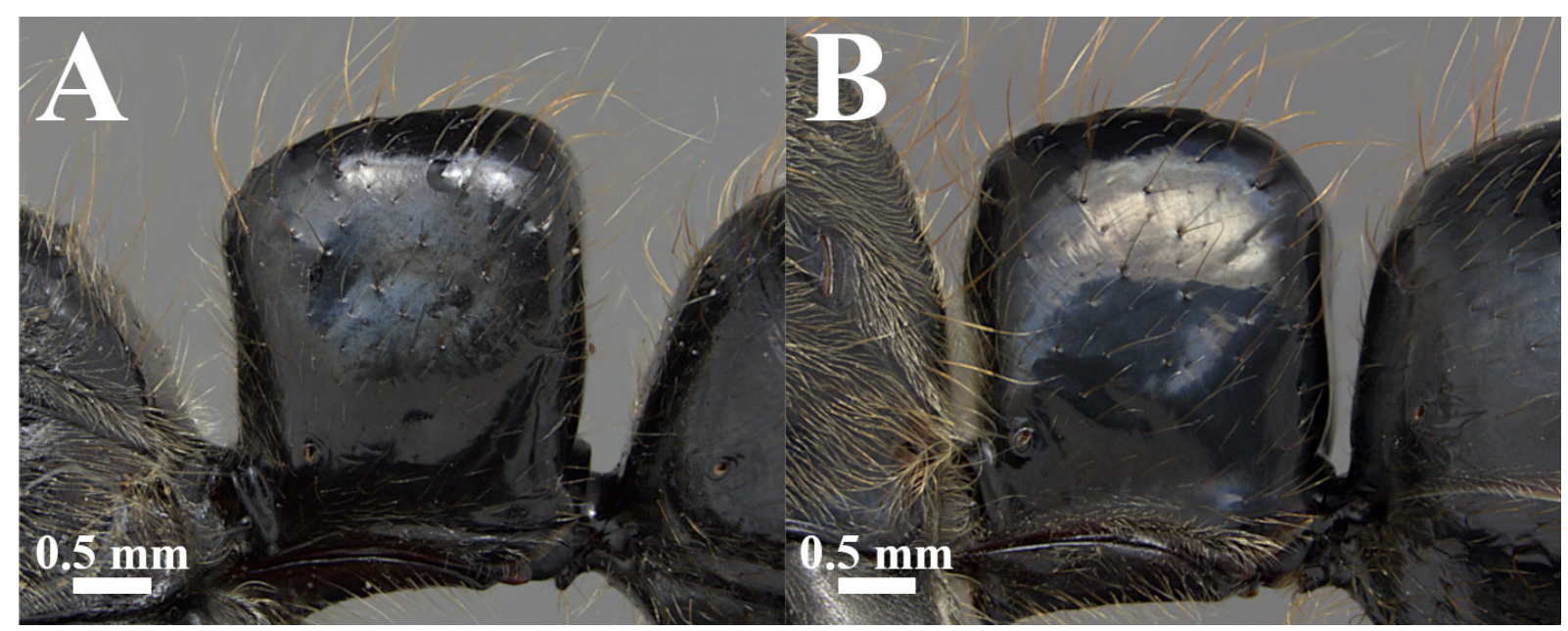

Fig. 4. Petiolar node in lateral view. A. Dinoponera lucida Emery, 1901. B. D. nicinha sp. nov. 
3. Body covered by thick and stiff hairs (Fig. 5A). Ventral surface of head posteriorly with wellmarked transverse strigulae posteriorly ......D. hispida Lenhart, Dash \& Mackay, 2013 (Brazil: Pará)

- Body covered by slender and flexuous hairs (Fig. 5B). Ventral surface of head posteriorly without strigulae; if strigulae present, only anterolaterally

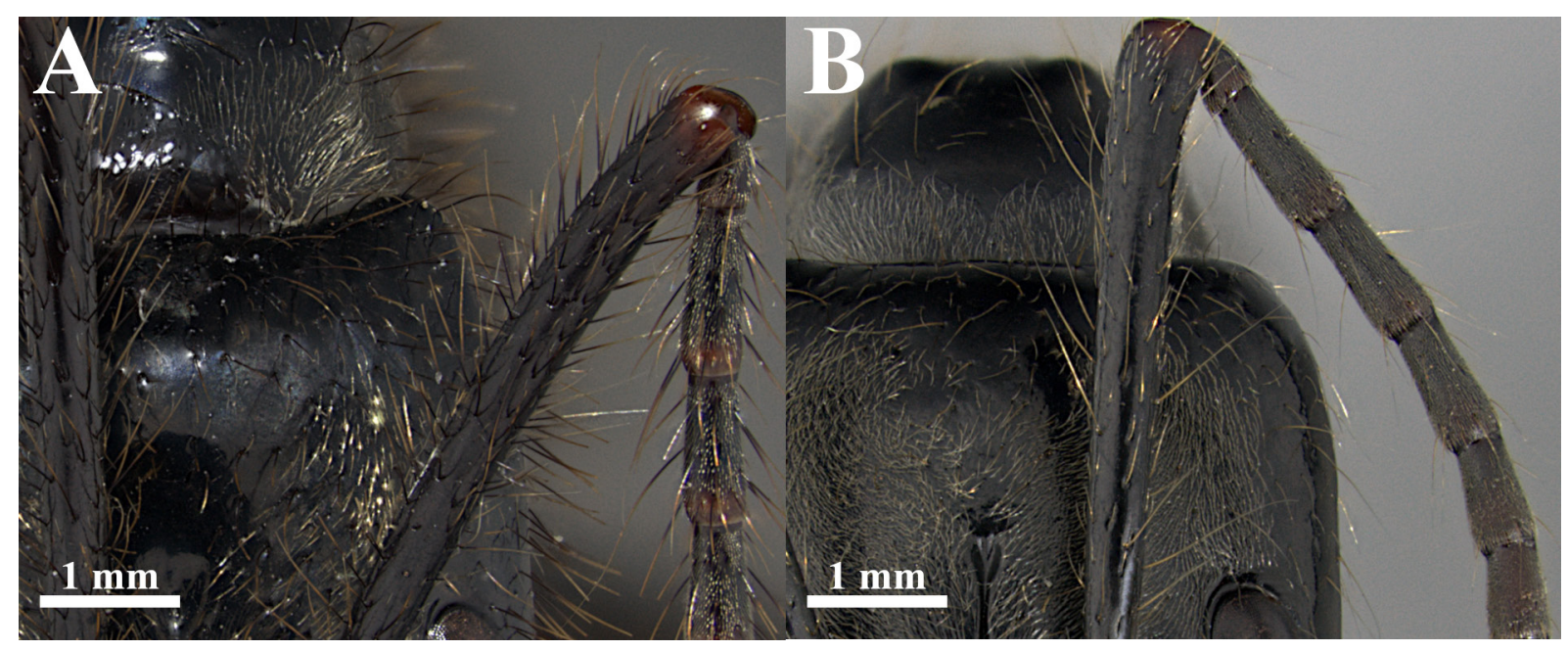

Fig. 5. Detail of pilosity types. A. Dinoponera hispida Lenhart, Dash \& Mackay, 2013. B. D. mutica Emery, 1901.

4. Petiolar node in lateral view with its anterodorsal angle at a level clearly higher than the posterodorsal angle (Fig. 6A) .....D. longipes Emery, 1901 (northwest of Brazil, Colombia and Peru)

- Petiolar node in lateral view with its anterodorsal angle slightly lower or at approximately the same level as the posterodorsal angle (Fig. 6B) .5

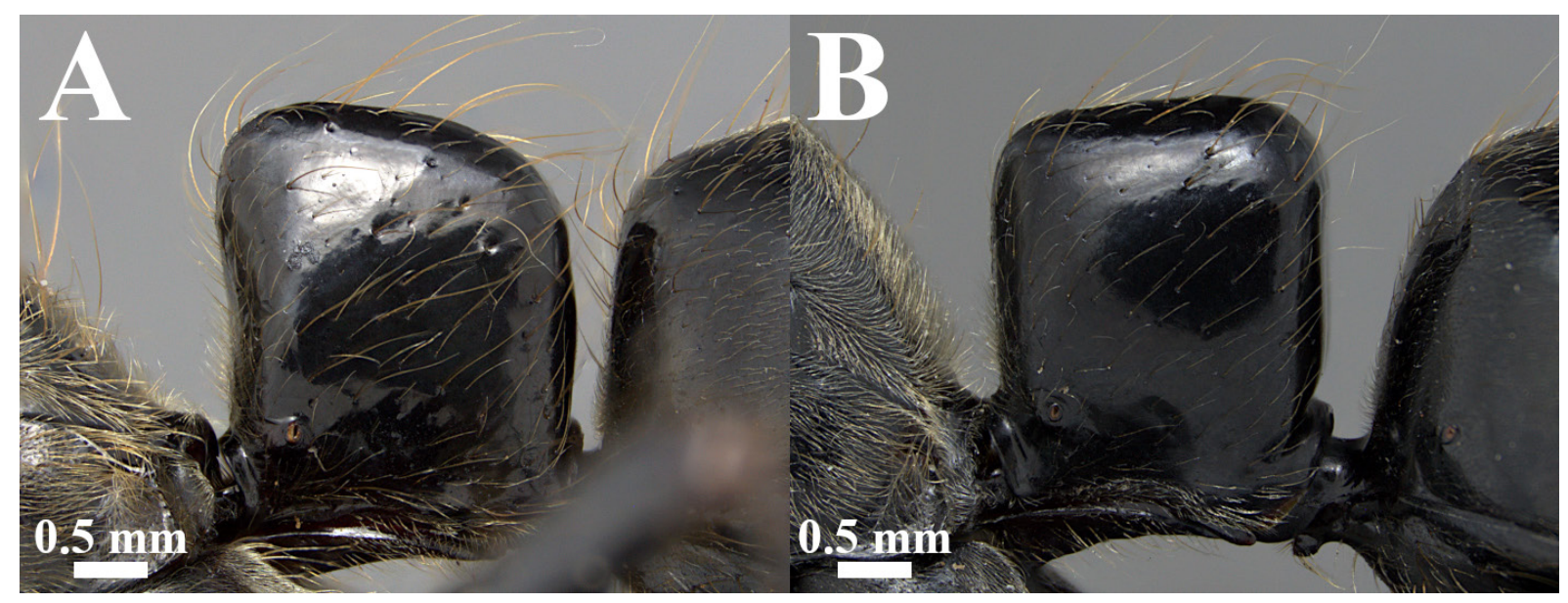

Fig. 6. Petiolar node in lateral view. A. Dinoponera longipes Emery, 1901. B. D. mutica Emery, 1901. 
5. Dorsal margin of petiolar node in lateral view convex (Fig. 7A). Golden pilosity present on frons and first gastric tergite. First gastric tergite with sparse pubescence on entire surface ......

..D. nicinha sp. nov. (northwest of Brazil)

- Dorsal margin of petiolar node in lateral view straight (Fig. 7B). Chestnut pilosity present on frons and first gastric tergite. First gastric tergite with dense pubescence laterally

D. mutica Emery, 1901 (northwest and midwest of Brazil, Bolivia and Paraguay)

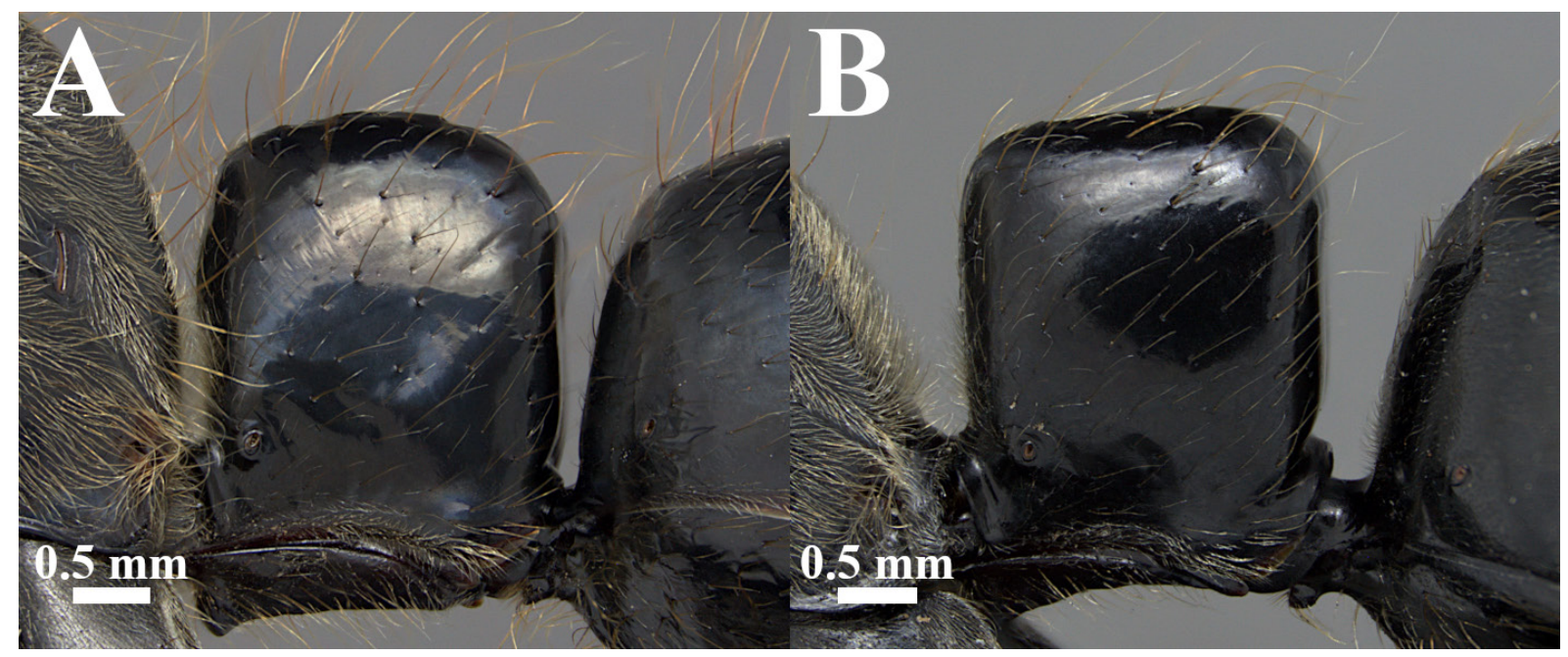

Fig. 7. Petiolar node in lateral view. A. Dinoponera nicinha sp. nov. B. D. mutica Emery, 1901.

6. Malar area with striae that reach entire anterior eye margin (Fig. 8A); hind basitarsus less than $6 \mathrm{~mm}$ long ........D. grandis (Guérin-Menéville, 1838) (Argentina, Bolivia, Brazil and Paraguay)

- Malar area without striae or with weak striae that do not reach entire anterior eye margin (Fig. 8B); hind basitarsus usually more than $6 \mathrm{~mm}$ long .7

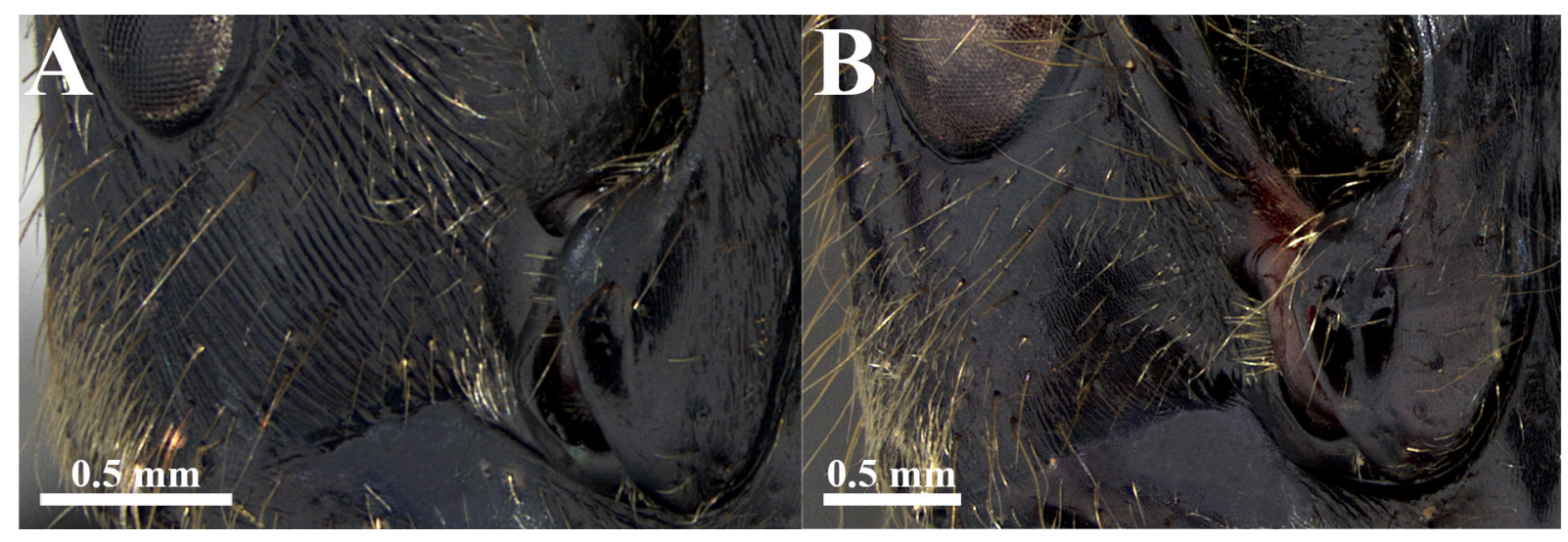

Fig. 8. Detail of malar area striae. A. Dinoponera grandis (Guérin-Menéville, 1838). B. D. gigantea (Perty, 1833). 
7. Anteroventral corner of pronotum in lateral view without tooth, at most forming an obtuse angle (Fig. 9A). Ventral surface of head without striae

D. quadriceps Kempf, 1971 (northeast of Brazil)

- Anteroventral corner of pronotum in lateral view with tooth or forming acute angle (Fig. 9B).

Ventral surface of head with striae at least on the anterior half

D. gigantea (Perty, 1833) (north of Brazil, Colombia and Peru)

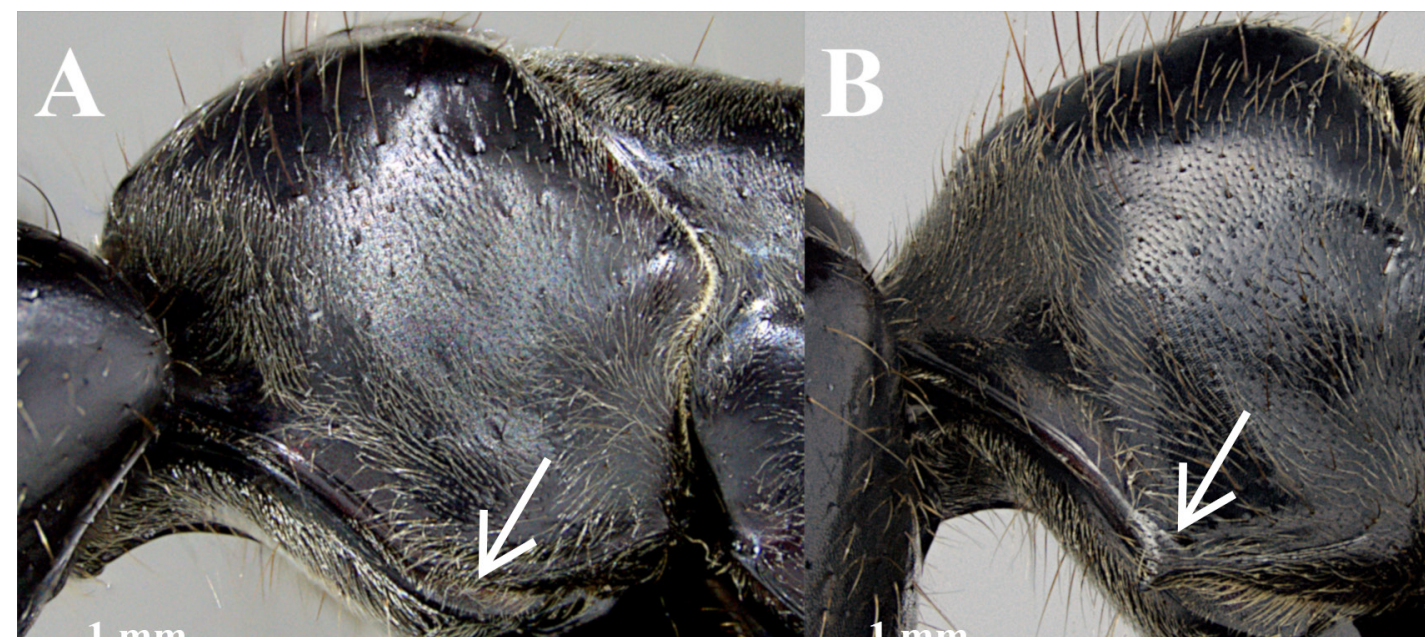

Fig. 9. Anteroventral corner of pronotum in lateral view. A. Dinoponera quadriceps Kempf, 1971. B. D. gigantea (Perty, 1833).

\section{Key to males of Dinoponera Roger, 1861}

For detailed images of genitalia see Tozetto \& Lattke (2020).

1. Antenna without long hairs (Fig. 10A). Anteroventral corner of volsella projecting ventrally D. grandis (Guérin-Menéville, 1838) (Argentina, Bolivia, Brazil and Paraguay)

- Antenna with long suberect to erect hairs, clearly longer than maximum scape diameter (Fig. 10B). Anteroventral corner of volsella bidentate

- Antenna with thick and stiff decumbent hairs, usually shorter than maximum scape diameter

(Fig. 10C). Anteroventral corner of volsella projecting anteriorly

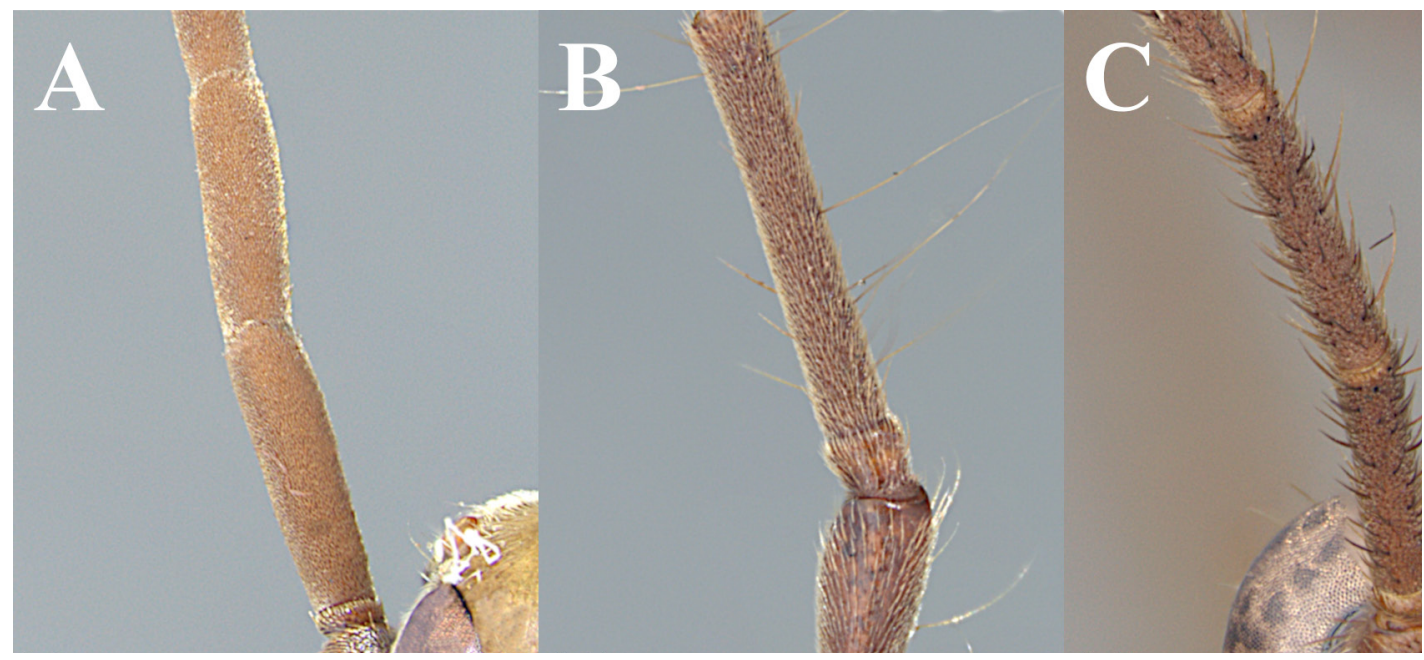

Fig. 10. Detail of antenna pilosity. A. Dinoponera grandis (Guérin-Menéville, 1838). B. D. quadriceps Kempf, 1971. C. Dinoponera morphospecies 1. 
2. Notaulus slightly impressed on mesoscutum (Fig. 11A). Penisvalva ending in rounded apex. Gaster with sparse suberect long hairs .....D. gigantea (Perty, 1833) (north of Brazil, Colombia and Peru)

- Notaulus absent (Fig. 11B). Penisvalva ending in a subacute apex. Gaster without long hairs .. D. quadriceps Kempf, 1971 (northeast of Brazil)

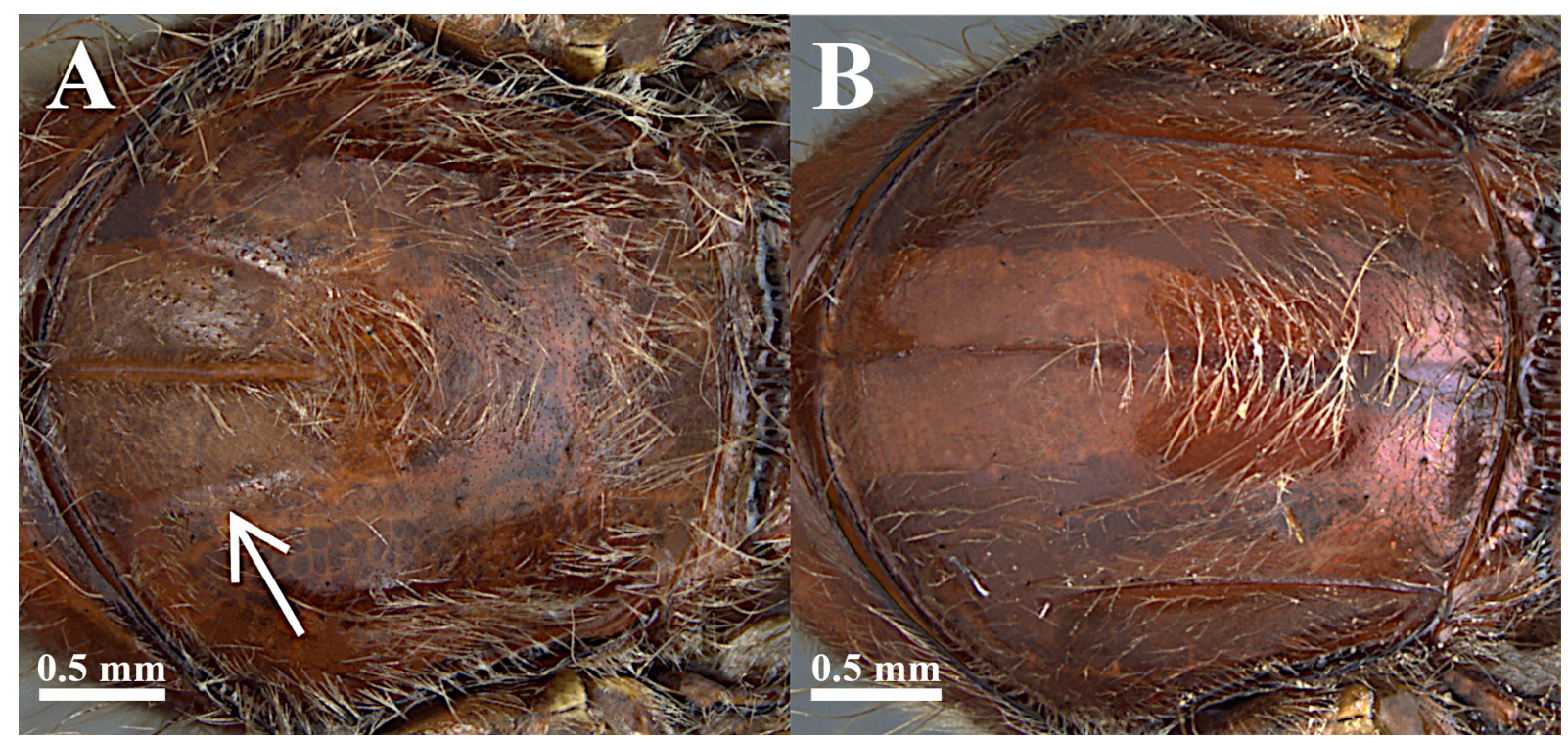

Fig. 11. A. Detail of mesoscutum with notaulus (see arrow) in Dinoponera gigantea (Perty, 1833). B. Detail of mesoscutum without notaulus in D. quadriceps Kempf, 1971.

3. Abdominal tergite VIII triangular, with a very sharp apex (Fig. 12A). Penisvalva ending in a posteroventral lobe D. lucida Emery, 1901 (east of Brazil)

- Abdominal tergite VIII spiniform (Fig. 12B). Penisvalva without a posteroventral lobe .......4

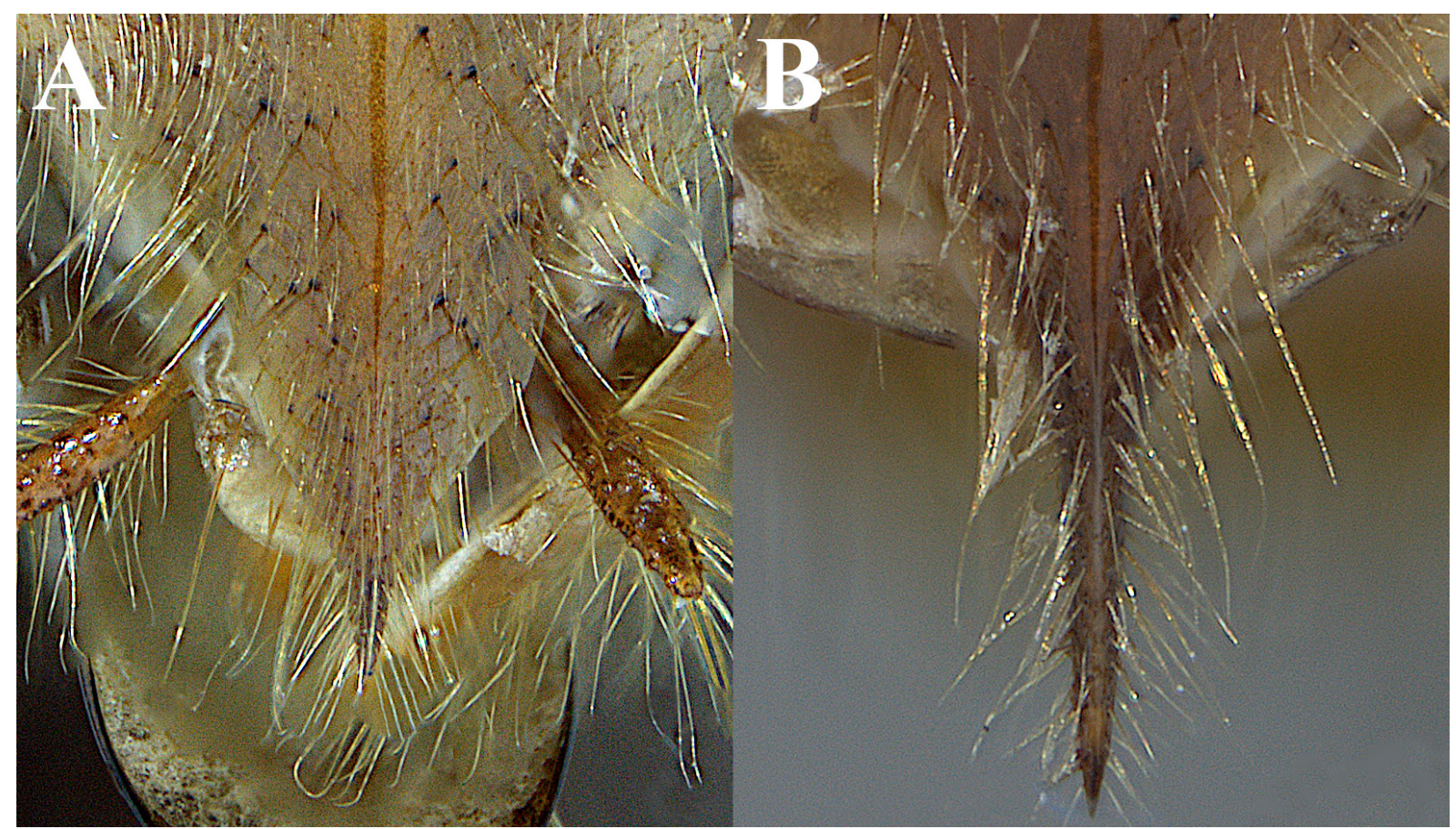

Fig. 12. Detail of abdominal tergite VIII. A. Dinoponera lucida Emery, 1901. B. Dinoponera morphospecies 1 . No scale. 
4. Penisvalva in lateral view with a rounded apex; anteroventral corner with a long and very sharp spine Dinoponera morphospecies 1 (northwest of Brazil)

- Penisvalva in lateral view with a wedge-shaped apex; anteroventral corner with a tooth ..... D. longipes Emery, 1901 (northwest of Brazil, Colombia and Peru)

Dinoponera gigantea (Perty, 1833)

Figs 13-14, 28A

Ponera gigantea Perty, 1833: 135, pl. 27 fig. 3 (ఫ).

Dinoponera gigantea - Kempf 1971: 372, figs 8-12 (male description). — Lenhart, Dash \& Mackay 2013: 139, figs 1d, 4a, f, k, 5c, 9c, 10c, 11c (redescription, male genitals, key). — Tozetto \& Lattke 2020: 5, figs 2-3, 6 (male genitals).

\section{Diagnosis}

Female

Malar area with weak longitudinal to oblique striae that do not reach anterior eye margin. Ventral head surface mostly strigulate. Anteroventral corner of pronotum in lateral view with tooth or acute angle. Dorsum of pronotum and abdominal tergite III strongly microareolate and opaque. Body length (BL) greater than $27 \mathrm{~mm}$.

\section{Male}

Antenna with long suberect to erect hairs, clearly longer than maximum scape diameter. Mesoscutum with notaulus. Gastral tergites with long hairs. Dorsal margin of basal ring in lateral view broadly convex to straight.

\section{Material examined}

\section{Lectotype}

BRAZIL - Amazonas • ఛ̧; Rio Negro; ZSM HYM-25181.

Paralectotypes $(2$ ఢ̧)

BRAZIL - Amazonas・1 ఫ; ZSM HYM-25182・1 ఫ্; ZSM HYM-25183.

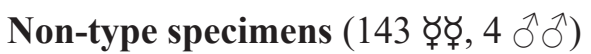

BRAZIL - Amazonas • 1 ఫ; Manaus; D. Dias leg.; MZSP. - Maranhão • 2 ఫॄఢ; Balsas, Gerais das Balsas; 9 Nov. 1999; Brandão, Yamamoto and Dietz leg.; lote 23; MZSP• 1 ఫ; Carolina; $7.21533^{\circ} \mathrm{S}, 47.31867^{\circ} \mathrm{W}$; 2 Oct. 2015; H. Vasconcelos and J. Maravalhas leg.; DZUP • 1 ६̧; Carolina, PN Chapada das Mesas; $7^{\circ} 12^{\prime} 55^{\prime \prime}$ S, 47¹9'7" W; 6 Oct. 2015; H. Vasconcelos, J. Maravalhas and F. Camarota leg.; DZUP • 2 ఫ̧ఛ; Estreito, assentamento Vitória; 8 May 2004; Herpetologia MZSP, pitfall; MZSP • 1 ఛ; Imperatriz; 1 Jul. 1974; Exc. Depto. Zool. exped.; DZUP • 1 ६; same collection data as for preceding; 4 Jul. 1974; DZUP • 2 ఫ६; same collection data as for preceding; 20 Jul. 1974; DZUP • 1 ६; Mirador, Reserva Mirador, Geraldina; 6³5' S, 4549' W; 3 Dec. 2009; M.W.A. Mendonça leg.; DZUP • 1 ६̧; Miranda do

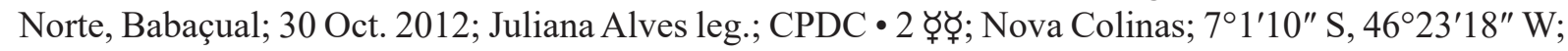
23 Sep. 2009; D. Muniz leg.; DZUP• 1 ఫ६; Rio Santana, Grajaú; 15 Jun. 1966; H. Reichardt leg.; MZSP.

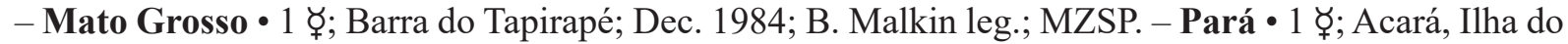
Combu; 16 Jul. 1988, J. Dias leg.; MPEG • 1 ర̧; Água Azul, Paragominas; 22 Jul. 1974; Exc. Depto. Zool. 
exped.; DZUP • 2 ఫ̛ర్; Alegre, 15 km NE of Marapanim; 10 Sep. 1965; Exp DZ-MG exped.; MZSP • 1 ఫ; Ananindeua; Aug. 1964; Machado and Pereira leg.; MZSP • 1 ६; Barcarena, Reserva Samaúma; $1.4963^{\circ} \mathrm{S}, 48.7088^{\circ} \mathrm{W} ; 15-16$ Nov. 2001; Iracenir and J. Dias leg.; MPEG • 1 ఢ̧; Belém; 12 Jun. 2000; Delabie leg.; CPDC • 2 ఫ६ఛ; same locality as for preceding; 12-19 Aug. 1962; K. Lenko leg.; 2200; MZSP • 1 ६; same locality as for preceding; 18 Dec. 1994; Gilberto leg.; MPEG • 1 ६; same locality as for preceding; 22 Jul. 2007; M.A. Rodrigues leg.; DZUP • 1 ఛ; same locality as for preceding; 26 Sep. 1934; Carvalho Neto leg.; MZSP • 1 ६; same locality as for preceding; Jan. 1976; V.P. Daniel and Lucia Repp leg.; MZSP • 1 ఫ;; same locality as for preceding; Feb. 1956; P. Azevedo leg.; DZUP• 1 ఢ;; same locality as for preceding; Sep. 1955; Martinez leg.; MZSP • 1 ఢ̧; Belém, Mocambo; 17 Apr. 1997; M.L. Macambira leg.; "coleta manual, floresta perturbada, área $10 \mathrm{~m}^{2}$ ”; MPEG • 1 ఫ; same locality as for preceding; 18 Apr. 1999; M. Barros leg.; "coleta manual, floresta perturbada, área 10m"; MPEG • 1 ఫ্; same collection data as for preceding; M.L. Macambira leg.; MPEG • 1 ఫ̛; Belém, MPEG C. pesquisa; 15-22 May 1997; C. Melo leg.; malaise; MPEG • 1 ఫ̧; Belém, Reserva Guamá; 31 May 1966; Coll Kempf 5074; MZSP • 1 đ̇; Benevides; 15 Mar. 1990; W.L. Overal leg.; MPEG HHY03045386•

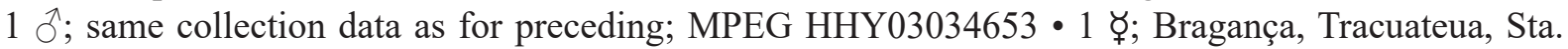
Maria; 1 Sep. 1988; F.F. Ramos leg.; MPEG • 1 ఫ;; Bujaru; 3 Feb. 1979; A.F. Ramos leg.; INPA • 1 ఫ; Canindé, Rio Gurupi; 1 May 1963; B. Malkin leg.; MZSP• 1 ఫ; same collection data as for preceding; 1 Oct. 1964; MZSP • 1 ६; same collection data as for preceding; 1 Dec. 1964; MZSP • 3 ఫॄ; same collection data as for preceding; 7-9 Feb. 1966; MZSP • 7 ఫఢఫ; same collection data as for preceding; Apr. 1963; MZSP • 1 ఫ̛; Goianésia; 16-18 Jun. 2003; A.M. Elizabeth leg.; CPDC • 1 ఫ; Igarapé Açu; 23-25 Jan. 2008; Santos J.A. leg.; pitfall 20 IASD0608; UFOPA • 1 ६; same collection data as for preceding; pitfall 18; UFOPA • 1 ६; same collection data as for preceding; pitfall 21; UFOPA • 1 ఫ; same collection data as for preceding; $1.0443^{\circ} \mathrm{S}, 47.5944^{\circ} \mathrm{W}$; pitfall 8; UFOPA • 2 ర్ఛఢ; same collection data as for preceding; pitfall 13; UFOPA • 1 ६; same collection data as for preceding; pitfall 7 IASD1138; UFOPA • 1 ६; same collection data as for preceding; pitfall 20 IASD0609; UFOPA • 1 ६; "Igarapé Uruaim, 40 km Rio Gurupi"; 2 May 1963; J. Carvalho leg.; MZSP • 1 ఫ̧; Marabá; 2017; DZUP • 1 ६̧; Marituba; $1^{\circ} 22^{\prime}$ S, $48^{\circ} 20^{\prime}$ W; 21 Oct. 2004; J.R.M. Santos leg.; CPDC • 1 ఢ̧; Óbidos; Dec. 1952; Pedro Telles leg.; MZSP • 2 ఫఛర్; Ourém, Patauateua; 1 May 1992; Delma leg.; arm. de luz; MPEG •

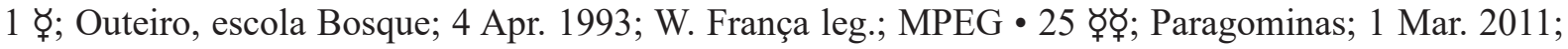
R. Solar leg.; DZUP • 27 ఫॄర; same collection data as for preceding; 1 Jul. 2011; DZUP • 1 ఢ; same collection data as for preceding; ANTWEB 1038257; UFV • 1 \%; same locality as for preceding; 2059'51" S, 47²1'13" W; alt. 85 m; Jan-Jul. 2011; R. Solar leg.; UFV LabEcol 449 • 1 ६; same locality as for preceding; 5 Oct. 1993; Fowler leg.; 3231; CPDC • 1 ф̧; Paragominas, Faz. Rio Capim, Empresa Cikel Brazil Verde; $3^{\circ} 33^{\prime}$ S, $48^{\circ} 38^{\prime}$ W; 1 Aug. 2002; DZUP • 1 ф̧; Paragominas, Fazenda Sete; 18-23 Sep. 1997; S.M. Ketellhut leg.; "corte seletivo"; T3.3 pitfall 2; MPEG • 1 ఫ্; Paragominas, Fazenda Vitória; 21 Dec. 1991; Paulo Moutinho leg.; HB-CP T-8 PT4 A15-1 col2; MPEG • 3 ఫఢఫ; same locality as for preceding; 1 Oct. 1999; P.S. Oliveira leg.; "mata seca"; MZSP • 1 ६; Peixe-Boi, Fazenda Santoca, área de mata; $1.13991^{\circ} \mathrm{S}, 47.3006^{\circ} \mathrm{W} ; 10$ Mar. 2010; J. Dias leg.; "rede entomológica"; MPEG • 1 ऽ̊; Primavera, Quadripaum Fal. Feitoria; 27 Nov. 1992; J. Dias leg.; "armadilha de luz"; MPEG 03006727 • 1 ఫ; Rio Tocantins, base 4; 18 Jul. 1987; Wynes Barbosa leg.; Coleção Diniz; DZUP • 1 ఫ్; S.C. Odivelas; 19 Nov. 1982; P. Tadeu leg.; MPEG • 2 రోఫ్; same locality as for preceding; 27 Feb. 1979; R.B. Neto leg.; INPA • 1 ఫ్; Serra Norte, Salobo; 17 Sep. 1985; Marcio Zanuto leg.; MPEG • 1 ఫ̛; Tailândia; 30 Jun. 2005; M. Silva leg.; MZSP • 1 ఫ̛; Tucuruí, Vila Brava; 22 Jun. 1980; Nunes de Melo leg.; INPA • 1 ф̧; same collection data as for preceding; 27 Jun. 1980; INPA • 1 ६; Tucuruí, Inajá; 20 Jun. 1980; B.M. Mascarenha leg.; INPA. - Tocantins - 1 ६; Araguaina; 2 Oct. 2015; H.L. Vasconcelos and J.B. Maravalhas leg.; 251, T70-3S; DZUP • 1 ఛ̧; Babaçulândia; $7^{\circ} 01^{\prime} 03^{\prime \prime}$ S, 4752'14" W; 10-15 Dec. 1961; Albuquerque and Silva leg.; "isca solo"; MZSP. 
PERU - Loreto • 2 ఫ̛⿱ Estirón, Río Ampiacú; 15 May 1966; B. Malkin leg.; 5881; MZSP • 1 ఫ̧; same collection data as for preceding; DZUP.

\section{Redescription}

\section{Female}

Measurements. Lectotype: HL 5.85; HW 5.35; MDL 4.52; SL 5.98; MSL 8.8; HFL 8.2; HBL 6.64; PL 2.44; PH 3; PW 1.73; ATS 8; BL 29.63 (mm); CI 0.91; SI 1.11; DPI 0.7. Paralectotypes ZSM HYM25183 and ZSM HYM-25182 (NA = not available): HL 5.35 and 5.95; HW 5 and 5.6; MDL 4.07 and 4.5; SL NA and 5.92; MSL 7.6 and 8.7; HFL 7 and 8.4; HBL 5.67 and 6.9; PL 2.24 and 2.57; PH 2.97 and 3.25; PW 1.78 and 1.89; ATS 6.96 and 8.4; BL 26.23 and $30.12(\mathrm{~mm})$; CI 0.93 and 0.94; SI NA and 1.05; DPI 0.79 and 0.73. Non-types $(\mathrm{n}=26)$ : HL 5.35-6.23; HW 5.29-6.11; MDL 4.09-4.97; SL 5.41-6.36; MSL 7.76-9.3; HFL 7.24-8.9; HBL 6.16-7.5; PL 2.32-2.69; PH 3.03-3.6; PW 1.67-2.07; ATS 7.52-9.6; BL 27.11-32.23 (mm); CI 0.94-1.03; SI 0.98-1.09; DPI 0.68-0.82.

HEAD. Malar area without striae or with weak longitudinal to oblique striae that do not reach anterior eye margin. Gena microareolate and opaque, usually without rugulae. Apressed brownish pubescence present between eye and frontal lobe, extending posteriorly to frons. Frons microareolate and opaque; with flexuous, brownish and suberect hairs, longer than scape diameter; pubescence densest laterally. Occipital corner strongly microareolate and opaque. Antennal scape microareolate and silky, suberect and long hairs usually present on antennal segments $1-3$. Ventral surface of head microareolate with arched strigulae covering entire surface or at least anterior half; posterior to postgenal suture with well-marked transverse strigulae. Hypostomal tooth with longitudinal strigulae. Labrum with median longitudinal sulcus weakly marked or absent; transverse rugulae absent. Mandibular dorsum weakly longitudinally strigulate on inner base, sculpture gradually fading apicad.

Mesosoma. Dorsal margin of pronotum in lateral view broadly convex, usually with no pronounced dorsoposterior swelling; anteroventral corner of pronotum toothed or forming acute angle. Pronotal dorsum strongly microareolate, rugulose and opaque. Metapleural-propodeal suture weak and sinuous, with at least one curve ventral to position of propodeal spiracle.

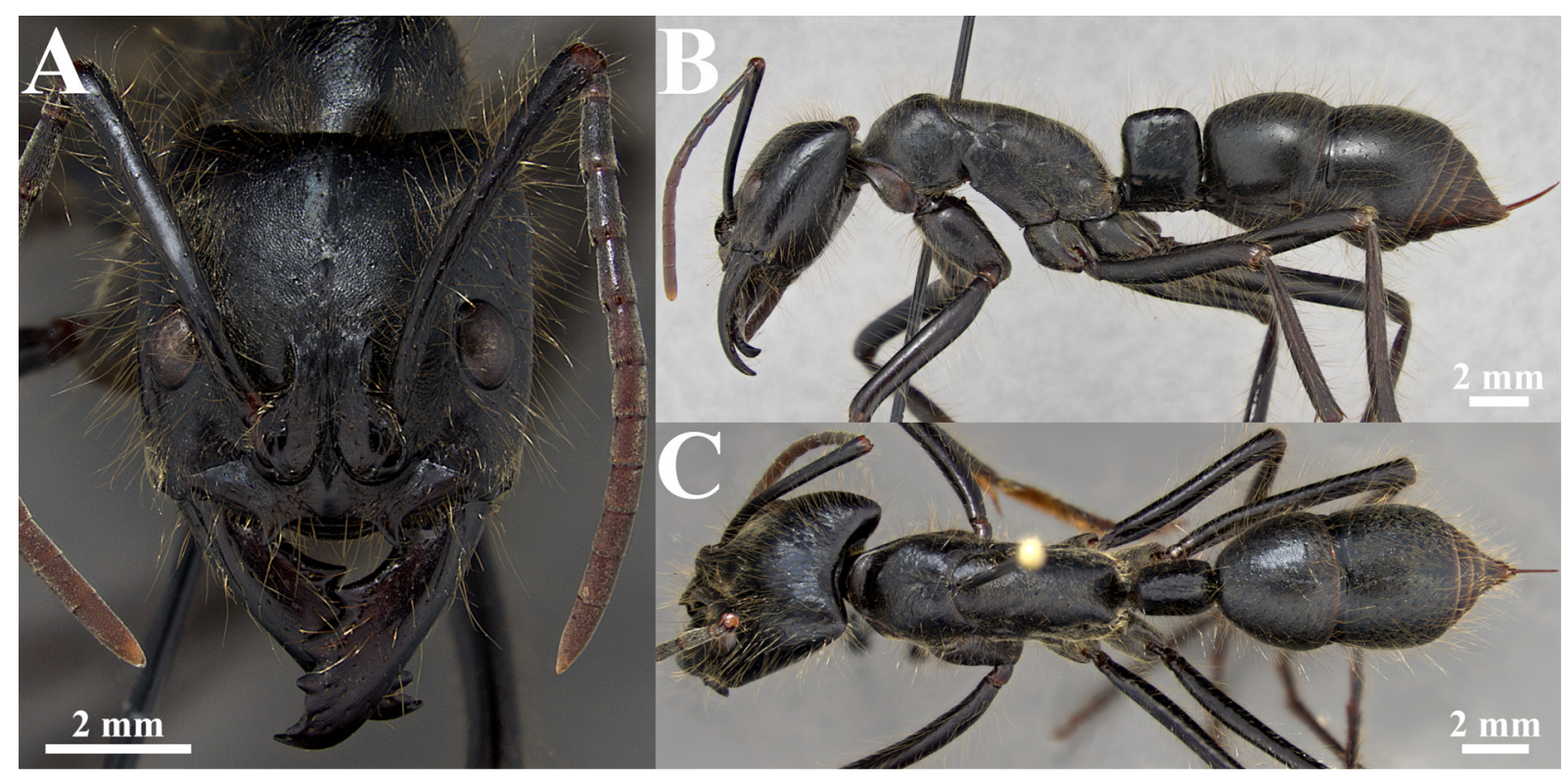

Fig. 13. Dinoponera gigantea (Perty, 1833), ఫ (specimen from Marituba, Pará, Brazil; CPDC). A. Fullface view. B. Full body in lateral view. C. Full body in dorsal view. 
Metasoma. Petiolar node in lateral view elongate (usually DPI $<0.8$ ); anterodorsal corner at same level as posterodorsal corner, sometimes slightly higher; anterior margin straight or slightly concave, forming blunt angle with dorsal margin; dorsal and posterior margin each broadly convex and forming blunt to rounded angle. Node lateral face microareolate and opaque (rarely silky). Node anterior margin in dorsal view slightly convex; posterior margin straight to broadly convex; lateral faces broadly convex. Abdominal tergite III strongly microareolate and opaque; densely punctulate on dorsal and lateral surfaces; distance between each punctulae approximately equal to their diameter; densely covered with brownish, flexuous, erect hairs and appressed pubescence on all surfaces.

\section{Male}

MeASuREMENTs. Non-types ( $\mathrm{n}=4$ ): HL 2.28-2.58; HW1 2.76-3.12; MDL 0.58-0.75; SL 0.9-0.92; EL 1.64-1.87; MOD 0.52-0.57; LOD 0.5-0.52; MSL 7-7.5; HFL 5.4-6.33; PL1 1.96-2.12; PH 1.68-2.01; PW 1.2-1.38; ASL 4.7-5.12; BL1 16.75-18.1 (mm); CI1 1.1-1.21; SEI 1.82-2.02; SI1 0.29-0.33.

HEAD. Frontal carina forming short longitudinal swelling. Lateral ocellus clearly surpassing posterior head margin in full-face view. Head punctulate, weakly microareolate and shining; with yellowish decumbent pubescence and long suberect to erect hairs longer than ocellus height in full-face view. Antenna with appressed pubescence and long suberect to erect hairs clearly longer than maximum scape diameter; third to fourth most apical antennomeres with few sparse hairs. Ventral surface of head punctulate and slightly microareolate with silky sheen.

Mesosoma. Mesoscutum with notaulus slightly impressed. Mesopleural sulcus punctate or slightly scrobiculate. Scutoscutellar sulcus scrobiculate. Mesoscutellum longitudinally strigulate laterally. Metapleural-propodeal suture with same microsculpture as rest of integument. Mesosoma mostly slightly microareolate and with silky sheen, becoming coarsely punctate on declivitous surface of propodeum; with decumbent to suberect pubescence and suberect hairs, distance between each hair usually less than

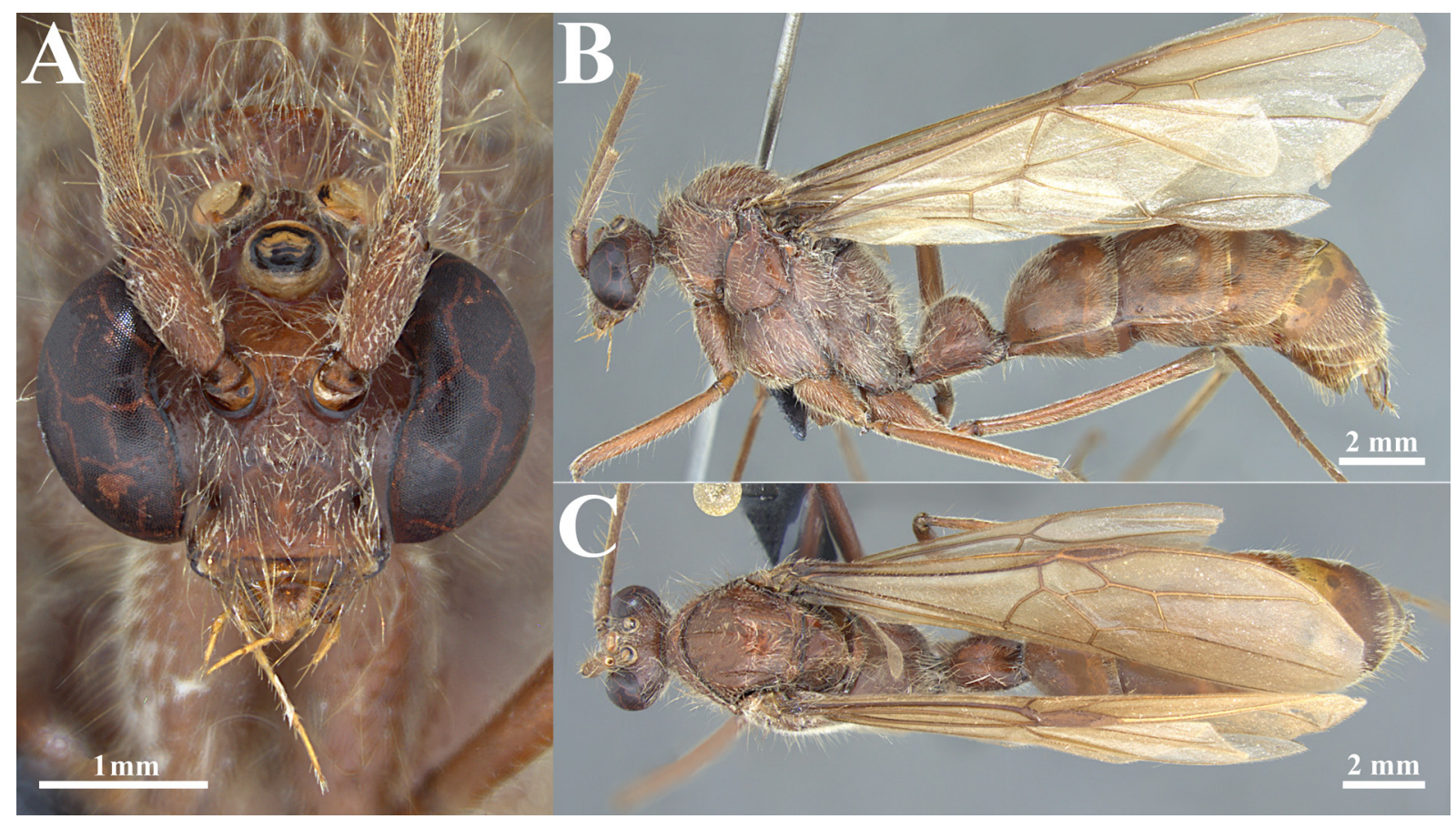

Fig. 14. Dinoponera gigantea (Perty, 1833), ô (specimen from Benevides, Pará, Brazil; MPEG HHY03034653). A. Full-face view. B. Full body in lateral view. C. Full body in dorsal view. 
half its length. Legs densely covered by decumbent pubescence; also with sparse suberect long hairs, greater than femur diameter, from coxa to tibia. Protibial apex with at least one robust seta.

Metasoma. Petiolar node microareolate and shining, densely covered by decumbent pubescence and abundant suberect hairs. Abdominal tergite VIII spiniform. Gaster very slightly microareolate and shining; tergites densely covered by appresed to decumbent pubescence and sparse suberect hairs.

GeNitALIA. Basal ring in dorsal view having slightly concave lateral margins, anteriorly narrower than posteriorly; fenestra rounded to slightly transversally directed; median invagination U-shaped; in lateral view, dorsal margin broadly convex to straight; anteroventral process rounded or slightly subquadrate. Gonostylus narrow and sharp. Dorsal margin of volsella in lateral view anteriorly straight to broadly convex and posteriorly concave; anteroventral corner with two anterior teeth; posteroventral margin strongly concave and forming sharp, triangular posterior lobe; digitus volsellaris with posterior margin straight or with a slight concavity. In lateral view, penisvalva with continuous dorsal and posterior margins, ending in rounded apex; ventral margin even and serrated; concave; anteroventral corner sharply pointed.

CoLor. Body mostly chestnut brown.

\section{Remarks}

A robust set of characters separate females of $D$. gigantea from the other species of the genus. It differs from $D$. hispida, D. longipes, $D$. mutica and $D$. nicinha sp. nov., all species with either an overlapping or close distribution, by the opaque and microareolate pronotal dorsum and abdominal tergite III. Additionally, D. gigantea usually has the anteroventral pronotal corner with a tooth or an acute angle in lateral view. The other species with a toothed pronotum are D. lucida and D. grandis. Dinoponera lucida has bluish iridescence on abdominal tergite III and striae on the malar area that reach the anterior eye margin. Dinoponera grandis has a body length (BL) less than $27 \mathrm{~mm}$ and a relatively shorter petiolar node in lateral view $(\mathrm{DPI}>0.8)$, besides the presence of well-marked striae on the malar area.

Rarely, some specimens may either have a small tooth or obtuse angle on the anteroventral pronotal corner or the third abdominal tergite with very sparse piligerous punctulae, and occasionally both. In such cases, $D$. gigantea may be confused with $D$. quadriceps, but this may be avoided by examining the ventral surface of head, which has arched strigulae covering the entire surface or at least the anterior half in D. gigantea. These variants are more commonly found in Maranhão and Tocantins, where the distribution of these species may overlap. Dinoponera gigantea and D. quadriceps are nevertheless maintained separate, as argued in the remarks for $D$. quadriceps.

Additional support for this separation is provided by the huge differences between their habitats, as D. gigantea is typically from the Amazon and D. quadriceps is from the Caatinga (IBGE 2019). It is worth noting that Maranhão and Tocantins, where the 'problematic' specimens are found, are mostly within the Cerrado Biome, which is located between the Amazon and Caatinga Biomes (IBGE 2019).

The lectotype and two paralectotypes of D. gigantea from the ZSM were examined. Diller (1990) designated the only labelled specimen as the lectotype in the type series of six ants. One of the examined paralectotypes (ZSM HYM-25183) is unusual in having a body length (BL) less than $2.7 \mathrm{~cm}$, a straight metapleural-propodeal suture, a relatively short petiolar node in lateral view (DPI $=0.79)$, the ventral cephalic surface weakly strigulate, abdominal tergite III with sparse piligerous punctulae and relatively short and thick body hairs, especially on the cephalic venter. Collectively these characters do not correspond with the typical characterization of any species in this genus. Nevertheless, recognizing a 
new species was not considered, as the exact collection locality is unknown. Perhaps this specimen is an atypical variant of $D$. gigantea. The worn integument and caked dirt may have abraded some hairs or made others appear more rigid than they should be, potentially complicating character interpretation. The specimen designated as lectotype by Diller (1990) is the one that better represents the forms described as D. gigantea and more resembles the specimens found in the North of Brazil.

Kempf (1971: 372) gave a diagnostic description of the male based on specimens from Belém, and Lenhart et al. (2013) described the genitalia of a male from Belém. Tozetto \& Lattke (2020) described the genitalia of 3 males, all from different sites in Pará. This last study found greater similarities between the basal ring, gonopod, volsella and penisvalva of $D$. gigantea and $D$. quadriceps than between other species. Lenhart et al. (2013), in their identification key to the males of the genus, separated D. gigantea and $D$. quadriceps from those of other species by the long and erect hairs of the funiculus. Kempf (1971) noted the similarities between these two species on account of eye and ocellus size. The aforementioned similarities between these two species suggest they are more closely related to each other than with any of the other known species. Nevertheless, males of $D$. gigantea can easily be separated from D. quadriceps by the presence of a notaulus on the mesoscutum and the abundant hairs on the body.

\section{Biology}

Within their known range these ants are found in areas where the average temperature of the coldest month is higher than $18^{\circ} \mathrm{C}$ and the annual precipitation is higher than $1000 \mathrm{~mm}$ (Alvares et al. 2013). They may be found at sites with different phytophysiognomies, ranging from dense forests to savannas with small woody plants (IBGE 2012). Their nests, which may be polydomic, are usually built at the base of trees and may be up to $40 \mathrm{~cm}$ deep (Fourcassié et al. 1999; Fourcassié \& Oliveira 2002). Each nest has from one to eight entrances surrounded by loose soil never piled into a mound (Fourcassié \& Oliveira 2002). On average, each nest has some 41 adult workers (Monnin et al. 2003).

Workers forage alone searching for a broad variety of resources such as seeds, fruits, and dead or live arthropods (Fourcassié \& Oliveira 2002). Foraging may be diurnal or nocturnal, with activity decreasing during the hottest hours of the day (Fourcassié et al. 1999; Fourcassié \& Oliveira 2002). Workers exhibit general fidelity, with minor deviations, to a foraging route (Fourcassié et al. 1999). Spatial orientation during foraging apparently uses relatively large-scale reference points in the landscape, as minor changes, such as sweeping the leaf litter, do not change their path (Fourcassié et al. 1999). Workers from different colonies may find themselves at the edge of their foraging routes and exhibit territoriality, beating each other with their antennae (Fourcassié \& Oliveira 2002). Hierarchical relationships within a colony are determined by the same agonistic interactions described for D. quadriceps, although with a lower frequency (Monnin et al. 2003).

\section{Distribution (Fig. 28A)}

Dinoponera gigantea has been recorded in northern Brazil and eastern Peru. In Brazil, the northernmost record is the type-locality along the Rio Negro (probably close to Barcelos, Amazonas, according to Kempf 1971). It is important to note that, except for the type-series, D. gigantea has only one record for Amazonas. All other records are mostly from Pará and Maranhão, with the southernmost record from Rio Tapirapé, Mato Grosso. The examined records from Peru date from 1966 and are close to the border with Brazil, more than $900 \mathrm{~km}$ from any other record. This may indicate a much more extensive distribution in the recent past. Lenhart et al. (2013) examined a specimen from Bartica, Cuyuni-Mazaruni, Guiana but this single record may be an artefact of a misplaced label, as it is $500 \mathrm{~km}$ from any other record for the genus. Despite numerous surveys and collecting, Dinoponera has yet to be recorded from the Guiana Shield (Wheeler 1916, 1918; Lapolla et al. 2007; Alonso 2012; Alonso \& Helms 2013; Helms et al. 2016; Groc et al. 2014; Franco et al. 2019). 


\section{Dinoponera grandis (Guérin-Méneville, 1838). Revived species}

Figs $15-18,28 \mathrm{~A}$

Ponera grandis Guérin-Méneville, 1838: 206 (ఫ).

Dinoponera grandis australis Emery, 1901: 48 (ఫ). syn. nov.

Dinoponera australis brevis Borgmeier, 1937: 227 (ఫ).

Dinoponera australis bucki Borgmeier, 1937: 228, fig. 7 (ఫ, ठో). syn. nov.

Dinoponera australis nigricolor Borgmeier, 1937: 228, figs 5-6, 8 (ఫ, ठૈ). syn. nov.

Dinoponera snellingi Lenhart, Dash \& Mackay, 2013: 152, figs 4d, i, n, 5b, 7, 9b, 10b, 11b (ठึ). syn. nov.

Dinoponera grandis - Roger 1861: 38 (combined in Dinoponera, synonym of D. gigantea). — Bequaert 1926: 188 (junior synonym of $D$. gigantea).

Dinoponera grandis australis - Santschi 1921: 85 (male description). - Borgmeier 1937: 227 (raised to species, lectotype designated). - Kempf 1975: 382, figs 6, 17-18 (redescription, key). — Lenhart, Dash \& Mackay 2013: 135, figs 4e, j, o, 5d, 9d, 10d, 11d (redescription, male genitalia, key). Tozetto \& Lattke 2020: 5, figs 2-3, 6 (male genitals).

Dinoponera australis brevis - Kempf 1971: 382 (junior synonym of D. australis).

Dinoponera australis nigricolor - Kempf 1971: 387 (lectotype male designated).

Non Dinoponera grandis australis brevis - Santschi 1928: 416 (invalid name).

\section{Diagnosis}

\section{Female}

Malar area with longitudinal to oblique striae that reach anterior ocular margin. Abdominal tergite III microareolate and opaque to slightly silky, never smooth and shining. Hind basitarsus length less than $6 \mathrm{~mm}$ long. Petiolar node short, DPI $\geq 0.8$. BL $\leq 27 \mathrm{~mm}$.

\section{Male}

Body, including antenna, without long hairs. Basal ring in lateral view with dorsal margin declining and extending anteriorly to form a broad lobe. Penisvalva in lateral view with a posterior rounded apex, projecting ventrolaterally.

\section{Material examined}

\section{Lectotype of Ponera grandis}

BRAZIL - Minas Gerais • ఛ̧; ZSM.

Other type specimens $(13$ ఢఫ, $2 \precsim ふ$ ふ)

BRAZIL - Goiás • $\widehat{O}$, lectotype of D. australis nigricolor; Campinas; 5 May 1933; Schwarzmaier leg.; MZSP 65801 - 1 ф, paralectotype of D. australis nigricolor; Campinas; 6-8 Feb. 1936; R. Spitz leg.; MZSP $67063 \cdot 1 \Varangle$, paralectotype of $D$. australis nigricolor; same collection data as for preceding; MZSP $67064 \cdot 1 \quad \zeta$, paralectotype of $D$. australis nigricolor; same collection data as for preceding; MZSP $67066 \cdot 1$ 1 , paralectotype of $D$. australis nigricolor; same collection data as for preceding; MZSP $67067 \cdot 1$ 1 , paralectotype of D. australis nigricolor; same collection data as for preceding; MZSP 67068 - 1 ఢ, paralectotype of D. australis nigricolor; same collection data as for preceding; MZSP $67069 \cdot 1$ 1 , paralectotype of $D$. australis nigricolor; same collection data as for preceding; MZSP $67070 \cdot 1 \Varangle$, paralectotype of $D$. australis nigricolor; same locality as for preceding; 4 Nov. 1937; Schwarzmaier leg.; MZSP $67071 \bullet 1$ ๖, paralectotype of D. australis nigricolor; same collection data as for preceding; MZSP $67072 \bullet 1 \Varangle$, paralectotype of D. australis nigricolor; same collection data as for preceding; MZSP $67073 \bullet 1 \Varangle$, paralectotype of D. australis nigricolor; same collection data as 
for preceding; MZSP 67074. - Rio Grande do Sul • 1 , lectotype of Dinoponera australis bucki (here designated); Palmeira das Missões; 27 Jan. 1929; P. Buck leg.; MZSP 65800 • 1 ఛ, paralectotype of D. australis bucki; same collection data as for preceding; MZSP $67061 \bullet 1 \Varangle$, paralectotype of $D$. australis bucki; same collection data as for preceding; MZSP 67062.

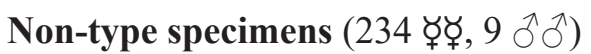

ARGENTINA - Missiones • 1 ఫ; Bruch leg.; MZSP • 2 ఫॄ్; Iguazú; Oct. 1964; A. Martinez leg.; MZSP.

BOLÍVIA - Icnilo • 1 ६;; Buenavista; Feb. 1950; A. Martinez leg.; MZSP. - Santa Cruz • 1 ఫ; Gutierrez, Nueva Moka [Moca]; 23 Nov. 1951; A. Martinez leg.; MZSP • 1 ఫ̛; "Samaipata - balneário mama Pascula"; 3 Jan. 1989; F.J.A. Peralta and Hansen leg.; INPA • 1 ६̧; San José de Chiquitos; 3-5 Mar. 1954; C. Gans and F. Pereira leg.; MZSP • 1 ఫ; Sara, Nueva Moka; Feb. 1950; A. Martinez leg.; MZSP• 1 ६; Nueva Moka; Mar. 1956; A. Martinez leg.; MZSP.

BRAZIL - Distrito Federal • 1 ఫ̧; APA Gama Cabeça de Veado; 2 Mar. 2000; Pic. Mireille leg.; CPDC - 2 ఫ̛ఫ; Brasília; Oct. 1961; R.L. Araújo leg.; MZSP • 1 ఫ; Brasília; $15.96565^{\circ}$ S, 47.91626º W; 8 Apr. 2011; H.L. Vasconcelos and T. Frizzo leg.; 1157, T5-6S; UFU • 1 ఫ̛; Brasília, Ceilândia; 15 Oct. 1976; 499; DZUP • 1 ఫ̛; Brasília, E. Ecol. Águas Emendadas; 15 Dec. 1992; A. Reis leg.; MZSP • 1 ఫ;; same locality as for preceding; 19 May 1993; J.H. Schoereder leg.; UFV LabEcol 437 • 1 ६; same collection

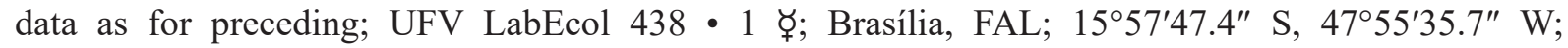
16 Oct. 2010; M.C. Galego-Ropero and P. Rezende leg.; "cupinzeiro C. cumulans"; MZSP • 1 ఫ̧; Brasília, Reserva Ecológica do IBGE (RECOR), Fisionomia campo limpo; $15.9166^{\circ} \mathrm{S}, 47.8666^{\circ} \mathrm{W}$ to

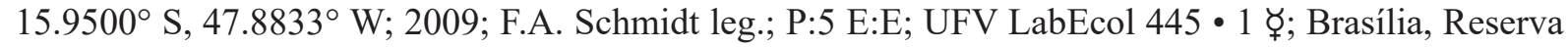
Ecológica do IBGE, cerrado sensu stricto; 6 Feb. 2008; J. Maravalhas leg.; MZSP • 1 ६; same collection data as for preceding; 7 Feb. 2008; MZSP • 1 ఛ̧; UnB Campus; 10 Nov. 1974; Bittencourt leg.; 11756, 500; DZUP • 1 ఫ; same collection data as for preceding; 11756, 501; DZUP. - Goiás • 1 ఢ; 7 km NW of Alto Paraíso, Morro das Cobras; 1-7 Jul. 1991; C.R.F. Brandão, M.L. Françoso and A.A. Reis leg.; pitfall stn 1; MZSP • 1 ఫ; Abadia de Goiás; 6 Nov. 1980; C.R. Krigger leg.; UFSC • 1 ఢ; Anápolis; Nov. 1938; M. Souza leg.; MZSP • 1 ఫ; Anápolis, UEG, Campus CCET; $16.3826^{\circ}$ S, $48.9446^{\circ}$ W; 5 Oct. 2010; H.F. Cunha leg.; UEG • 6 ఫర్;; same collection data as for preceding; 18 Oct. 2010; UEG • 1 ६; same collection data as for preceding; 20 Oct. 2010; UEG • 1 ఛ; same collection data as for preceding; 27 Oct. 2010; UEG • 1 ६; same collection data as for preceding; 1 Nov. 2010; UEG • 1 ఫ; same collection data as for preceding; 12 Nov. 2010; UEG • 2 ఫర్ఛ; same collection data as for preceding; 8 Dec. 2010; UEG • 2 ఫ̛ఫ; same collection data as for preceding; 14 Dec. 2010; UEG • 1 ఛ; same collection data as for preceding; 21 Dec. 2010; UEG • 4 ర̧ఠ్; same collection data as for preceding; 13 Jan. 2011; UEG • 4 రోఫ; same collection data as for preceding; 20 Jan. 2011; UEG • 3 రోర్;; same collection data as for preceding; 3 Feb. 2011; UEG • 2 ఫॄర;; same collection data as for preceding; 17 Feb. 2011; UEG • 1 ఫ; same collection data as for preceding; 24 Feb. 2011; UEG - 3 ఫ६孔; same collection data as for

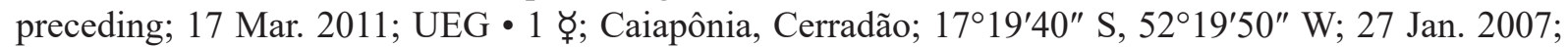
Vitor M. Carvalo leg.; Coleção Diniz; 8-9h A7; DZUP • 2 ఫఢఫ; same collection data as for preceding;

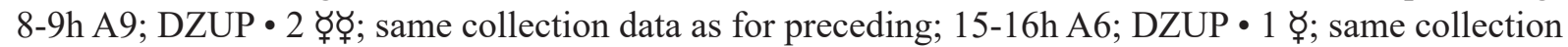
data as for preceding; 19-20h A7; DZUP • 2 ఫర్ఛ; same collection data as for preceding; 10 Feb. 2007; 19-20h A9; DZUP • 1 ఫ్; same collection data as for preceding; 24 Feb. 2007; 15-16h A6; DZUP • 1 ६; same collection data as for preceding; $15-16 \mathrm{~h} \mathrm{A7;} \mathrm{DZUP・} 1$ ६; same collection data as for preceding; 19-20h A6; DZUP • 1 ६̧; same collection data as for preceding; 10 Mar. 2007; 15-16h A8; DZUP • 1 ఫ̛; same collection data as for preceding; 19-20h A9; DZUP • 1 ఢ̧; Caiapônia, pasto; $17^{\circ} 19^{\prime} 40^{\prime \prime}$ S,

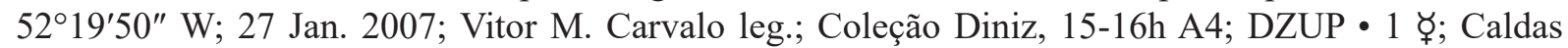
Novas; 1 Nov. 2011; H.L. Vasconcelos and T. Frizzo leg.; 952, T31-11S; DZUP • 1 ६; same collection data as for preceding; 1020, T32-11S; DZUP • 1 ६; same collection data as for preceding; 983, T33-17S; DZUP • 1 ६; same collection data as for preceding; 1020, T32-17S; DZUP • 1 \%; Campinas; 1935; 
R. Spitz leg.; MZSP 62281 • 1 ఫ; Chapada dos Veadeiros; 13 Apr. 2015; J.B. Maravalhas leg.; 1088,

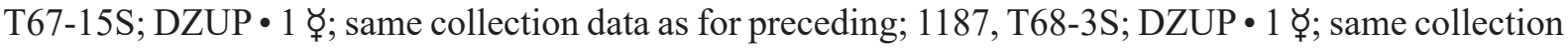
data as for preceding; 1187, T68-15S; DZUP • 1 ఫ; Cocalzinho de Goiás, cerrado rupestre; $15^{\circ} 47^{\prime} 43^{\prime \prime}$ S, 4849'45.76" W; alt. 1321 m; 31 Jan. 2010; Eduardo de Oliveira Emery leg.; DZUP • 2 ఫ̛ఫ్; Goiânia, campus Euc. De veterinária; 23 Dec. 2001; Luciano Lozi leg.; Coleção Diniz; DZUP • 1 ఫ̧; Goiás Velho; 2 Jan. 1976; Guiflord leg.; MZSP • 1 đ̇; Jataí; Dec. 1972; F.M. Oliveira leg.; 8843; MZSP 62282 • 1 ६; Mineiros; 8 Feb. 2012; T. Frizzo leg.; 849, T38-11S; DZUP • 1 ६; Mineiros, Parque Nacional das Emas; 1754'30.3" S, 5300'29.6" W; 8 Feb. 2012; F. Camarota, T. Frizzo and R. Pacheco leg.; DZUP •

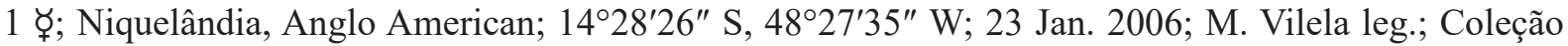
Diniz, IDSC (right) 19; DZUP • 1 ఫ; same collection data as for preceding; INSC (right) 82; DZUP • 2 ఫఢఫ; same collection data as for preceding; INSC (left) 65; DZUP • 1 ६̧; same collection data as for preceding; INSC (left) 23; DZUP • 1 ६; same collection data as for preceding; IDSC (left) 77; DZUP • 1 ६; same collection data as for preceding; 22 Mar. 2006; IDSC (right) 88; DZUP • 1 ६; same collection data as for preceding; 24 May 2006; INSC (right) 52; DZUP • 1 ६; Parque das Emas; 11 Nov. 1990; C.R. Krigger leg.; UFSC • 1 ఫ̛; P.E. Serra de Jaraguá; $15.7964^{\circ}$ S, 49.3335 W; 3 Jan. 2017; D.E. Oliveira leg.; DEO 843; DZUP • 1 ఛ; same collection data as for preceding; DZUP 549812 • 1 ६̧; P.N. Emas, Mineiros; 25 Oct.-2 Nov. 1986; Bechara, Viviani, Ferro and Sanche leg.; MZSP • 1 ఫ;; Santa Bárbara; 9 Dec. 2014; H.L. Vasconcelos and J.B. Maravalhas leg.; 643, T61-19S; DZUP • 1 ఫ;; same collection data as for preceding; 631, T63-11S; DZUP. - Mato Grosso • 1 ఢ̧; Barra do Garça; 6 May 2011; H.L. Vasconcelos and T. Frizzo leg.; 539, T11-7S; UFU • 1 ఢ̧; Bonito; 10 Jul. 2012; T. Frizzo leg.; 436, T43-11S; DZUP• 1 ఫ६; Buriti; 15 Feb. 1967; N. Tangerini leg.; DZUP • 1 ఢ; Cachoeira da Fumaça; 9 May 2011; H.L. Vasconcelos and T. Frizzo leg.; 330, T13-3S; DZUP・ 1 đ; Chapada dos Guimarães; 23 Nov. 1983; Dep. Zool - UFPR (polonoroeste) exped.; DZUP • 1 ఫ̛; same locality as for preceding; 24 Nov. 1983; Depto. Zool. (polonoroeste) exped.; DZUP • 1 ६̧; same collection data as for preceding; 1-4 Feb. 1965; Sebastião Laroca leg.; DZUP • 1 ६̧; same collection data as for preceding; 27 Jan. 1965; DZUP • 6 ఫ६; same collection data as for preceding; Nov. 1963; Alvarenga and Werner leg.; MZSP • 1 ६;; same collection data as for preceding; May 1959; Fr. Cannto leg.; MZSP • 4 ఛఢఛ; Jan.

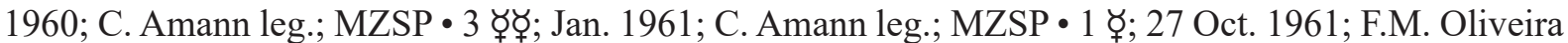

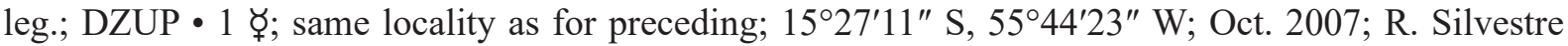
et al. leg.; manual UFGD • 1 ఛ̧; Chapada dos Guimarães, Fazenda Buriti; 18 Nov. 1982; Márcio Zanuto; MPEG HYM11513596 • 1 ఫ; same collection data as for preceding; MPEG HYM11513598 • 1 ६̧; Chapada dos Guimarães, Buriti; Oct. 1972; G.R. Kloss and F. Val leg.; MZSP • 1 đ̂; Itaum; Mar. 1974; M. Alvarenga leg.; 10877; MZSP 62284 • 1 ○ं; same data as for peceding; 10878; MZSP • 1 ô; Maracaju; Shannon Lane leg.; DZUP • 1 ६̧; Nova Xavantina; 10 May 2011; T. Frizzo leg.; 321, T16-7S; DZUP • 1 ఫ; same collection data as for preceding; 311 T17-3S; DZUP • 1 ఫ; PARNA Chapada dos Guimarães, Trilha do Cerrado; $15^{\circ} 24^{\prime}$ S, 55 50' W; alt. 617 m; Mar. 2016; R. Silvestre et al. leg.; UFGD • 1 ఫ̧; Vale dos Sonhos, Barra do Garças; alt. 400 m; 22 Jun. 1972; Mielke and Brown leg.; DZUP 548841 • 1 ఛ̧; Vale dos Sonhos, S. pr. B. do Garças; 14 Jan. 1977; Kunze leg.; Coleção Diniz; 1394;

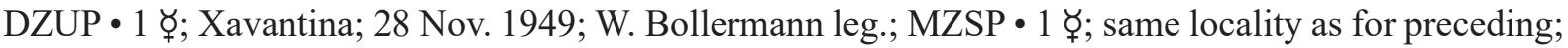
10 Jan. 1977; Kunze leg.; Coleção Diniz, 1392; DZUP. - Mato Grosso do Sul • 1 ఛ; Bodoquena, Parque Nacional da Bodoquena, mata ciliar; 10 Apr. 2008; T. Marques, J.H. Schoereder, R. Silvestre and interns leg.; arm 1 solo; UFV LabEcol 442 • 1 ఫ६; Bonito; 9 Oct. 1989; Paiva R. leg.; MZSP • 1 ఫ;; Bonito,

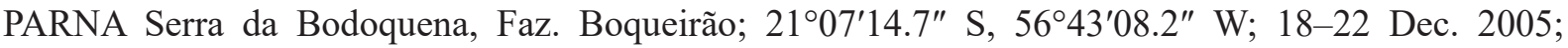
R. Silvestre et al. leg.; Hym 93-F; UFGD • 1 ఫ६; Bonito, PARNA Serra da Bodoquena, Faz. Harmonia;

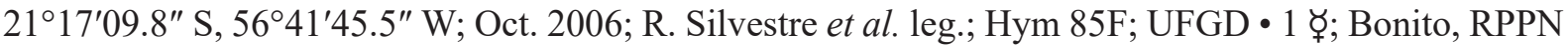

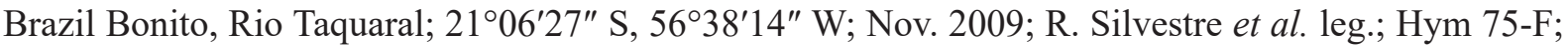
UFGD • 1 ఫ; Campo Grande; 9 Oct. 1989; C.R.F. Brandão leg.; MZSP• 1 ఫ; Campo Grande, Universidade Federal de Mato Grosso do Sul, RPPN UFMS; 21 Oct. 2017; P.R. Souza leg.; ZUFMS 3064 • 1 ఫ; Morraria do Sul, PN Serra da Bodoquena, Faz. Califórnia; 2042'07" S, 5652'47.7" W; Nov. 2009; R. Silvestre et al. leg.; UFGD • 1 ఢ ; Paranaíba, R. Paranaíba; 14 Aug. 1972; em solo 506; Coleção Diniz; 
DZUP • 1 ఛ; PARNA Serra da Bodoquena, Faz. Sta Laura da Vicunha, Rio Salobra; 20 46'56.2" S, 56 44'31.2" W; 22-29 Jun. 2006; $3^{\circ}$ exp., R. Silvestre et al. leg.; pitfall A-10, Hym 83-F; UFGD •

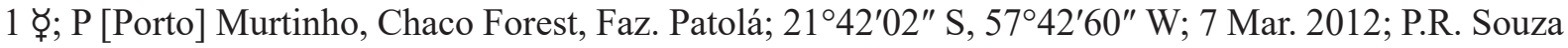
et al. leg.; busca ativa; UFGD • 1 ६; same collection data as for preceding; DZUP 548837 • 1 ६ ; S do Paranaíba [Santana do Parnaíba], Fazenda Olho D'água; 21 Feb. 1972; Diniz leg.; Coleção Diniz, 512, Em 9010; DZUP • 1 ఢ̧; snt.do Paranaíba [Santana do Parnaíba], Faz. Olho D’Água; 12 Jul. 1971; Diniz leg.; Coleção Diniz, 499, Em 9010; DZUP • 1 ఛ̧; same locality as for preceding; 12 Jul. 1972; Diniz leg.; em solo; MZSP - 2 ఫ̧ర్; Serra da Bodoquena, Cara da Onça RPPN; 20 44'24" S, 5644'11" W; alt. 196 m; Dec. 2011; R. Silvestre leg.; manual; UFGD • 1 ఫ; Serra da Bodoquena, Faz. Campo Verde; $21.3755^{\circ} \mathrm{S}, 56.7177^{\circ} \mathrm{W}$; alt. 444 m; Dec. 2008; R. Silvestre leg.; manual; UFGD • 2 ర̛⿱్;; Três Lagoas, Jardim Alvorada; 3 Aug. 1985; J.L.M. Diniz leg.; Coleção Diniz, 2194; DZUP. - Minas Gerais • 1 ఫ;; Campo Florido; 12 Feb. 1964; H.M. Canter leg.; MZSP • 1 ఫ;; Monte Carmelo; $18.8000^{\circ} \mathrm{S}, 47.8000^{\circ} \mathrm{W}$ (3 min error); 23-25 May 2016; J.J.M. Aguiar leg.; amostra 355/176; ANTWEB 1038256; UFV • 1 ఫ্; S do Salito [Serra do Salitre]; 4 Apr. 1965; C. Elias leg.; DZUP • 1 ఫ; Uberaba; Oct. 1961; C. Elias leg.; DZUP • 1 ఫ̛; Uberlândia; Jan. 1999; W.L. de Melo leg.; DZUP 548840; DZUP. - Paraná • 1 ఢ̧; C Mourão [Campo Mourão]; Jul. 1950; coleção F. Justus; DZUP • 1 ఢ̧; F do Iguaçu, Foz de Iguaçu cataratas; 24 Aug. 2000; J.O. Schmidt leg.; MPEG • 1 ô; Guarapuava; Mar. 1947; 4380, Coleção F. Justus Jr; DZUP 548845 • 1 ఛ̧; Guarauna; Dec. 1940; coleção F. Justus, DZUP 548839; DZUP • 1 ఢ; Laranjeira do Sul; Mar. 1947; coleção F. Justus, 4384; DZUP • 1 đ;; same locality as for preceding; Jan. 1962; S. Sakagami leg.; DZUP 548844 • 1 ६̧; same collection data as for preceding; DZUP 548838 • 1 ६;; Palmas; Dec. 1928; F. Schroer leg.; MZSP. - Santa Catarina • 1 ఫ; Chapecó; 2004; Funir leg.; P06; UFSC • 3 ఫఛర్;; Nova Teutonia; Fritz Plaumann leg.; MZSP • 1 ఫ্; same locality as for preceding; 30 Dec. 1940; Diringe leg.; MZSP • 1 ६; same locality as for preceding; May 1957; Fritz Plaumann leg.; MZSP. - São Paulo • 1 ఢ̧; Agudos; May 1959; C. Gilbert leg.; 3524; MZSP • 3 రఢఫ;; same collection data as for preceding; Mar. 1960; MZSP • 1 ఢ̧; Boa Esperança do Sul, Faz. Itaquerê; 28 Nov. 1963; K. Lenko leg.; 2946; MZSP • 1 ६̧; Botucatu; 1 Sep. 1963; Mantovan leg.; MZSP • 1 ఢ̧; same locality as for preceding; 18 Oct. 1968; M. Artamiro leg.; 6423; MZSP • 2 రోఫ్; same locality as for preceding; 4 Dec. 1968; M. Artamiro leg.; 6422; MZSP • 1 ६; Botucatu, CESP; 15 Apr. 1991; B.H. Dietz leg.; MZSP • 12 ఫ̛ఫ; Corumbataí; 30 Dec. 1962; H.A. Britski leg.; MZSP • 1 ఫ; Corumbataí, Fac. Fil. Rio Claro; 1 Nov. 1963; DZUP • 1 ठ̊; Itirapina; 10 Apr. 1990; R. Paiva leg.; MZSP 62283 • 2 ఫఢఫ; same locality as for preceding; 27 Feb. 1968; D. Dias leg.; 4857; MZSP • 1 ६̧; same locality as for preceding; 24 Oct. 1987; H.G. Fowler leg.; CPDC • 1 ६̧; same locality as for preceding; 18 Nov. 1999; Thibaud Monnin leg.; MZSP • 1 ఫ;; Jundiaí; Nov. 1929; J. Lane leg.; MZSP • 1 ఫ; Rio Claro; 1 Jul. 1962; S. Laroca leg.; DZUP • 1 ६̧; same locality as for preceding; 18 Nov. 1983; Caetano and Brandão leg.; MZSP • 1 ६; same locality as for preceding; Feb. 1992; E. Tomatake leg.; 4530; CPDC・ 1 ६;; S [São] Carlos, Faz. Canchiu; 9 Jun. 1987; R.R. Martins leg.; MZSP. - Rio Grande do Sul • 1 ६; Derrubadas, Parque Estadual do Turvo, Floresta Semidecídua; 25 Apr. 2009; T. Marques leg.; pitfall hipogeico; UFV LabEcol 441 • 1 ఢ̧; Derrubadas, Parque Estadual do Turvo, mata seca; 25 May 2009; T. Marques and interns leg.; arm 10 estrato sol; MZSP • 2 ఫ̛ర్; Sto [Santo] Ângelo; 23 Feb. 1974; R.L. Araújo leg.; MZSP • 1 ఛ̧; Santa Bárbara [Santa Bárbara do Sul]; 23 Dec. 1944; C.R. Gonçalves leg.; MZSP • 2 ఫ̛ఫ্; Soledade, PPBio, Natural Grassland Ecossystem, campo; $28.8725^{\circ}$ S, $52.4588^{\circ}$ W; Nov. 2013; L.R. Podgaiski leg.; manual collection; UFRGS • 1 ఫ; Tem [Tenente] Portela, P. Est. Rio Turvo; Oct. 1978; E.P. Albuquerque leg.; MZSP • 1 ६̧; Uruguaiana; Aug. 2014; E. Gazbe leg.; MZSP. - Tocantins • 1 ఫ; Paranã, cerrado sensu stricto; $12.8140^{\circ}$ S, $47.8980^{\circ}$ W; 13 Oct. 2004; R.R. Silva and B.H. Dietz leg.; at night; MZSP.

PARAGUAY - Amambaí • 1 ఢ̧; Parque Nac. Cerro Corá; 2 Nov. 1983; T. Bonace leg.; ibn0070; MNHNP HX68 • 1 ఫ; same locality as for preceding; 24 Feb. 1981; ibn0066; MNHNP HX62 • 1 ६; same locality as for preceding; 7-27 Mar. 1982; H. Ferreira da Cunha leg.; ibn0062; MNHNP HX66 • 1 ६; same locality as for preceding; 5 Nov. 1983; H. Ferreira da Cunha leg.; MNHNP HX63・1 ६̧; same collection 
data as for preceding; ibn0065; MNHNP HX64 • 1 ६; same collection data as for preceding; ibn0063; MNHNP HX67 • 1 ఫ; same locality as for preceding; 5 Jun. 1984; T. Bonace leg.; ibn0059; MNHNP HX65 • 1 ६; same collection data as for preceding; ibn0067; MNHNP HX69 • 1 ఫ; same locality as for preceding; 2 Nov. 1985; P. Muller leg.; MNHNP HX55 • 1 ६̧; same collection data as for preceding; MNHNP HX56 • 1 ఛ; same collection data as for preceding; MNHNP HX57・1 ६̛; same collection data as for preceding; MNHNP HX58 • 1 ६̧; PN Cerro Corá; 12-16 Oct. 1981; J.A. Kolchaka leg.; MNHNP HX53 • 1 ఫ; same collection data as for preceding; MNHNP HX54 • 1 ఫ; same locality as for preceding; $22^{\circ} 38^{\prime} 19^{\prime \prime} \mathrm{S}, 56^{\circ} 01^{\prime} 12^{\prime \prime} \mathrm{W}$; alt. 269 m; 3 Apr. 2015; R. Silvestre et al. leg.; UFGD. - Itapúa • 1 ఫ; Alto Verá; 10 Nov. 1999; J.A. Kolchaka leg.; MNHNP HX59 • 1 ६; same collection data as for preceding; MNHNP HX60 • 1 ఫ;; same collection data as for preceding; MNHNP HX61 • 1 ६; Encarnación; $\mathrm{n}^{\circ} 2646$ coll Borgm.; MZSP • 1 ఫ; same locality as for preceding; 2 Oct. 1898; C. Schrottky leg.; MZSP. - Misiones • 1 ఢ্; Santiago; Oct. 1975; H. Fowler leg.; HFXXX, 13418; MZSP. - San Pedro • 1 ఢ; Choré; 25 Feb. 1988; Maria Noce de Meza leg.; MNHNP HX52.

\section{Redescription}

Female

Measurements. Lectotype: HL 5.1; HW 4.97; MDL 3.85; SL 4.78; MSL 7.36; HFL 6.4; HBL 5.6; PL 1.93; PH 2.99; PW 1.89; ATS 6.72; BL 24.97 (mm); CI 0.97; SI 0.96; DPI 0.97. Non-types (n=61): HL 4.38-5.63; HW 4.04-5.35; MDL 3.05-4.28; SL 4.08-5.48; MSL 6.28-7.8; HFL 5.6-6.88; HBL 4.725.9; PL 1.67-2.23; PH 2.48-3.2; PW 1.48-1.92; ATS 5.68-7.72; BL 22.06-27 (mm); CI 0.88-1.03; SI $0.85-1.07$; DPI $0.8-1$.

HEAD. Malar area with longitudinal to oblique striae that always reach anterior eye margin, sometimes extending to gena. Gena microareolate and opaque, sometimes silky, never smooth and shining, usually without rugulae. Apressed pubescence present between eye and frontal lobe, extending posteriorly to frons. Frons microareolate and opaque or with weak silky sheen; with flexuous, brownish and decumbent to suberect hairs, longer than scape diameter; pubescence short, appressed and scarce. Occipital corner varying from strongly microareolate and opaque to smooth and silky. Antennal scape microareolate

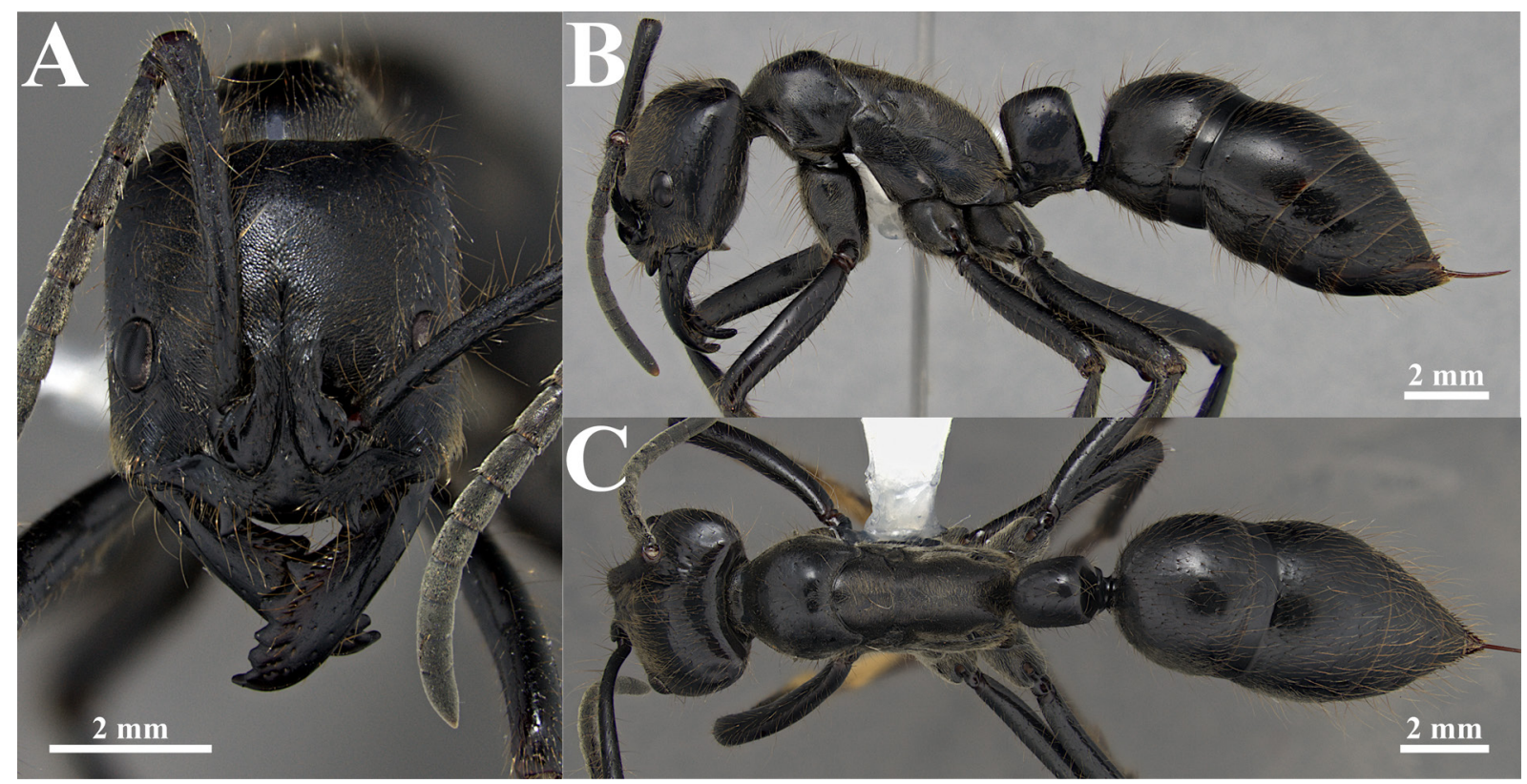

Fig. 15. Dinoponera grandis (Guérin-Méneville, 1838), ఫ (specimen from Jaraguá, Goiás, Brazil; DZUP549812). A. Full-face view. B. Full body in lateral view. C. Full body in dorsal view. 
and silky, suberect and long hairs usually present on antennal segments 1-3. Ventral surface of head microareolate with arched strigulae covering entire surface or just close to postgenal suture (rarely absent). Hypostomal tooth longitudinally strigulate. Labrum with median longitudinal sulcus weakly marked; with transverse rugulae. Mandibular dorsum weakly longitudinally strigulate on inner base, sculpture gradually fading apicad.

Mesosoma. Dorsal margin of pronotum in lateral view broadly convex, usually with no pronounced dorsoposterior swelling; anteroventral corner of pronotum toothed or forming acute angle, rarely obtuse. Pronotal dorsum strongly microareolate and opaque to weakly microareolate and silky. Metapleuralpropodeal suture sinuous, with at least one curve ventral to position of propodeal spiracle.

Metasoma. Petiolar node in lateral view relatively short (DPI $\geq 0.8)$; anterodorsal corner at same level as posterodorsal corner, sometimes slightly lower; anterior margin straight or slightly concave, forming blunt angle with dorsal margin; dorsal and posterior margin each varying from broadly convex to straight and forming blunt to slightly rounded angle. Node lateral face usually microareolate and opaque, rarely slightly smooth and silky. Node anterior margin in dorsal view convex; posterior margin straight to broadly convex; lateral margins broadly convex and converging anterodorsally. Abdominal tergite III strongly microareolate and opaque to weakly microareolate and silky; punctulae in variable density, always denser laterally than dorsally; densely covered with brownish, flexuous, decumbent to suberect hairs on entire surface; appressed pubescence very sparse on dorsum, denser laterally.

\section{Male}

Measurements. D. a. nigricolor lectotype: HL 2.07; HW1 2.3; MDL 0.56; SL 0.55; EL 1.19; MOD 0.31; LOD 0.33; MSL 5.93; HFL 4.6; PL1 1.34; PH 1.14; PW 1.12; ASL 3.25; BL1 13.16 (mm); CI1 1.1; SEI 2.14; SI1 0.24. D. a. bucki lectotype: HL 2.17; HW1 2.25; MDL 0.55; SL 0.62; EL 1.06; MOD 0.26; LOD 0.3; MSL 5.62; HFL 4.5; PL1 1.27; PH 1.09; PW 1; ASL 3.22; BL1 12.85 (mm); CI1 1.03; SEI 1.7; SI 10.27. Non-types $(\mathrm{n}=7)$ : HL 1.9-2.12; HW1 2.15-2.37; MDL 0.51-0.68; SL 0.46-0.68; EL 1.11-1.3; MOD 0.31-0.43; LOD 0.27-0.43; MSL 5.37-6.66; HFL 3.74-4.68; PL1 1.3-1.48; PH

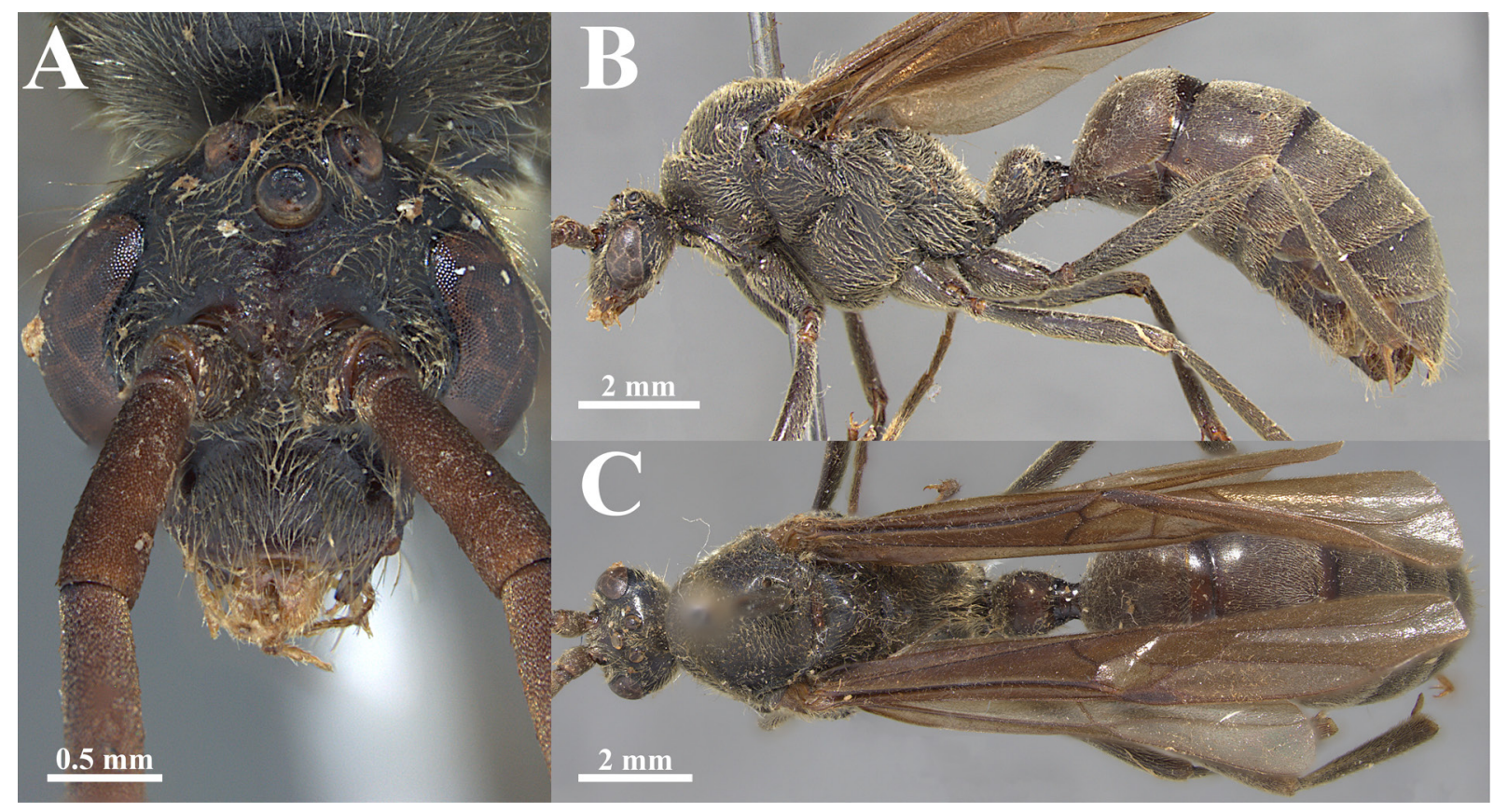

Fig. 16. Dinoponera grandis nigricolor Borgmeier, 1937 syn. nov., lectotype, đ (Campinas, Goiás, Brazil; MZSP 65801). A. Full-face view. B. Full body in lateral view. C. Full body in dorsal view. 
1.14-1.42; PW 1.06-1.25; ASL 3.06-4.12; BL1 12.39-14.9 (mm); CI1 1.04-1.24; SEI 1.83-2.53; SI1 $0.2-0.31$.

HEAD. Frontal carina forming a short longitudinal line. Lateral ocellus usually reduced, sometimes not surpassing posterior head margin in full-face view. Head punctulate, very slightly microareolate and with silky sheen; with pallid decumbent pubescence and very few decumbent hairs only on clypeus and vertex. Antenna with very short appressed pubescence, without hairs. Ventral surface of head punctulate and slightly microareolate with silky sheen.

Mesosoma. Mesoscutum without notaulus. Mesopleural sulcus usually mostly smooth. Scutoscutellar sulcus scrobiculate. Mesoscutellum usually longitudinally strigulate laterally to variable degrees. Metapleural-propodeal suture with same microsculpture as rest of integument. Mesosoma varying from microareolate and subopaque to smooth and shining, not becoming coarsely punctate on declivitous surface of propodeum; with short decumbent pubescence; without hairs. Legs densely covered by decumbent pubescence; without long hairs. Protibial apex usually without a stout seta.

Metasoma. Petiolar node usually slightly microareolate and with silky sheen; densely covered by decumbent to suberect pubescence, without hairs. Abdominal tergite VIII triangular, sometimes with a very sharp apex. Gaster usually microareolate and subopaque; tergites densely covered by appressed to decumbent pubescence; without long hairs.

Genitalia. Basal ring in dorsal view with slightly concave lateral margins, anteriorly narrower than posteriorly; maximum diameter of fenestra longitudinally directed; median invagination usually V-shaped; in lateral view dorsal margin declining and extending anteriorly to form a broad lobe; anteroventral process subtriangular to trapezoid. Gonostylus broad and rounded. Dorsal margin of volsella in lateral view anteriorly straight to broadly convex and posteriorly concave; anteroventral corner projecting ventrally as a subtriangular, subquadrate or rounded lobe; rarely as a narrow and sharp process; posteroventral margin usually continuous, broadly concave and forming a discrete posterior

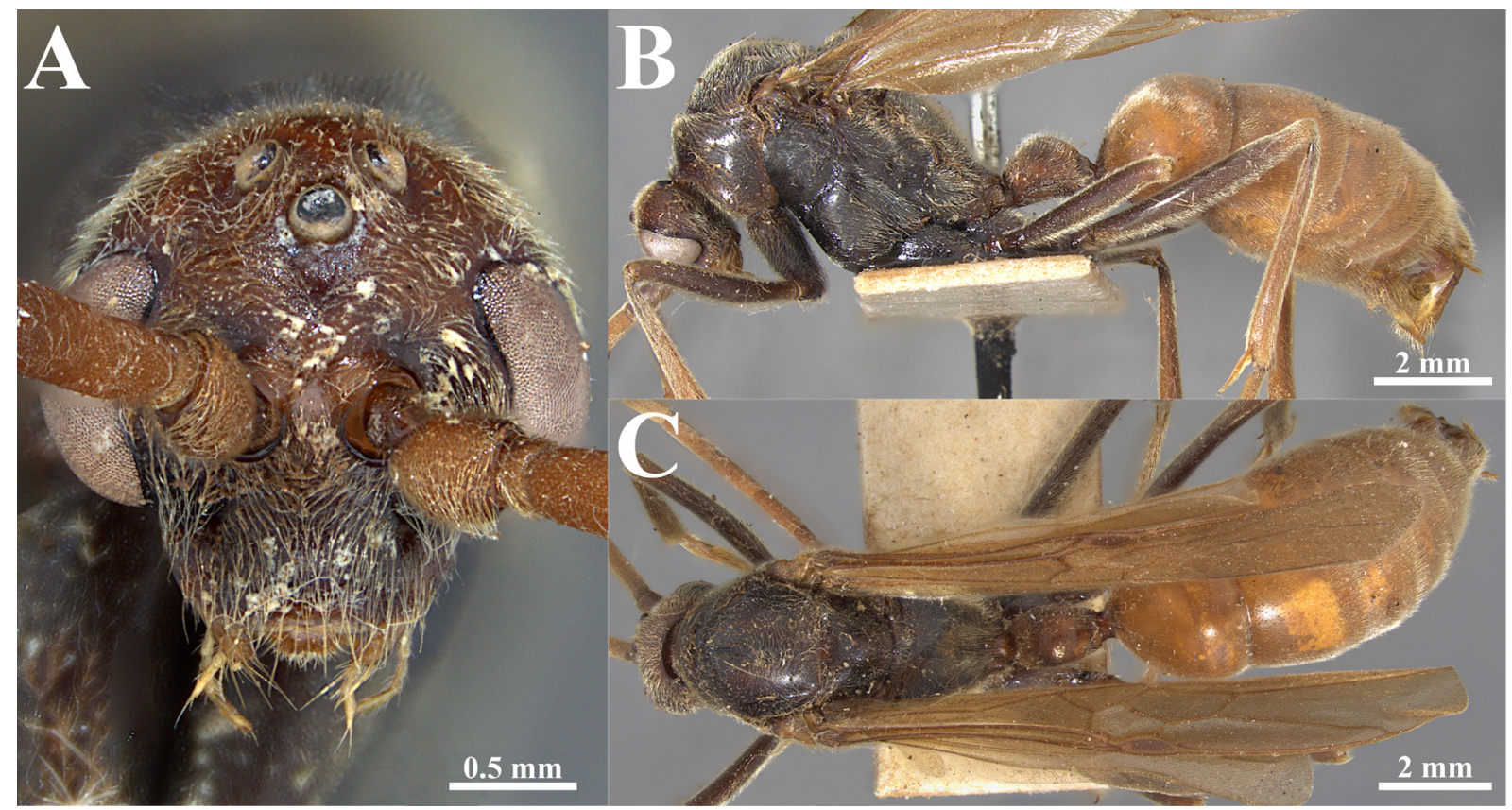

Fig. 17. Dinoponera grandis bucki Borgmeier, 1937 syn. nov., lectotype, $\widehat{\jmath}$ (Palmeiras das Missões, Rio Grande do Sul, Brazil; MZSP 65800). A. Full-face view. B. Full body in lateral view. C. Full body in dorsal view. 
rounded to acute lobe; digitus volsellaris with posterior margin straight to broadly convex. In lateral view, penisvalva with continuous dorsal and posterior margins, usually ending in a rounded apex which projects ventrolaterally; ventral margin uneven, usually with a concavity containing a short tooth or a spiniform projection; posteriorly with serrated rounded or triangular ventral lobe of variable size; anteroventral region concave or with a short triangular lobe.

CoLor. Body varying from completely light brown to black, sometimes with gaster much lightercolored.

\section{Remarks}

Dinoponera grandis, as discussed below, is strongly polymorphic. The paradox about this species is that females and males tell different histories when examined separately. While males of $D$. grandis will vary discretely in some characters, variation is more continuous in females. Because of this, even recognizing that $D$. grandis may represent a complex of several cryptic species, this is not tenable, based on the current information that separates these forms.

Females from southwestern Mato Grosso do Sul, Brazil, to Amambai, Paraguay, tend to have abdominal tergite III strongly microareolate and opaque and the anteroventral pronotal tooth long and acute, almost spiniform. Ants from Distrito Federal to the northeast of Goiás, Brazil, usually have the pronotal dorsum and abdominal tergite III weakly microareolate and with a silky sheen, and the anteroventral pronotal margin obtusely angular, edentate. Some specimens from southern Brazil have the pronotal dorsum and abdominal tergite III weakly microareolate and with a silky sheen. Some specimens from Paraná could be tentatively identified as D. lucida on account of their having the anterodorsal petiolar node angle slightly lower than the posterior angle, but in D. lucida this character is more pronounced plus the pubescence on the frons is abundant and long, quite different from $D$. grandis.

Besides the above-mentioned variation, all examined females of $D$. grandis have the malar striae reaching the eye, a relatively short petiolar node (DPI $\geq 0.8$ ), a body length of less than $27 \mathrm{~mm}$ and a

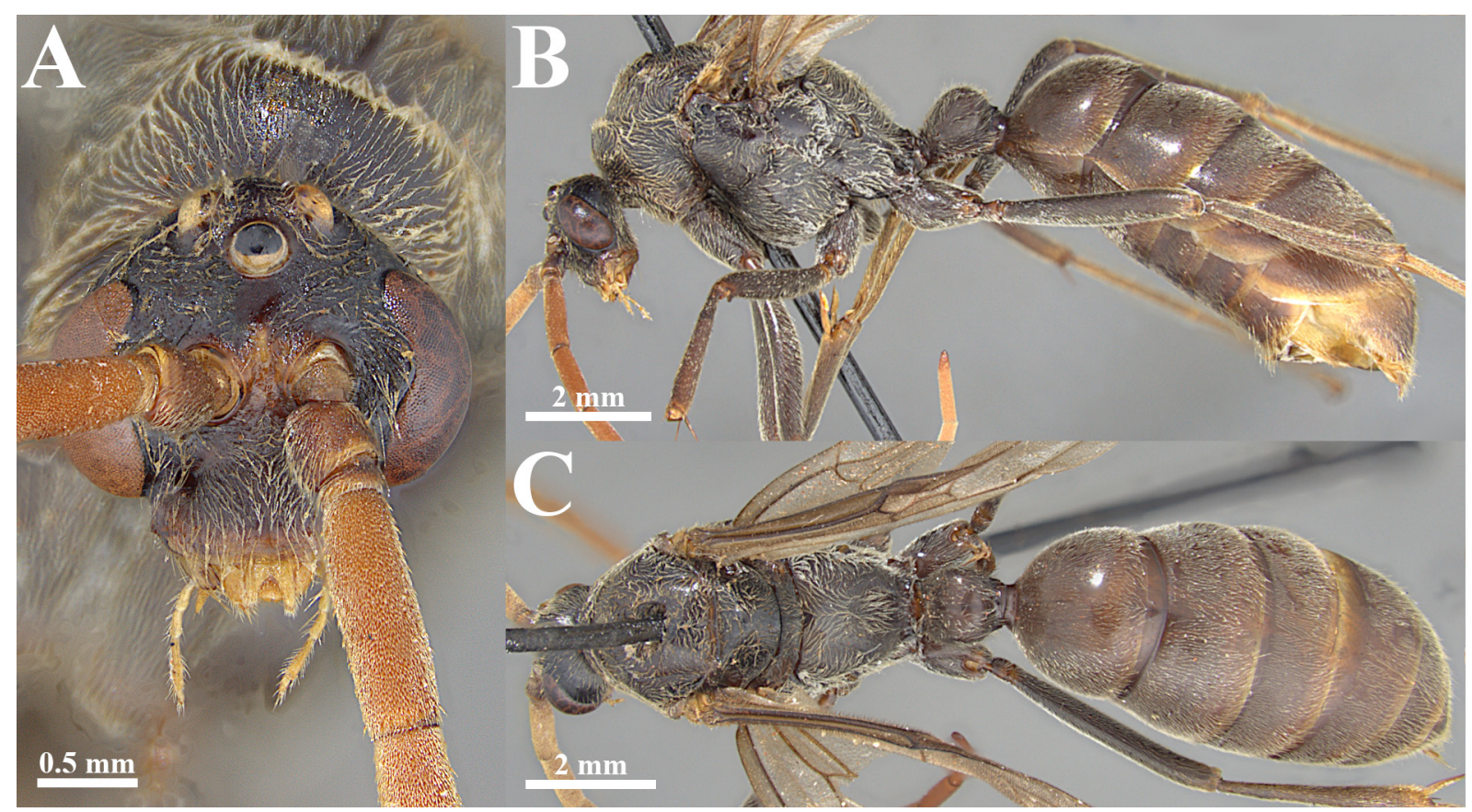

Fig. 18. Dinoponera grandis (Guérin-Méneville, 1838), đ̊ (specimen from Itahum, Mato Grosso do Sul, Brazil; MZSP 62284). A. Full-face view. B. Full body in lateral view. C. Full body in dorsal view. 
hind basitarsus less than $6 \mathrm{~mm}$ long. Occasionally, D. quadriceps and D. lucida may have some of these characters, but besides being usually larger, the following traits will also separate them. The petiolar node of $D$. lucida is anterodorsally lower than the posterodorsal corner and its abdominal tergite III is very smooth, with bluish iridescence. In $D$. quadriceps, the malar striae clearly fail to reach the eye and the petiolar node often has a higher anterodorsal corner.

Santschi (1928) described a form from Paraguay as Dinoponera grandis australis brevis based on female characters such as a scape length as long as the head length and a short petiolar node, one third higher than long. Borgmeier (1937) considered it as a subspecies, making the name D. australis brevis valid. However, Kempf (1971) did not consider these differences to be significant and he synonymized brevis under $D$. australis. Scape length in the studied specimens of $D$. grandis ranges from being longer to shorter than the head length. The node length was found to be one third higher than long in several specimens, leading to the conclusion that such differences are intraspecific.

Guérin-Méneville (1838) apparently described $D$. grandis based on two specimens. In the original description, the author referred to the extremely smooth and shining integument and to the petiolar node shape, which is rounded "up and forward". These characters could refer to what is now considered D. longipes; however, Guérin-Méneville also mentioned the type locality, probably in Minas Gerais, Brazil. Roger (1861) analyzed Guérin-Méneville's specimens and recognized that one ant had somewhat sculptured and opaque integument, while the other was mostly smooth and shining. Roger also noted that one specimen had the petiolar node relatively narrower in lateral view, but despite this he synonymized $D$. grandis and $D$. gigantea. Dinoponera grandis, the more recent name, thus became a junior synonym of D. gigantea. In recent revisions, neither Kempf (1971) nor Lenhart et al. (2013) were able to study the types of these two species, so doubts lingered as to the status of $D$. grandis.

One of Guérin-Méneville's syntypes in the ZSM was designated as the lectotype by Diller (1990). It corresponds to the form Roger described as opaque and with a short petiolar node, collected in Minas Gerais, Brazil.

Examining this type, we saw that it is definitely a different species than $D$. gigantea, its current synonym. It thus became obvious we had to separate these two species. Based on the type locality, it would be possible that $D$. grandis was a synonym of $D$. australis, $D$. lucida or D. quadriceps. These last two species, however, are easily separated from $D$. grandis. In addition, the lectotype of $D$. grandis was revealed to have the same characters used by Emery (1901) to describe D. grandis australis and later used by Borgmeier (1937) to raise D. australis to species level: body size smaller than in other species of Dinoponera; anteroventral pronotal tooth present; integument less shining than in either D. longipes, D. lucida or D. mutica but more so than in D. gigantea; short petiolar node, slightly longer than broad; short legs and antennae; and the scape surpassing the posterior head margin.

Due to the similarities between the lectotype of $D$. grandis and the description and the known forms of $D$. australis, allied with the fact that both occur in sympatry, these two species are synonymized. Dinoponera grandis, which is the oldest name, thus becomes the valid name (senior synonym) and $D$. australis becomes the junior synonym. Although the type of $D$. australis has not been examined, choosing not to synonymize these names would mean that there would be two names with the same diagnosis.

In this study three other names are synonymized under $D$. grandis: the species $D$. snellingi Lenhart, Dash \& Mackay, 2013, and the subspecies Dinoponera australis nigricolor Borgmeier, 1937 and Dinoponera australis bucki Borgmeier, 1937. This decision is discussed below. 
Borgmeier (1937) described D. australis nigricolor and D. australis bucki based on females and males taken from their respective nests, the former in central Goiás and the latter in Rio Grande do Sul, Brazil. He found $D$. a. nigricolor females to be identical to $D$. a. bucki females except for having the dorsal margin of the petiolar node margin slightly convex, a difference we consider as intraspecific. However, he considered male characters to be more reliable indicators, particularly gonostylus width. Other male differences he also considered diagnostic included the petiolar node shape, body color, shade of wing color and slight differences in the relative scape length. Unfortunately, he only had one male for each subspecies.

Lenhart et al. (2013) described D. snellingi based on 3 males collected at a light in Campo Grande, Mato Grosso do Sul, Brazil. The ants were initially identified as D. australis because they were collected at the same locality and on the same day as some females of $D$. australis. They compared these males with the descriptions by Kempf (1971) and found similarities in the short pygidial spine and bicolored body, but they also discerned a number of differences. They recognized it as a different species on account of the following combination of characters: bicolored body; head with bulging compound eyes and ocelli; penisvalva with a large ventral lobe and finger-like serrated flange; a short and broad digitus volsellaris with a finely toothed basal lobe; and a distinctively shaped paramere.

The present study was able to gather the largest number of $D$. grandis male specimens with the widest geographic coverage until now (11 male specimens, contrasting with five and four in Lenhart et al. 2013 and Kempf 1971, respectively). Below we discuss variation in the diagnostic characters given by Borgmeier (1937) and Lenhart et al. (2013), finding many of them to be ineffective for species delimitation and thus weakening the validity of these names.

Node shape, in general, is convex as seen laterally, but it can vary from evenly convex to unevenly convex, with the highest point shifting from mid-petiolar distance to points just anterior or posterior to it. Variability was found even in the relative height of the node. Given such variation, the differences in node shape used by Borgmeier to distinguish $D$. a. bucki from D. a. nigricolor becomes ineffective when more specimens are compared.

The male specimen of the D. a. bucki type series is designated here as the lectotype, given the apparent greater discreteness of male characters. It is strikingly bicolored with the gaster light chestnut and the rest of the body dark brown, but the bicolor pattern is also present in a male from Goiás (Jataí) and in another from São Paulo (Itirapina), the latter with a more yellowish gaster and darker body. Lenhart et al. (2013) described D. snellingi as having the same colors, but a male from Mato Grosso do Sul (Itaum), with genitalia very similar to those of $D$. snellingi, is entirely chestnut. The lectotype male of D. a. nigricolor is entirely black, with the gaster slightly lighter. This pattern was also found in males from Paraná (Guarapuava and Laranjeiras do Sul) and Mato Grosso do Sul (Itaum). Another male collected at the type locality of D. a. nigricolor is entirely light chestnut, as well as a specimen from Mato Grosso (Chapada dos Guimarães).

The relative scape length was found to be slightly less in D. nigricolor than in D. a. bucki by Borgmeier (1937). The ratio of scape width divided by scape length varies from 0.73 to 0.93 in six males, including the types, so this variation becomes muddled when studying more specimens.

In general, all males studied here have reduced eyes and ocelli compared with other species of Dinoponera, but only in the lectotype of D. a. bucki are they as small as those of the D. grandis male of fig. $4 \mathrm{e}$ in Lenhart et al. 2013. The lectotype of D. a. nigricolor, a topotypic male, and a specimen from Itirapina, São Paulo, all have the lateral ocelli surpassing the posterior head margin in dorsal view, as in the description of $D$. snellingi and fig. $4 \mathrm{~d}$ in Lenhart et al. 2013. Therefore, this character is not exclusive to $D$. snellingi and its usefulness in separating species becomes doubtful. 
Borgmeier (1937) found the gonostylus in $D$. a. nigricolor to be relatively wider than in D. a. bucki. Lenhart et al. (2013) described the gonostylus shape in D. snellingi as distinct from that in D. grandis. We detected differences in the shape and relative width of the gonostylus of other $D$. grandis males that are similar to those in $D$. a. bucki and D. a. nigricolor. Thus, these observed differences prove continuous among specimens, rendering them useless for diagnosis.

The anteroventral corner of the volsella in lateral view usually varies from rounded to subtriangular between specimens, with no evident pattern. An exception is provided by the lectotype of $D$. a. nigricolor and a topotype male, which have their anteroventral process narrow and sharp (spiniform). The posteroventral margin of the volsella of these specimens also differs by having a small subquadrate lobe close to the apex. All other males have a continuous margin. In the Itirapina male this margin is more strongly convex, giving the whole volsella an arched appearance.

All the observed males have a large anteroventral lobe on the penisvalva. The anteroventral corner, however, has two different states: either a concavity or a short triangular lobe. The latter state was found only in the Itaum and Itirapina males. The penisvalva illustration of $D$. snellingi in Lenhart et al. (2013) does not show this triangular lobe; instead it shows a more rounded and convex corner, which is also different from the concave corner found in other $D$. grandis males.

Penisvalva shape is the most variable character among examined males. In $D$. snellingi it is described by Lenhart et al. (2013) as having a large triangular ventral lobe with a vertical ridge running through the middle. This ventral lobe is longer than wide and is strikingly different from that of other Dinoponera males. Additionally, the ventral margin of the penisvalva has a small tooth. Males from Itaum and Itirapina have a very similar penisvalva shape, although the vertical ridge is inconspicuous. The penisvalva in the type of $D$. a. nigricolor and the topotypic specimen have a ventrally pronounced posteroventral lobe that forms a blunt angle, but it is never longer than wide, as in the illustration of the type of $D$. snelling $i$ (Lenhart et al. 2013: fig. 11b). The penisvalva of D. a. bucki has a rounded posteroventral lobe and a long, acute ventral spine, as do the other $D$. grandis males. It is very similar to the description of males from Argentina (Lenhart et al. 2013).

Most of the characters mentioned above are not solid enough to justify the validity of $D$. snellingi, D. a. nigricolor or D. a. bucki. Even though the shape of the anteroventral corner in the volsella and penisvalva seems to vary discretely in $D$. a. nigricolor and $D$. snellingi, there are more gaps than certainties about the delimitation of these entities.

These males were taken during the same collection events as $D$. grandis females, but these few males do not allow us to know whether these seemingly distinct characters simply represent extremes of continuous variations.

A last consideration is that the validity of D. snellingi, D. a. nigricolor and D. a. bucki would imply we know the form of the $D$. grandis male, a tenuous assumption. The first description of a $D$. grandis male (Santschi 1921: 85) was based on specimens from Argentina, very far from the type locality in Minas Gerais, Brazil. It is much more likely that the male of $D$. grandis corresponds to one of the specimens described as D. snellingi, D. a. nigricolor or D. a. bucki, all of which occur much closer to the type locality.

Based on all of this evidence, we argue for the synonymy of these names; however, we strongly encourage future studies on $D$. grandis, as the high variability of this species can be a sign of the existence of a complex of cryptic species. For future studies, we recommend that the first question addressed be: what is the form of the $D$. grandis male? The next step must be to gather fresh specimens by extensive fieldwork in all distribution areas, the results of which would also enable molecular and 
phylogeographic studies. In the light of human-induced climate change, and continuing deforestation and forest fires, we consider such fieldwork to be of utmost importance. Not only would it help elucidate the questions surrounding the situation of $D$. grandis, but it would also inform conservation measures that could help preserve the remaining populations of these giant ants.

\section{Biology}

Dinoponera grandis is found in a wide variety of environments, with predominance in savannas, at least for Brazilian records. Nests have a random spatial distribution and may have a density of up to 180 nests per hectare (Tillberg et al. 2014). Each nest has an entrance without a surrounding mound and may reach a depth of $143 \mathrm{~cm}$ (Paiva \& Brandão 1995). Despite the relatively large nest size, colonies have on average only 14 workers, which indicates that nests are constantly reused and not completely constructed every generation (Paiva \& Brandão 1995; Monnin et al. 2003). Pheidole dinophila Wilson, 2003 has been recorded as nesting within nests of $D$. grandis at more than one locality (Wilson 2003).

They are omnivorous, but favor hunting other invertebrates (Tillberg et al. 2014). Foraging strategies involve route fidelity for individual workers and the distribution of different routes among workers, favoring greater efficiency in the area being covered (Tillberg et al. 2014). Organization inside the nest reflects division of tasks, with foraging workers occupying chambers closer to the surface and higher status workers occupying deeper chambers (Paiva \& Brandão 1995). This nest occupation dynamic was confirmed by Smith et al. (2011), demonstrating that workers of deeper chambers have up to $39 \%$ of their dry body mass composed of fat, while workers found in shallow chambers may have less than $1 \%$ body fat. Dominance hierarchy is determined by agonistic conflicts similar to those in D. quadriceps, guaranteeing colony monogyny (Monnin et al. 2003).

\section{Distribution (Fig. 28A)}

Dinoponera grandis is a widely distributed species, occurring in most of the Central West, South and Southeast regions of Brazil as well as Paraguay, Argentina and Bolivia. The northernmost record is in Paranã (Tocantins) and the southernmost Brazilian record is in Uruguaiana (Rio Grande do Sul). These ants are not present in eastern Brazil.

Dinoponera hispida Lenhart, Dash \& Mackay, 2013

Figs 19, 28B

Dinoponera hispida Lenhart, Dash \& Mackay, 2013: 141, figs 1c, g, 2 (ఫ).

\section{Diagnosis}

Female

Body covered by thick and stiff hairs. Ventral surface of head posteriorly with transverse strigulae. Anteroventral pronotal corner in lateral view rounded or forming obtuse angle, never toothed. Dorsum of pronotum and abdominal tergite III mostly smooth and with bluish iridescence. Petiolar node in dorsal view usually slender (DPI $<0.71)$.

\section{Material examined}

Holotype

BRAZIL - Pará • 1 ఫ̛; Tucuruí; Jan. 1979; coll. M. Alvarenga; examined by images; MCZC.

Non-type specimens $(21$ ఫఢ)

BRAZIL - Pará • 1 ఫ; Curionópolis, Faz. Serra Grande; 9 Jul. 1991; C. Melo and F. Melo leg.; 1385/1/79; DZUP • 1 ६; FloNa Carajás, Parauapeba; Mar. 2016; V.C. Rocha leg.; UFSC • 1 ఫ; Marabá; 2017; DZUP • 1 ఫ;; Marabá, Gruta do Gavião; 5 Oct. 1986; GEP; MZSP • 1 ६̧; Melgaço, Caxiuanã, ECFPn; 
$1.7815^{\circ}$ S, $51.5919^{\circ}$ W; 5-7 Nov. 2003; A.Y. Harada, E.P. Fagundes and C. Renato leg.; VI: transecto 16-900; MPEG • 1 ఫ్; Melgaço, Caxiuanã, Estação Científica Ferreira Penna; $1^{\circ} 45^{\prime}$ S, 51 ${ }^{\circ} 31^{\prime}$ W; 30 Oct. 2003; J. Souza and C. Moura leg.; plote VI transecto 5-600, pitfall 05; INPA • 1 ६; Novo Repartimento, Fazenda Arataú; 25-26 Jun. 2003; A.M. Elizabeth leg.; CPDC • 1 ६̧; Parauapebas, FLONA de Carajás; 24 Feb. 2010; A.A. Matias leg.; "isca de sardinha, 10 trilha F Canga Controle - solo"; INPA • 1 ఫ; same collection data as for preceding; "5 trilha F Canga Controle - solo"; INPA • 1 ఫ; Portel,

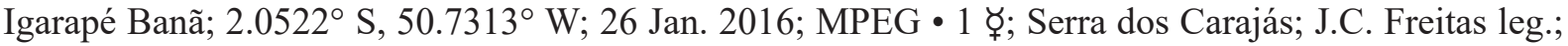
1501, Coleção Diniz; DZUP • 1 ఫ̛; Serra Norte, Carajás; Jul.-Aug. 1985; Brandão and Benson leg.; Unicamp Ecol. Campo exped.; N3 mata trilha; MZSP • 1 ఫ; same collection data as for preceding; N3 canga Arrm. Berlese; MZSP • 1 ६; same collection data as for preceding; N1 Canga gramínea; MZSP • 1 ఛ; same collection data as for preceding; N1 Canga gramínea \#4; MZSP • 1 ఛ; Serra Norte, Manganês; 16 Aug. 1984; W. França leg.; lote 2550; MPEG HYM11506519 • 1 ఢ̧; same locality as for preceding; 17 Jun. 1985; R.D. Thomaz leg.; lote 2552; MPEG HYM11506521 • 1 ६;; Serra Norte, N-1 Canga; 24 Oct. 1984; Márcio Zanuto leg.; lote 2537; MPEG HYM11506495 • 1 ६; Serra Norte, N-3 mata; 6 Oct. 1986; M. Martins leg.; lote 2536; MPEG HYM11506496 • 1 ఫ̧; Tucuruí; 7 Jul. 1978; P. Maurício leg.; MPEG HYM11513011 • 1 ఫ; same locality as for preceding; 8 Jul. 1978; W. França leg.; MPEG HYM11513016.

\section{Redescription}

Female

Measurements. Non-types $(\mathrm{n}=10)$ : HL 4.8-6.17; HW 4.6-5.73; MDL 3.95-4.66; SL 5.67-6.42; MSL 7.52-8.7; HFL 7.24-8.5; HBL 6.08-7.1; PL 2.17-2.51; PH 2.75-3.5; PW 1.36-1.64; ATS 6.96-8.4; BL 25.4-30.12 (mm); CI 0.87-0.96; SI 1.13-1.27; DPI 0.6-0.71.

HEAD. Malar area with longitudinal to oblique striae which gradually fade posteriorly, sometimes not reaching anterior eye margin. Gena smooth or weakly microareolate, with bluish iridescence, usually without rugulae. Appressed pubescence present between eye and frontal lobe, extending posteriorly to frons. Frons smooth to weakly microareolate, with bluish iridescence; integument slightly irregular close to hair insertions; decumbent to suberect thick, stiff hairs; pubescence densest laterally. Occipital corner

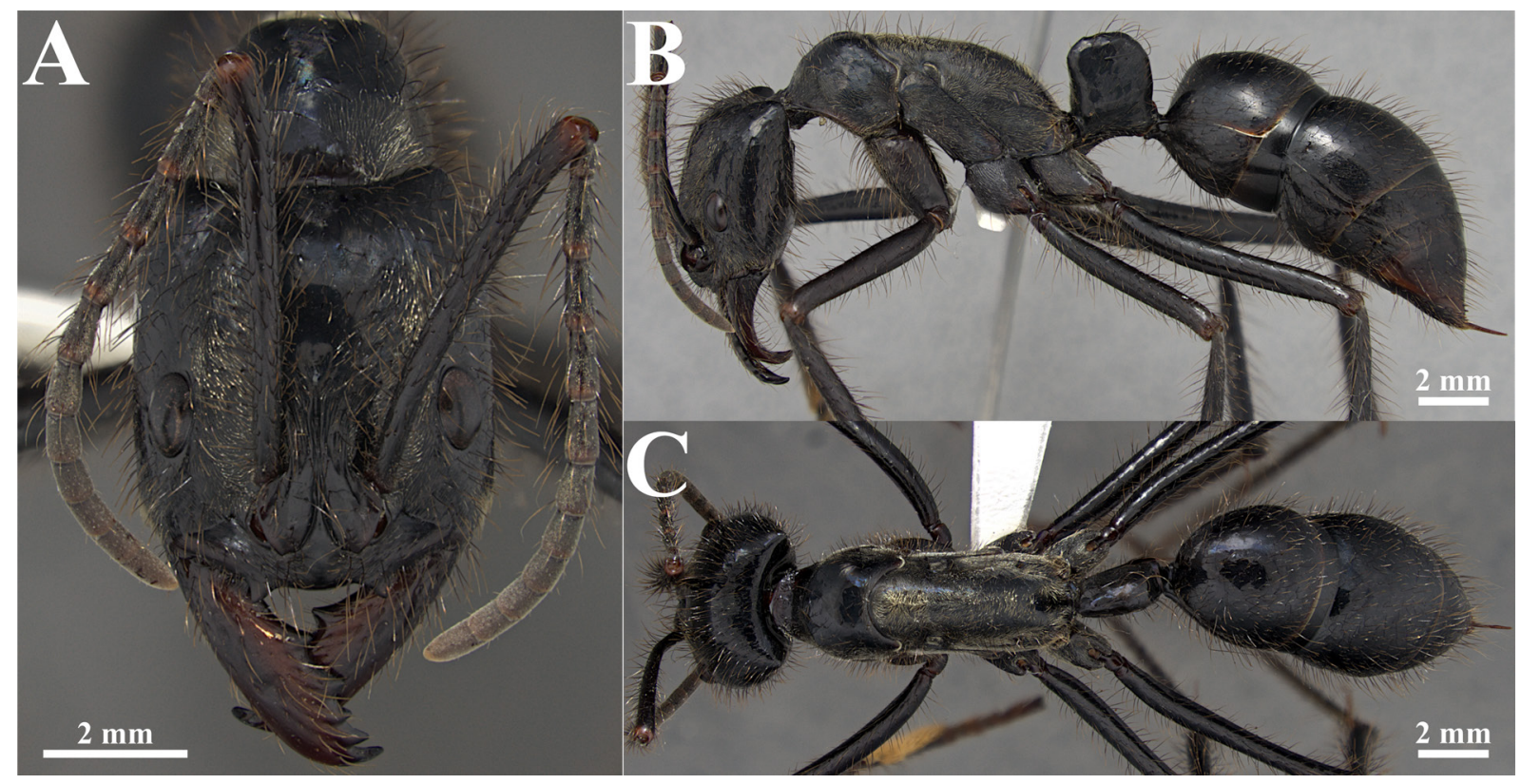

Fig. 19. Dinoponera hispida Lenhart, Dash \& Mackay, 2013, ఫ (specimen from Parauapebas, Pará, Brazil; UFSC). A. Full-face view. B. Full body in lateral view. C. Full body in dorsal view. 
smooth and with bluish iridescence. Antennal scape weakly microareolate and shining; antenna with suberect, thick, stiff hairs except for 4-5 apical segments. Ventral surface of head weakly microareolate to smooth; arched, weakly impressed strigulae present on anterior half; well-marked transverse strigulae posteriorly. Hypostomal tooth with longitudinal strigulae. Labrum with weak median longitudinal sulcus that extends from anterior margin to half its length; with transverse rugulae. Mandibular dorsum with longitudinal strigulae along inner margin, gradually fading apicad.

Mesosoma. Dorsal margin of pronotum in lateral view broadly convex, with no pronounced dorsoposterior swelling; anteroventral corner of pronotum rounded or forming obtuse angle, never toothed. Pronotal dorsum smooth, with bluish iridescence. Metapleural-propodeal suture well-marked and straight, rarely sinuous.

Metasoma. Petiolar node in lateral view elongate (DPI $<0.8)$; anterodorsal corner usually higher than posterodorsal corner; anterior margin slightly concave, forming blunt angle with dorsal margin; dorsal and posterior margins each broadly convex and forming rounded angle. Node lateral face smooth or weakly microareolate with bluish iridescence. Node anterior margin in dorsal view strongly convex; posterior margin broadly convex; lateral margins broadly convex, slightly converging anterodorsally. Abdominal tergite III smooth or weakly microareolate, with bluish iridescence; punctulae sparse, slightly denser laterally than dorsally; covered by suberect thick, stiff hairs on entire surface; appressed pubescence very sparse on dorsum, denser laterally.

\section{Male \\ Unknown.}

\section{Remarks}

The diagnostic characters easily separate $D$. hispida from any other Dinoponera. This species occurs in sympatry with $D$. gigantea, which differs by having a microareolate and opaque integument with slender, flexous hairs. It may be confused with either D. longipes, D. mutica, or D. nicinha sp. nov., which also have a shining integument and occur in northern Brazil. Dinoponera mutica and D. nicinha sp. nov. can be separated by not having the petiolar node with a blunt anterodorsal angle or a rounded posterodorsal angle in lateral view. Dinoponera longipes may have the node slightly similar to that of D. hispida, but it lacks strigulae on the head venter and has flexible golden hairs throughout the body. Another species with smooth and shining integument is D. lucida, but it differs by having the anterodorsal node angle lower than the posterodorsal angle in lateral view. Dinoponera lucida only occurs in the Atlantic forest of eastern Brazil.

The holotype of $D$. hispida was examined by images available in the online database of the MCZC (https://mczbase.mcz.harvard.edu, Identifiers: Entomology, 36191) and additional images. Besides that, the description of Lenhart et al. (2013) is very complete and detailed, permitting a clear recognition of the species.

\section{Biology}

The life history of this species is unknown. It is restricted to the Amazon, characterized by humid forests and large trees (IBGE 2012). According to the Köppen classification system, the predominant climate in southeastern Pará is Tropical Monsoon, with the average temperature of the coldest month over $18^{\circ} \mathrm{C}$ and high annual precipitation (Alvares et al. 2013).

Distribution (Fig. 28B)

Dinoponera hispida has a relatively restricted distribution, known only from a few sites in Pará that are being affected by large-scale mining, a large hydroelectric plant (Tucuruí Hydroelectric Power Plant) and 
extensive deforestation. This combination of habitat disturbance makes the species a likely candidate for being considered as threatened. However, its distribution could be greater if there are more specimens in collections presently misidentified as the sympatric $D$. gigantea.

\section{Dinoponera longipes Emery, 1901}

Figs 20, 29A

Dinoponera grandis longipes Emery, 1901: 48 (ఫ)).

Dinoponera longipes - Kempf 1971: 375 (raised to species). — Lenhart, Dash \& Mackay 2013: 143, figs 1a, b, 3, 4c, h, m, 5e, 8, 9e, 10e, 11e (redescription, male description, key).

\section{Diagnosis}

\section{Female}

Anteroventral corner of pronotum in lateral view unarmed, forming obtuse angle. Petiolar node in lateral view with anterodorsal corner clearly higher than posterodorsal corner. Abdominal tergite III smooth and with bluish iridescence; covered with sparse golden pubescence. Body covered with flexible golden hairs.

\section{Material examined}

\section{Holotype}

PERU - Cumbase • 1 ६; examined by images; MCSN.

Non-type specimens (15 ఫ̛)

BRAZIL - Acre • 1 ६; Cruzeiro do Sul; Dec. 1963; P.L. Herbst leg. MZSP • 1 ६; same collection data as for preceding; Coleção Diniz; DZUP • 2 ఫ̛ర్; Marechal Thaumaturgo, Vila Taumaturgo; Feb.1962; Pe.L. Herbst leg.; MZSP • 1 ६̧; Porto Acre, Humaita; 15 Jun.-2 Jul. 1992; Gorayeb, Pena Henriques and Edmar leg.; MPEG • 1 ఫ্; Rio Branco, mata terra firme; 25 Oct.-8 Nov. 1991; F. Ramos, A. Henrique, I. Gorayeb and N. Bittencourt leg.; MPEG.

COLOMBIA - Amazonas • 1 ६̧; Letícia, 7 km via Tarapacá; 4 Dec. 1971; S. Franky leg.; CPDC. Caquetá • 1 ६̧; Florencia; alt. 266 m; 10-20 Oct. 1990; G. Medina and C. Rodriguez leg.; ICN 078906; ICNC.

PERU - Amazonas • 2 ఫ̧ఢ ; Montenegro, Rio Marañon; 16 Apr. 1960; alt. 350 m; V. Weyrauch leg.; MZSP. - Leoncio Prado • 1 ६; Tingo Maria, Rio Huallaga; 26 Jul. 1955; alt. 670 m; Weyrauch leg.;

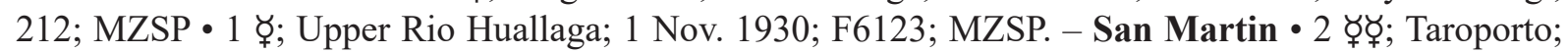
A. Velásquez leg.; MZSP. - Tocache • 1 ఛ̧; Uchiza, Palmas del Espino; 19 Aug. 1987; G. Couturier leg.; DZUP 549808.

\section{Redescription}

\section{Female}

Measurements. Non-types $(\mathrm{n}=6)$ : HL 5.54-6.07; HW 5.22-5.73; MDL 4.22-4.97; SL 5.92-6.17; MSL 8.1-8.9; HFL 8.08-8.8; HBL 7-7.6; PL 2.32-2.69; PH 2.97-3.4; PW 1.55-1.82; ATS 7.8-8.5; BL 28.31-31.02 (mm); CI 0,91-0,98; SI 1,04-1,18; DPI 0,63-0,67.

HEAD. Malar area with weak longitudinal to oblique striae that do not reach anterior eye margin. Gena weakly microareolate with bluish iridescence, usually without rugulae. Golden appressed pubescence present between eye and frontal lobe, extending posteriorly to frons. Frons smooth and with bluish iridescence; with flexuous, golden and decumbent to suberect hairs, longer than scape diameter; 
pubescence densest laterally. Occipital corner smooth and with bluish iridescence. Antennal scape weakly microareolate and silky; antenna with decumbent to suberect and long hairs, except for 4-5 apical segments. Ventral surface of head smooth, with silky sheen; longitudinal strigulae mostly absent or, if present, only near hypostomal tooth. Labrum without median longitudinal sulcus, transverse rugulae absent. Mandibular dorsum weakly longitudinally strigulate on inner base, sculpture gradually fading apicad.

Mesosoma. Dorsal margin of pronotum broadly convex in lateral view, usually with no pronounced dorsoposterior swelling; anteroventral corner of pronotum forming obtuse angle, never toothed. Pronotal dorsum smooth, with bluish iridescence. Metapleural-propodeal suture well-marked and slightly sinuous, with at least one curve ventral to position of propodeal spiracle.

Metasoma. Petiolar node in lateral view elongate $(\mathrm{DPI}<0.8)$; anterodorsal corner higher than posterodorsal corner; anterior margin slightly concave, forming blunt angle with dorsal margin; dorsal and posterior margins broadly convex, forming rounded angle. Node lateral face smooth with bluish iridescence. Node anterior margin in dorsal view strongly convex, posterior margin straight to broadly convex, lateral margins broadly convex and converging anterodorsally. Abdominal tergite III smooth with bluish iridescence; punctulae in variable density, evenly distributed laterally and dorsally; covered by flexuous, golden suberect hairs and appressed pubescence evenly distributed on dorsal and lateral surfaces, ranging from dense to sparse.

Male

Not examined.

\section{Remarks}

Dinoponera longipes may occur in sympatry with $D$. gigantea, but the females are easily separated by the microareolate and opaque integument and anteroventral pronotal tooth of $D$. gigantea. Females of D. mutica and D. nicinha sp. nov. are the most similar to D. longipes as both have a shining integument

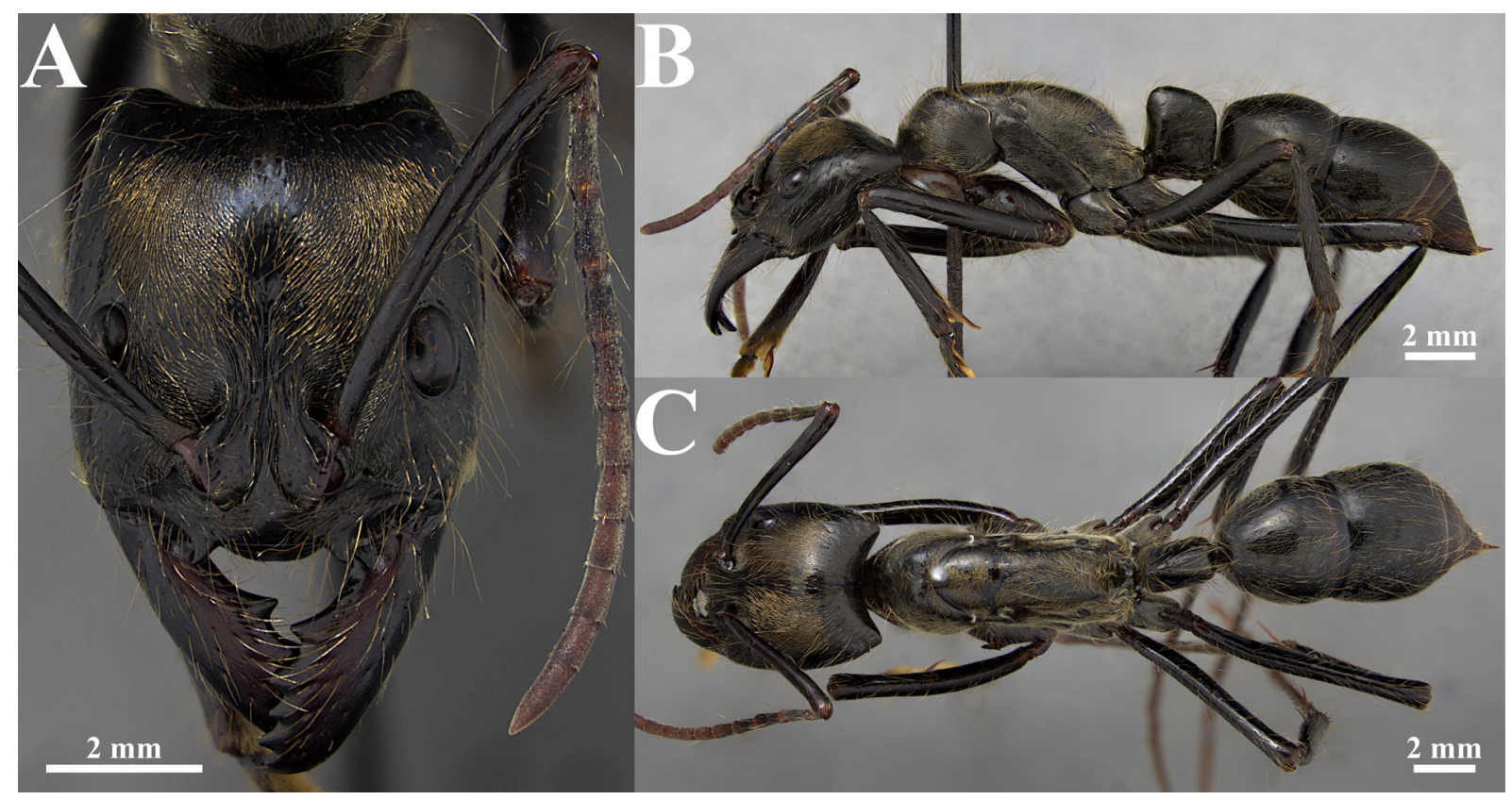

Fig. 20. Dinoponera longipes Emery, 1901, ఫ̛ (specimen from Uchiza, Peru; DZUP 549808). A. Fullface view. B. Full body in lateral view. C. Full body in dorsal view. 
and a toothless anteroventral pronotal margin in lateral view. However, the node shape of $D$. longipes separates it from these two species. Dinoponera quadriceps may have a similar node shape, but differs by having abdominal tergite III microareolate and opaque with brownish, not golden, hairs.

Images of the holotype (AntWeb, CASENT 0903861) were examined. The original description includes some characters that are at odds for all the examined specimens, such as the length of the legs and the antennae being longer in comparison with other Dinoponera. Despite this, the node shape and golden pilosity were considered sufficient to maintain the validity of this species. The density of the pilosity and pubescence on abdominal tergite III varies greatly. A specimen from Rio Branco, Acre State, has the body completely covered by dense long and appressed pubescence, but specimens from Colombia have sparse pubescence. The availability in Brazil of $D$. longipes in collections is meagre and several female specimens identified as $D$. longipes actually belong to $D$. nicinha sp. nov.

The male was described by Lenhart et al. (2013) based on 2 specimens from Tingo María, Peru. According to these authors, $D$. longipes can be separated from other species by the thick decumbent antennal setae and by the shape of abdominal tergite VIII, which is shorter than in D. gigantea and D. quadriceps and longer than in D. grandis and D. snellingi. Comparing the description and illustrations of $D$. longipes with the males of $D$. lucida, it seems that they are similar, but the shape of the penisvalva is very different, not forming a rounded ventral lobe in $D$. longipes.

\section{Biology}

Dinoponera longipes occurs in regions with dense tropical rainforests, but Morgan (1993) found most nests in areas with sparse understory vegetation. Each nest can have one to thirty entrances with soil particles forming mounds around each (Morgan 1993). Most nests are close to roots or in areas shaded by vegetation and the distance between them averages $35 \mathrm{~m}$ (Morgan 1993). In two nests observed by Morgan (1993), the number of workers was seven in a young colony and 120 in a mature colony.

The diet is predominantly carnivorous and foraging is solitary and mainly nocturnal (Morgan 1993). The ants interact, displaying agonistic behaviors similar to those described in other species, such as immobilization and antennal beating (Morgan 1993; Monnin et al. 2003).

Distribution (Fig. 29A)

Dinoponera longipes is present in Brazil, Colombia and Peru. Lenhart et al. (2013) also examined specimens from Ecuador. In this study, the northernmost record is from Florencia, Caquetá, Colombia, and the southernmost record is from Porto Acre, Acre State. This species has not been collected in Brazil in over 25 years.

Dinoponera lucida Emery, 1901

Figs 21-22, 29A

Dinoponera grandis lucida Emery, 1901: 48 (ఫ).

Dinoponera lucida - Kempf 1971: 376: figs 1-2 (raised to species). — Lenhart, Dash \& Mackay 2013: 146, fig. 1h (redescription, key, male genitals). — Escárraga et al. 2017 (male description). Tozetto \& Lattke 2020: 5, figs 2-3, 6 (male genitals).

\section{Diagnosis}

Female

Malar area with longitudinal to oblique striae that always reach entire anterior ocular margin and extend to gena until at least half of eye length. Anteroventral corner of pronotum in lateral view with tooth or 
acute angle. Dorsum of pronotum and abdominal tergite III smooth, with bluish iridescence. Anterodorsal corner of petiolar node in lateral view lower than posterodorsal corner.

\section{Male}

Antenna with stiff decumbent hairs shorter than maximum scape diameter. Gastral tergites with long hairs. Abdominal tergite VIII triangular, with a very sharp apex. Penisvalva ending in a rounded ventral lobe.

\section{Material examined}

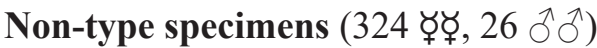

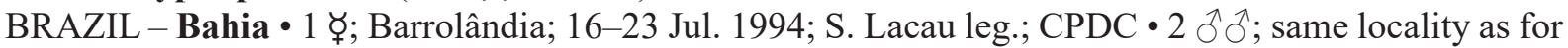
preceding; 4 Aug. 2004; J.R.M. Santos leg.; CPDC • 1 ६̧; Faz. Amaralina, Guaratinga; 27 Aug. 1993; O.S.A. Paula leg.; 4675c; CPDC• 1 ६; Fazenda Limeira, Itapebi; 25 Apr. 1988; J. Raimundos leg.; 4369;

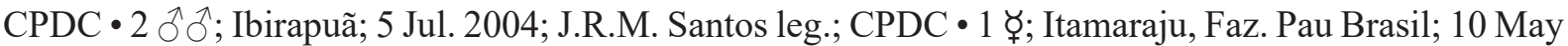
1969; Ventocilla leg.; 2744; INPA • 2 ふ̂̉ं; Itamaraju; 8 Jul. 2004; J.R.M. Santos leg.; CPDC • 1 ఫ; Itanhem; 12 Nov. 2009; Jonathas leg.; 5580; CPDC • 1 ६; Jacobina; 1996; J. Jardim leg.; CPDC•

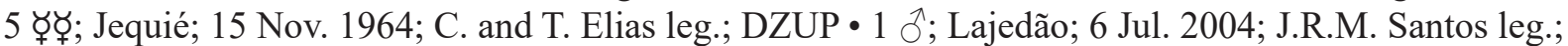
CPDC • 1 ६; same locality as for preceding; 21 Jul. 1967; K. Brown leg.; DZUP • 1 ६; Monte Pascoal; 20 Jan. 1994; J.C. Nascimento leg.; 4795; CPDC • 1 ఫ̧; Mucuri; 1-10 Mar. 1971; C. Elias leg.; DZUP• 1 ६; Pau Brasil; 14 Jan. 1998; L.A. Matos Silva leg.; 5220; CPDC • 1 ఫ; Porto Seguro; 13 Dec. 1992; A.B. Casimiro leg.; 4600b; CPDC • 1 ф্; Porto Seguro, E.E. Pau Brazil; 16²2'17" S, 39¹0'55" W;

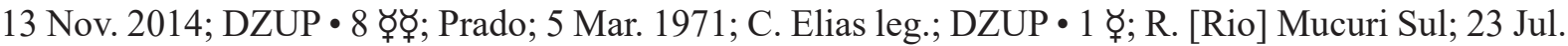
1967; K. Brown leg.; DZUP • 1 ఫ; T [Teixeira] de Freitas, zona rural; 30 Jul.-3 Aug. 2007; F.B. Fraga leg.; UFES 55843. - Espírito Santo • 1 ఫ̛; Alfredo Chaves; 20²7'53" S, 4042'35" W; alt. 714 m; 15 Oct. 2007; C.O. Azevedo and team leg.; UFES 39348 • 1 ऊं; Alfredo Chaves, Matilde, RPPN Oiutrem; $20^{\circ} 33^{\prime} \mathrm{S}, 40^{\circ} 48^{\prime} \mathrm{W}$; 14-21 Oct. 2009; C.O. Azevedo and team leg.; Malaise 600-800 m; UFES •

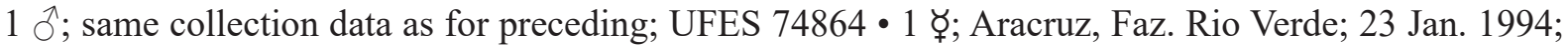
Delabie leg.; 4788; CPDC • 3 రోఫ్; Baixo Guandu; 17 May 1970; C. and C.T. Elias leg.; DZUP •

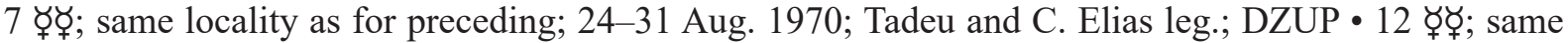
locality as for preceding; 25 Apr. 1970; C. and C.T. Elias leg.; DZUP • 2 ఫॄర్; same locality as for preceding; 29 Jun. 1970; C. and C.T. Elias leg.; DZUP • 3 ఫॄఫ; same locality as for preceding; 7-13 May 1970; Tadeu and C. Elias leg.; DZUP • 5 రోఫ్; same locality as for preceding; 1 Jun. 1970; C.T. and C. Elias leg.; DZUP • 1 ఛ̧; same locality as for preceding; 10-16 Aug. 1970; C. and C.T. Elias leg.; DZUP • 4 ఫఢఫ; same locality as for preceding; 16-22 Sep. 1971; C. Elias leg.; DZUP • 1 ఢ; same locality as for preceding; 17-22 Aug. 1970; C. and C.T. Elias leg.; DZUP • 4 ఫॄఘ; same locality as for preceding; 1-8 Aug. 1970; C. and C.T. Elias leg.; DZUP • 1 ఛ;; same locality as for preceding; 22 Jun. 1970; Claudionor Elias leg.; DZUP • 5 ఫॄ孔; same locality as for preceding; 23-30 Apr. 1970; C. and C.T. Elias leg.; DZUP • 23 ఫॄ;; same locality as for preceding; 23-30 Sep. 1970; C. and C.T. Elias leg.; DZUP • 1 ६; same collection data as for preceding; DZUP 549807 • 1 ६̧; same locality as for preceding; 26-30 Apr. 1970; C. and C.T. Elias leg.; DZUP • 4 ఫॄర్; same locality as for preceding; 29 Apr.-6 May 1970; C. and C.T. Elias leg.; DZUP • 2 ఫఢఫ; same locality as for preceding; 6 Jul. 1970; C. and C.T. Elias leg.; DZUP • 4 ఫఢఫ; same locality as for preceding; 8 Jun. 1970; C.T. and C. Elias leg.; DZUP • 1 ఢ; Buenos Aires, 10 km W of Guarapari; alt. 500 m; 6 Jan. 1996; G.A.R. Melo leg.; DZUP • 1 ఫ; Cariacica, Res. Biol. De Duas Bocas; 16 Sep. 2006; R. Kawada and team leg.; UFES $124428 \bullet 1$ §; same locality as for preceding; 28 Feb. 2004; R. Kawada leg.; UFES 132366 • 2 ఫ̛ఫ్; Colatina; Jan. 1962; C. Elias leg.;

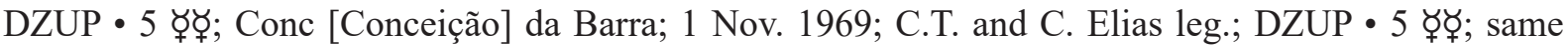
locality as for preceding; 11 Oct. 1969; C.T. and C. Elias leg.; DZUP 1 ६ ; same locality as for preceding; 15 Nov. 1968; C. and C.T. Elias leg.; DZUP • 1 ६; same collection data as for preceding; DZUP

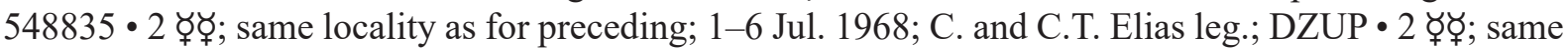
locality as for preceding; 16-22 Jan. 1970; C. and C.T. Elias leg.; DZUP • 1 ६; same locality as for 
preceding; 16-22 Mar. 1969; C. and C.T. Elias leg.; DZUP• 1 ఛ; same locality as for preceding; 16-23 Apr. 1969; C. and C.T. Elias leg.; DZUP • 5 ఫ̧ఫ్; same locality as for preceding; 17 Sep. 1969; C.T. and C. Elias leg.; DZUP • 3 ఫॄర; same locality as for preceding; 17-22 Mar. 1969; C. and C.T. Elias leg.; DZUP • 24 ఫ̛ఫ; same locality as for preceding; 18 Aug. 1969; C.T. and C. Elias leg.; DZUP • 1 ఫ; same collection data as for preceding; DZUP 548824 - 4 ఫ६ఛ; same locality as for preceding; 18 Oct. 1969; C.T. and C. Elias leg.; DZUP• 1 ६̧; same locality as for preceding; 19 Jun. 1969; C.T. and C. Elias leg; DZUP • 4 ఫॄర; same locality as for preceding; 20 Dec. 1969; C.T. and C. Elias leg.; DZUP • 1 ఛ; same collection data as for preceding; DZUP 548826 • 1 ६̧; same collection data as for preceding; DZUP 548827 • 1 ६ ; same collection data as for preceding; DZUP 548828 • 1 ఛ; same collection data as for preceding; DZUP 548829 • 1 ఫ; same collection data as for preceding; DZUP 548830 • 8 ఫ६孔; same locality as for preceding; 25 Sep. 1969; C.T. and C. Elias leg.; DZUP• 1 ఢ; same locality as for preceding; 26 May 1968; C.T. and C. Elias leg.; DZUP • 4 ఫఢఫ; same locality as for preceding; 27 Mar. 1969; C.T. and C. Elias leg.; DZUP • 18 ఫఢఝ్; same locality as for preceding; 27 Dec. 1969; C.T. and C. Elias leg.; DZUP • 3 ఫॄ‡; same locality as for preceding; 29 Nov. 1969; C.T. and C. Elias leg.; DZUP • 1 ६; same collection data as for preceding; DZUP 548833 • 1 ६ ; same locality as for preceding; 4 Jul. 1969; C.T. and C. Elias leg.; DZUP 548825 • 5 ఫॄ孔; same locality as for preceding; 4 Aug. 1969; C.T. and C. Elias leg.; DZUP • 1 ६; same collection data as for preceding; DZUP 548821 • 1 ६; same collection data as for preceding; DZUP 548822 - 1 ६; same collection data as for preceding; DZUP 548823 • 2 ఫఢఢ; same locality as for preceding; 4-8 Apr. 1969; Tadeu and C. Elias leg.; DZUP • 1 ६; same locality as for preceding; 5 May 1968; C.T. and C. Elias leg.; DZUP 548834 • 4 ఫఢఫ; same locality as for preceding; 6 Dec. 1969; C.T. and C. Elias leg.; DZUP • 1 ६̧; same collection data as for preceding; DZUP 548831 • 1 ఫ; same collection data as for preceding; DZUP 548832 • 1 ఫ; same locality as for preceding; 6-22 Jan. 1970; C. and C.T. Elias leg.; DZUP • 2 ఫఢఫ; same locality as for preceding; 8 Nov. 1969; C.T. and C. Elias leg.; DZUP • 2 ఫఢఫ; same locality as for preceding; 9-15 Apr. 1969; C. and C.T. Elias leg.; DZUP • $1 \mathrm{~J}^{\top}$; Domingos Martins, Mata do Pico do Eldorado; 20²2'17" S, 40³9'29" W; 26 Nov.-3 Dec. 2004; M.T. Tavares and team leg.; Malaise T1; UFES $107891 \bullet 1$; same locality as for preceding; 3-10 Dec. 2004; M.T. Tavares and team leg.; Malaise T1; UFES $106427 \bullet 1$; ; same collection data as for preceding; Malaise B4; UFES $104604 \bullet 1$; ; same collection data as for preceding; Malaise T7; UFES $64441 \bullet$ 1 ; ; same collection data as for preceding; Malaise B4; UFES $104603 \bullet 1$; ; same collection data as for preceding; Malaise T1; UFES $106426 \bullet 1$; ; same collection data as for preceding; Malaise T1; UFES

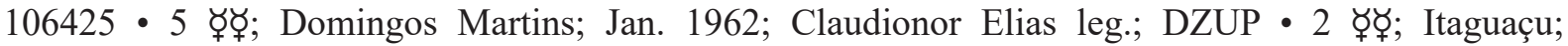
19 Mar. 1970; C.T. and C. Elias leg.; DZUP • 1 đ̄; Itagauçu, Alto Lajinha, Fazenda Binda; 22-29 Sep. 2008; M.T. Tavares and team leg.; Malaise; UFES $82143 \bullet 1$; ; same collection data as for preceding; UFES 82138 • 1 ఛ̧; Laranja da Terra, Joatuba, Faz. Betzel; 1950'25" S, 4049’40" W; 5-12 Oct. 2012; Tavares and team leg.; UFES137307 1 त ; same collection data as for preceding; Malaise B-1; UFES $135693 \cdot 1$ \%; same collection data as for preceding; Malaise B-4; UFES 135132 • 1 त; Santa Leopoldina, Suíça, mata; $20.08183^{\circ} \mathrm{S}, 40.59413^{\circ} \mathrm{W}$; alt. $361 \mathrm{~m}$;05-12 Nov. 2007; C.O. Azevedo and team leg.; Malaise; UFES 68910 • 1 ఫ̧; Linhares; 19 Oct. 1967; Kloss leg.; Coleção Diniz; DZUP • 1 ఢ̧; same locality as for preceding; 24-31 Jul. 1972; C. Elias leg.; DZUP • 17 ఫ̧ర్; same locality as for preceding; 8-14 Aug. 1972; Claudionor Elias leg.; DZUP • 15 ఫ६;; same locality as for preceding; 8-14 Dec. 1972; Claudionor Elias leg.; DZUP• 1 ६; same locality as for preceding; 20 Sep. 1983; M.A. Penha leg.; UFES 39355 - 1 ఫ; same locality as for preceding; 10 Oct. 1993; Ademar Luz leg.; 1392; CPDC •

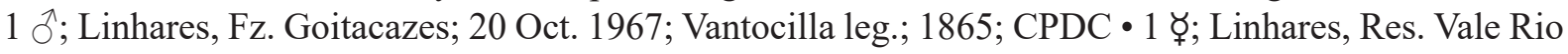
Doce; $19.2461^{\circ} \mathrm{S}, 39.9611^{\circ} \mathrm{W}$; alt. $12 \mathrm{~m}$; 5-6 May 2007; J.A. Rafael and F.F. Xavier F. leg.; manual; INPA • 1 ఫ్; Res. de Linhares; 20 Oct. 1999; C. Villemant leg.; DZUP • 1 ఫ; Morro Mestre Alvaro, Serra; 16 Apr. 1987; A.P. Aguiar leg.; UFES 39363 • 1 ○’; Pancas, Faz. Juliberto Stur; $19.21958^{\circ} \mathrm{S}, 40.77327^{\circ} \mathrm{W}$; 24-31 Jan. 2003; Tavares, Azevedo and team leg.; Malaise T4; UFES 99293 • 1 ६; Piúma, ilha; 6 Nov. 2007; R.S. Ferreira leg.; CPDC • 1 ఫ; Regência; 23 Jan. 1994; J.C. Nascimento leg.; 4794; CPDC • 1 ఫ; Sta. Tereza [Santa Teresa]; 13 Jan. 1970; C.T. and C. Elias leg.; DZUP • 16 ఫఢఫ; same locality as for preceding; 7 Dec. 1964; C. Elias leg.; DZUP • 1 ఫ̧; Santa Teresa, Est. Biológica de Santa Lúcia; 
20-24 Oct. 2007; M.T. Tavares and team leg.; UFES 70534 • 1 ఫ; same collection data as for preceding; UFES $70535 \cdot 1$ ऊं; same locality as for preceding; 17-23 Oct. 2011; M.T. Tavares and team leg.; Malaise; UFES 118173 • 1 ६; Serra Mestre Alvaro; 27 Jul. 2002; T.S. Soares leg.; UFES 39347 • 1 ఈ; Soretama, Reserva Natural Vale; $19.1333^{\circ} \mathrm{S}, 40.0500^{\circ} \mathrm{W}$; Feb. 2015; T. Vargas leg.; UFV LabEcol 43 - 1 ఫ; same collection data as for preceding; UFV LabEcol 432 • 1 ఫ;; Vila Valério, Sítio Benincá; $18^{\circ} 58^{\prime} \mathrm{S}, 40^{\circ} 27^{\prime} \mathrm{W} ; 14-28$ Sep. 2011; C.O. Azevedo and team leg.; UFES 119467 • 1 ६̧; Vitória, Fradinhos; 18 Sep. 1986; R.P. Moure leg.; UFES 38457 • 1 ఫ̧; Vitória, Maruípe; 14 Aug. 2002; Silva, A.S. leg.; UFES 21962 • 1 ఫ̧; Vitória, Morro TV Gazeta; 6 Oct. 1993; H. José leg.; UFES 39362 • 1 ఫ; Parque Fonte Grande; 25 Apr. 1987; R.B. Frigeri leg.; UFES 39529 • 1 ఫ; Vitória, Pq. Estadual Fonte Grande; alt. 290 m; $20.3091^{\circ}$ S, 40.3413 ${ }^{\circ}$ W; 3 May 2007; J.A. Rafael and F.F. Xavier F. leg.; light; INPA. - Minas Gerais - 2 ఫॄథ; Aimorés; 1-7 Apr. 1970; C. and Tadeu Elias leg.; DZUP • 1 ఢ̧; Ataleia; 27 Jan. 1994; I. Cardoso leg.; 4772; CPDC • 1 ఢ̧; Ponto dos Volantes, margem BR 116; 10 Jul. 2009; Isac H. Cordeiro leg.; 5563; CPDC • 1 ఛ;; Salto da Divisa; 10 Feb. 2004; Andre Amorim leg.; 160142653955172; CPDC • 1 ६̧; Serra dos Amorés; 7 Jul. 2004; J.R.M. Santos leg.; CPDC • 1 ơ; same collection data as for preceding; CPDC. - São Paulo • 1 ఫ̧; Cruzeiro; 26 Sep. 1933; Pedro S. de Myra leg.; MZSP. - Rio de Janeiro • 1 ६; Rio das Ostras; Jan.1989; M.L. Rets leg.; DZUP.

\section{Redescription}

Female

Measurements. Non-types ( $\mathrm{n}=34$ ): HL 4.9-5.71; HW 4.5-5.33; MDL 3.8-4.33; SL 5.15-5.58; MSL 7.2-8.13; HFL 6.78-7.62; HBL 6-7.2; PL 2.13-2.96; PH 2.91-3.35; PW 1.55-1.98; ATS 6.88-8.7; BL 25.7-29.46 (mm); CI 0.87-1; SI 1.01-1.16; DPI 0.61-0.81.

HEAD. Malar area with longitudinal to oblique striae that always reach entire anterior eye margin, striae extend to gena until at least half of eye length. Gena weakly microareolate and silky, usually without rugulae. Longitudinal to oblique striae and brownish appressed pubescence present between eye and frontal lobe, pubescence extends posteriorly to frons. Frons slightly microareolate and silky; with

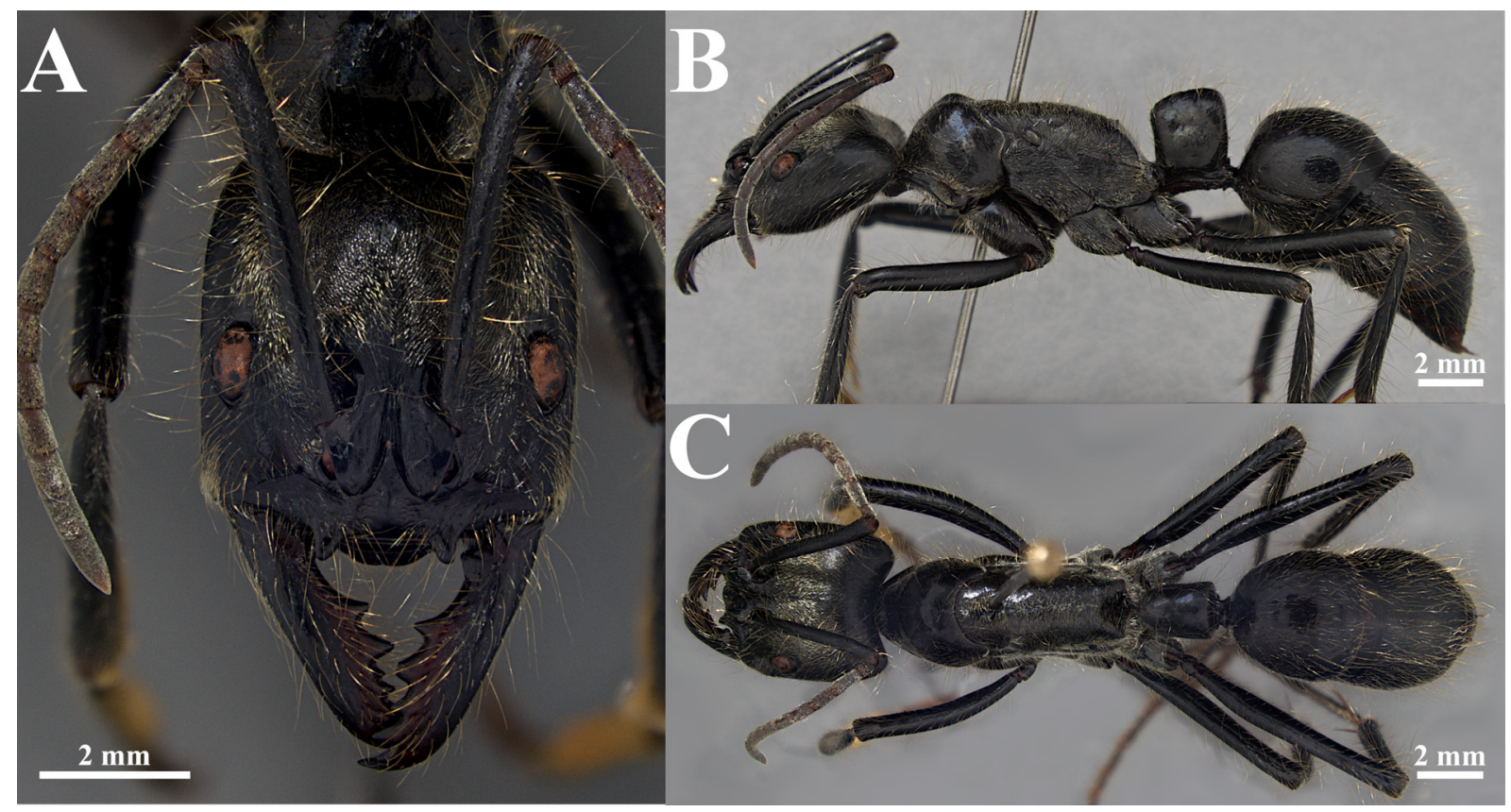

Fig. 21. Dinoponera lucida Emery, 1901, $\Varangle$ (specimen from Baixo Guandu, Espírito Santo, Brazil; DZUP 549807). A. Full-face view. B. Full body in lateral view. C. Full body in dorsal view. 
flexuous, brownish, suberect hairs, longer than scape diameter. Occipital corner slightly microareolate and silky. Antennal scape microareolate and silky, antenna with long suberect hairs, except for 4-5 apical segments. Ventral surface of head microareolate with arched strigulae that may cover entire surface or just anterior half. Hypostomal tooth with longitudinal strigulae. Labrum with weak transverse rugulae, without median longitudinal sulcus. Mandibular dorsum longitudinally strigulate, irregularly impressed along inner margin, gradually fading apicad.

Mesosoma. Dorsal margin of pronotum in lateral view sharply convex, usually with very pronounced dorsoposterior swelling; anteroventral corner of pronotum toothed or forming acute angle. Pronotal dorsum smooth, with bluish iridescence. Metapleural-propodeal suture weak and sinuous, with at least one curve ventral to position of propodeal spiracle.

Metasoma. Petiolar node in lateral view elongate (usually DPI $<0.8$ ), anterodorsal corner lower than posterodorsal corner; anterior margin straight to slightly concave and forming blunt angle with dorsal margin, dorsal and posterior margins broadly convex to straight and forming blunt angle. Node lateral face slightly microareolate and silky. Node anterior margin in dorsal view convex, posterior margin broadly convex to straight, lateral margins broadly convex, slightly converging anterodorsally. Abdominal tergite III mostly smooth with bluish iridescence, usually with anterior rugulosity; punctulae denser laterally than dorsally; densely covered by brownish, flexuous, suberect hairs on entire surface; decumbent pubescence very sparse on dorsum, denser laterally.

\section{Male}

Measurements. Non-types ( $\mathrm{n}=5$ ): HL 1.85-2; HW1 2.21-2.32; MDL 0.53-0.6; SL 0.62-0.7; EL 1.171.26; MOD 0.38-0.41; LOD 0.36-0.38; MSL 5.87-6.25; HFL 4.56-4.87; PL1 1.57-1.58; PH 1.231.38; PW 0.92-1.08; ASL 4-4.05; BL1 14.04-14.35 (mm); CI1 1.1-1.21; SEI 1.7-1.92; SI1 0.28-0.3.

HEAD. Frontal carina forming a longitudinal line. Lateral ocellus clearly surpassing posterior head margin in full-face view. Head punctulate, very slightly microareolate and shining; with yellowish suberect

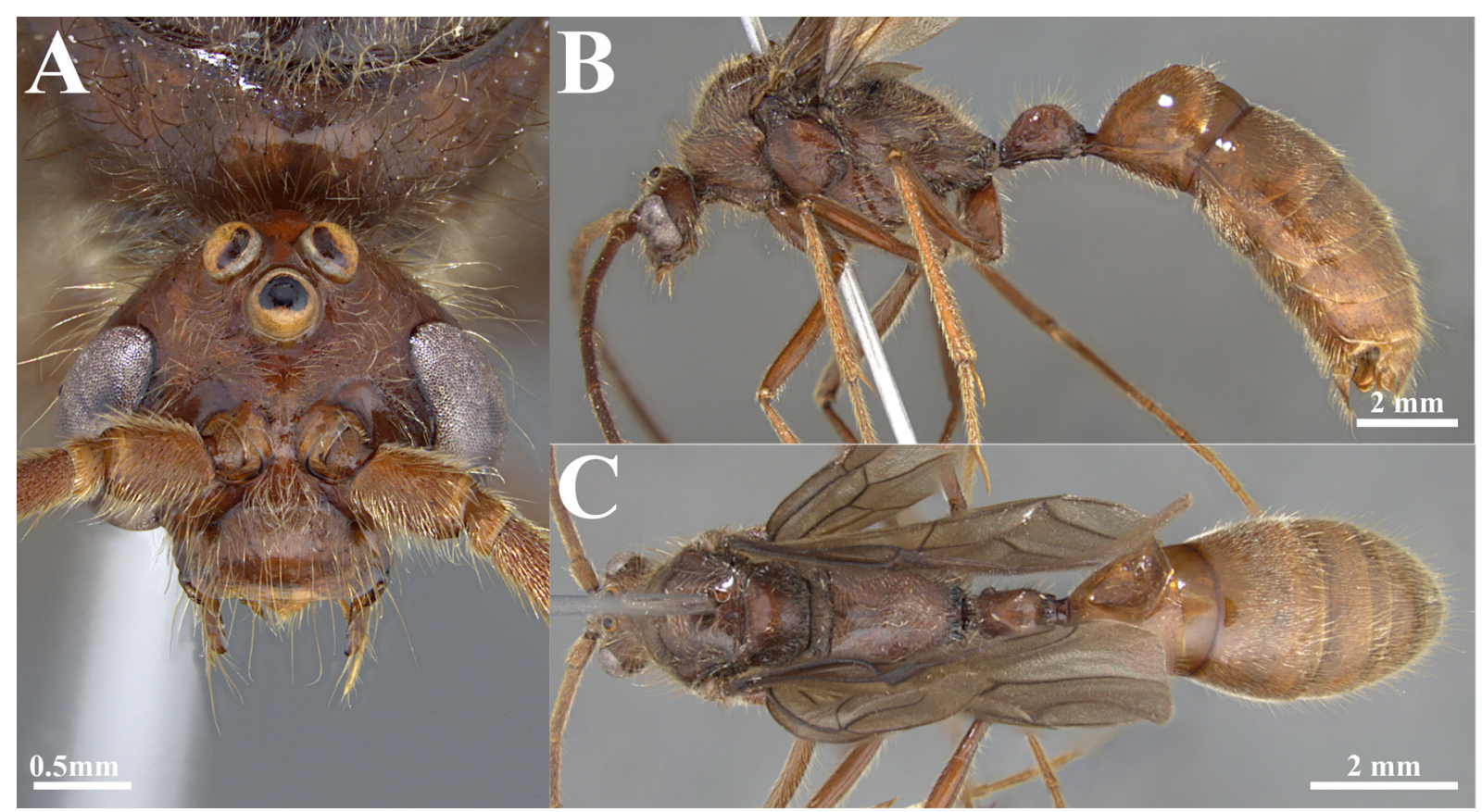

Fig. 22. Dinoponera lucida Emery, 1901, $\widehat{\jmath}$ (specimen from Domingos Martins, Espírito Santo, Brazil; UFES 106427). A. Full-face view. B. Full body in lateral view. C. Full body in dorsal view. 
pubescence and long suberect to erect hairs, longer than ocellus height in full-face view. Antenna with appressed pubescence and stiff decumbent hairs shorter than maximum scape diameter. Ventral surface of head punctulate and slightly microareolate with silky sheen.

Mesosoma. Mesoscutum without notaulus. Mesopleural sulcus usually scrobiculate. Scutoscutellar sulcus scrobiculate. Mesoscutellum longitudinally strigulate laterally. Metapleural-propodeal suture usually slightly scrobiculate. Mesosoma mostly smooth and shining, becoming coarsely punctate on declivitous surface of propodeum; with decumbent to suberect pubescence and suberect hairs, distance between each hair usually less than half its length. Legs densely covered by suberect pubescence; with sparse suberect long hairs, greater than femur diameter, ranging from coxa to tibia. Protibial apex without a stout seta.

Metasoma. Petiolar node smooth and shining; with sparse suberect pubescence and abundant suberect hairs. Abdominal tergite VIII triangular, with a very sharp apex; mostly smooth and shining. Tergites with sparse suberect pubescence and abundant suberect hairs.

Genitalia. Basal ring in dorsal view with lateral margins slightly convex, anteriorly narrower than posteriorly; maximum diameter of fenestra longitudinally directed; median invagination V-shaped; in lateral view, dorsal margin broadly concave and extending anteriorly to form a lobe; anteroventral process subquadrate to rounded. Gonostylus broad and rounded. In lateral view, dorsal margin of volsella anteriorly convex and posteriorly slightly concave; anteroventral corner projecting anteriorly as a rounded to subquadrate lobe; posteroventral margin concave, sometimes forming a posterior subtriangular lobe; digitus volsellaris usually with posterior margin broadly convex. In lateral view, penisvalva with continuous dorsal and posterior margins, ending in a rounded ventral lobe; ventral margin uneven and serrated, with a short median spine placed in a concavity; anteroventral corner rounded to subquadrate.

CoLOR. Body mostly chestnut brown.

\section{Remarks}

Females of Dinoponera lucida are distinct from other Dinoponera by having the anterodorsal corner of the petiolar node in lateral view lower than the posterodorsal corner. Additionally, D. lucida also has longitudinal to oblique striae on the malar area that reach the entire anterior ocular margin, extending on to the gena until at least half of eye length. Rarely, $D$. grandis may exhibit a similar node shape, but the anterodorsal corner is not as low as in D. lucida. Dinoponera lucida may also be separated from $D$. grandis by the bluish iridescence of the dorsum of abdominal tergite III, with no visible microsculpturing. Besides that, D. lucida and D. grandis are allopatric. Dinoponera mutica may have the anterodorsal node corner slightly lower than the posterodorsal corner, but it does not have wellmarked striae on the malar area that reach the entire anterior ocular margin and no anteroventral pronotal tooth. Dinoponera lucida is currently considered endangered according to the red book of threatened Brazilian fauna (ICMBio 2018).

Escárraga et al. (2017) described the male of D. lucida. It differs from D. gigantea and D. quadriceps mainly by not having long antennal hairs. Besides that, in these two species and in Dinoponera morphospecies 1 , the dorsal margin of the genital basal ring in lateral view does not form an anterior lobe as in $D$. lucida. D. longipes may be similar to $D$. lucida, but they can be separated by the penisvalva shape, which forms a ventral rounded lobe only in $D$. lucida. In $D$. grandis and $D$. snellingi, the ventral penisvalva lobe is curved laterally and not continuously rounded; neither does the antenna have stiff hairs. 


\section{Biology}

Dinoponera lucida occurs mainly in dense ombrophilous forest, characterized by high humidity, medium to large trees, and large numbers of epiphytes (Campanili \& Schaffer 2010). These forests are predominantly hot and humid, with average temperatures varying from 20 to $26^{\circ} \mathrm{C}$ (Alvares et al. 2013). Nests of $D$. lucida are found always in the soil, usually less than $1 \mathrm{~m}$ away from trees and in shaded areas (Peixoto et al. 2010). Each nest can contain one to four entrances with small sticks, leaves and loose soil all around (Peixoto et al. 2010). The distribution pattern of the nests is aggregated, with local densities varying from 20 to 52 nests per hectare (Peixoto et al. 2010). On average, each nest is $35 \mathrm{~cm}$ deep, with four to five chambers (Paiva \& Brandão 1995; Peixoto et al. 2010). The number of adult workers per colony can vary from 22 to 106, but rarely exceeds 50 (Paiva \& Brandão 1995; Peixoto et al. 2008, 2010). Peixoto et al. (2010) suggested that the number of workers tends to be higher before and at the beginning of summer, the period before nest fission. The number of males, however, does not seem to have seasonal variation, since a gamergate can be substituted at any time of the year (Peixoto et al. 2010).

Dinoponera lucida is omnivorous, feeding mainly on small dead invertebrates or angiosperm seeds (Peixoto et al. 2010). The workers forage alone during the day, even at warmer hours (Peixoto et al. 2010). During foraging, a worker may forage up to $20 \mathrm{~m}$ from the nest entrance (Paiva \& Brandão 1995; Peixoto et al. 2010). However, the distance traveled may be higher when local nest density is smaller, suggesting intraspecific competition for territory (Peixoto et al. 2010).

Founding of new colonies occurs by fission, i.e., some workers (among them a newly fertilized one) migrate to a nearby nest probably doing tandem running (Hölldobler \& Wilson 1990; Peixoto et al. 2008, 2010). This process can happen gradually, since the older colony goes through a polydomic stage before the total separation (Peixoto et al. 2010). Newly founded colonies are monogynous and with age exhibit polyethism, the older ants foraging and younger ones taking care of the brood (Hölldobler \& Wilson 1990; Peixoto et al. 2008, 2010). In contrast to D. quadriceps, agonistic interactions among workers are uncommon in colonies with gamergates and when they occur the gamergate does not participate in the interactions (Peixoto et al. 2008). The existence of a dominance hierarchy within the colonies of D. lucida has not yet been clearly determined by researchers (Peixoto et al. 2008).

Many arthropods live in D. lucida nests, including a species of Pheidole Westwood, 1839 which occurs only in this association (Paiva \& Brandão 1995; Peixoto et al. 2010). Buys et al. (2010) recorded a wasp of the genus Kapala Cameron, 1884 (Eucharitidae) parasitizing a pupa of D. lucida, which had about 70 to $90 \%$ of the body consumed.

\section{Distribution (Fig. 29A)}

Dinoponera lucida is endemic to the Atlantic Forest biome of eastern Brazil, occurring throughout Espírito Santo State, south of Bahia, the eastern boundary of Minas Gerais and north of São Paulo. The northernmost record for this study is Jacobina, Bahia, and the southernmost is in Cruzeiro, São Paulo dating from 1933. This is the only known record for São Paulo and could imply that D. lucida had a wider distribution or that this is a labeling error. The state of Rio de Janeiro, which is between the states of São Paulo and Espírito Santo, does not have records of Dinoponera. A specimen was received with a label from Rio das Ostras, Rio de Janeiro, but it is a probable labeling error for two reasons: (1) no published records of Dinoponera were found for the state, despite being a heavily collected region for insects in general; and (2) before the fire at the National Museum of Rio de Janeiro, consultation with researchers there found that the collection of ants did not have any Dinoponera from the state. For these reasons, this record was not included in the distribution map. 
Dinoponera mutica Emery, 1901

Figs 23, 28B

Dinoponera grandis mutica Emery, 1901: 48 (ఫ).

Dinoponera mutica - Kempf 1971: 378, fig. 4 (raised to species). — Lenhart, Dash \& Mackay 2013: 148, figs 1e, f, $12 \mathrm{~b}$ (redescription, key).

\section{Diagnosis}

Female

Anteroventral corner of pronotum in lateral view forming obtuse angle. Petiolar node in lateral view with dorsal margin straight. Abdominal tergite III smooth and shining. Sparse brownish pubescence on dorsum, denser laterally. Body with brownish hairs.

\section{Material examined}

Non-type specimens ( 80 ఫఢ)

BOLÍVIA - Santa Cruz • 1 ఫ;; ‘7W’ P [Puerto] Juarez, 'n' cerrito; 1938; Wittmer leg.; MZSP • 1 ఫ; San Ignacio [San Ignacio de Velasco]; 1 Jan. 1963; L.J. Hammerschmidt leg.; MZSP.

BRAZIL - Goiás • 3 ర̧ఫ్; Aragarças, R. Araguaia; Sep. 1946; H. Sick leg.; MZSP • 1 ఫ; Parque Nacional das Emas; 10 Nov. 1990; Cesar Kriger leg.; UFSC • 2 ఫ̛ఫ్; same locality as for preceding; 25 Oct.2 Nov. 1986; Bechara, Viviani, Ferro and Sanches leg.; MZSP • 13 ఫఢర్; same locality as for preceding; 15-30 Oct. 1994; MZSP • 1 ఫ্; Parque Nacional das Emas, torre; 1 Jun. 2008; Valentim, Schmidt, Pereira and Ribas leg.; parcela 8 armadilha E; MZSP. - Mato Grosso • 1 ఛ̛; "Eot. Da Colônia R. Itumbolt"; 3 Oct. 1975; L.P. Albuquerque and J.B. Moraes leg.; MPEG HYM11513005 • 1 ६;; Barra dos Bugres; 1 Jul. 1973; B. Dias leg.; MZSP • 1 ఫ; Barracão Queimado; Nov. 1960; M. Alvarenga leg.; DZUP • 1 ఫ; Itiguira [Itiquira]; 2013; T. Semido leg.; coleta manual; DZUP • 1 ఫ; Juara; $11^{\circ} 5^{\prime} 21.3^{\prime \prime}$ S, 57 $7^{\circ} 43^{\prime 2} 26^{\prime \prime}$ W; Feb. 2015; Santo R. leg.; M1L2 pitfall 8; DZUP • 1 ६̧; same collection data as for precedig; DZUP 549809 • 1 ఫ; Juara, UHE Castanheira, floresta secundária; $11.0892^{\circ} \mathrm{S}, 57.7238^{\circ} \mathrm{W}$; M1L2; MPEG • 1 ఫ; Novo Mundo, PE Cristalino; May 2013; R.E. Vicente leg.; parcela 12 pitfall 6; DZUP• 1 ఫ; Poconé; 1 May 1948; C. Valette leg.; MZSP • 1 ६;; Rio Correntes; 5 Mar. 1978; Olavo Seifert leg.; 6228; MZSP - 1 ఫ; Ricardo Franco; 2 Jun. 2014; H.L. Vasconcelos and J.B. Maravalhas leg.; 518, T58-9S; DZUP • 1 ఫ; same collection data as for preceding; 629, T59-1S; DZUP • 3 ఫఢఛ; Rondonópolis; Diringe leg.; MZSP • 1 ६̧; Sto [Santo] Antônio de Leverger, Águas Quentes; 26 Oct. 1984; J.C.Trager leg.; isca carne, High cerrado, 169; MZSP • 1 ఫ; Tangará da Serra; 2003; CPDC • 1 ఫ; Utiariti, Rio Papagaio; 1 Aug. 1961; K. Lenko leg.; MZSP• 1 ६; same locality as for preceding; 1 Nov. 1966; Lenko and Pereira leg.; 4917; MZSP • 1 ఫ; same locality as for preceding; 23 Oct. 1966; Lenko and Pereira leg.; MZSP • 1 ఛ; same collection data as for preceding; Coleção Diniz; DZUP • 1 ६̧; Vila Bela da Santíssima Trindade, Serra Ricardo Franco; $14.9076^{\circ}$ S, 60.0644 W; 7 Feb. 2014; J. Maravalhas et al. leg.; T59 11S²; DZUP • 3 ఫఫర; Xingu; Nov. 1961; Alvarenga and Werner leg.; MZSP. - Mato Grosso do Sul • 1 ఢ; Camapuã; 15 Oct. 1960; Evangelista leg.; MZSP • 1 ६̧; Rio Verde de Mato Grosso; Diringe leg.; MZSP • 1 ఫ; Serra do Urucum, Corumbá; 25 Nov. 1960; K. Lenko leg.; 940; MZSP. - Pará • 1 ఛ; Altamira, Castelo de Sonhos; $8.2033^{\circ} \mathrm{S}, 55.0202^{\circ} \mathrm{W}$; alt. 265 m; 10 Nov. 2005; A.L. Nunes leg.; área 18; MPEG •

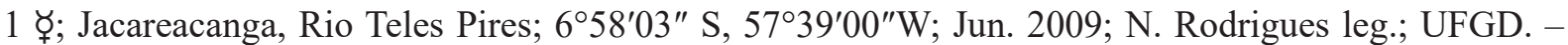

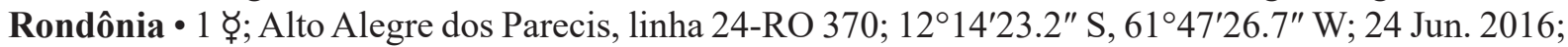
I.O. Fernandes leg.; coleta manual; INPA • 1 ६̧; "EXTEX"; 10¹9'17" S, 64³3'47" W; 13 Mar. 1998; J.R.M. Santos leg.; CPDC • 1 ६; same collection data as for preceding; DZUP • 8 ఫఢఫ; Forte Príncipe da Beira; 10 Nov. 1961; F.M. Oliveira leg.; MZSP • 1 ఫ̧; same locality as for preceding; 1 Nov. 1952; Coleção Campos Seabra; MZSP • 1 ఢ̧; Ji-Paraná; 11 Aug. 1984; R.B. Neto leg.; MPEG HYM11513006 - 1 ఫ̛; Monte Negro-Cacaulândia, mata na margem, direita do Rio Jamari; Jul. 2001; S.E. Favorito 
et al. leg.; pitfall; MZSP • 1 ఫ; Ouro Preto do Oeste; 1997; O. Trevizan leg.; "in. natural de Monalonion spp"; CPDC • 1 ఫ; Ouro Preto do Oeste, Sítio Deus é amor; 26 Mar. 1985; M.F. Torres leg.; MPEG HYM11513007 • 4 ర్థ; Ouro Preto do Oeste, Reserva Biológica de Ouro Preto do Oeste; 10 42'59.3" S, 62¹4'39.3" W; 13-18 Jul. 2009; I.O. Fernandes leg.; alt. 287 m; INPA • 1 ఢ̧; Pres [Presidente] Médici; 23 Aug. 1984; MPEG • 1 ఫ̛; R [Rio] Urupá, Ji-Paraná; 1 Jul. 1983; C.E.R. Coimbra leg.; MZSP • 1 ఫ̛; Rio Madeira, M. Três Praias; 7 Oct. 2001; F.D. Santana leg.; \#5696; CPDC • 1 ఫ; V [Vila] Rondônia, 378 km from P [Porto] Velho; 25 Jan.-9 Feb. 1961; Pereira and Machado leg.; MZSP • 2 ఫర్ఛ; Vilhena; Nov. 1960; M. Alvarenga leg.; DZUP.

PARAGUAY - Alto Paraguai - 1 ఛ; Parque Nacional Defensores del Chaco, Cruce, 4 de Mayo; 20¹8'03" S, 60³3'02" W; 18 Jan. 2001; B. Garcete leg.; MNHNP HX70. - Boquerón • 1 ఛ; Parque Nacional Teniente Enciso; $21^{\circ} 11^{\prime}$ S, 61 ${ }^{\circ} 40^{\prime}$ W; 16-18 Sep. 2002; B. Garcete leg.; MNHNP HX71.

\section{Redescription}

Female

MeAsurements. Non-types ( $\mathrm{n}=24)$ : HL 4.85-6.23; HW 4.55-6.3; MDL 4.05-4.97; SL 5.1-6.07; MSL 7.52-8.8; HFL 7.2-8.1; HBL 6-7.3; PL 2.13-2.57; PH 2.1-3.55; PW 1.55-1.86; ATS 7.24-8.8; BL 23.72-30.66 (mm); CI 0.9-1.01; SI 0.95-1.16; DPI 0.67-0.78.

HEAD. Malar area punctulate and weakly striate; striae longitudinal to oblique, usually not reaching anterior eye margin. Gena smooth (rarely weakly microareolate) with bluish iridescence; usually transversely rugulose in median area. Appressed brownish pubescence present between eye and frontal lobe, extending posteriorly to frons. Frons smooth, with bluish iridescence; with flexuous, brownish, suberect to erect hairs, longer than scape diameter; pubescence densest laterally. Occipital corner smooth and with bluish iridescence. Antennal scape weakly microareolate and silky; antenna with long decumbent to suberect hairs, except for 5-6 apical segments. Ventral surface of head mostly smooth and silky; longitudinal strigulae present on anterolateral cephalic margin, including hypostomal tooth. Labrum usually without median longitudinal sulcus; transverse rugulae absent. Mandibular dorsum with well-marked longitudinal strigulae on inner base that gradually fade apicad.

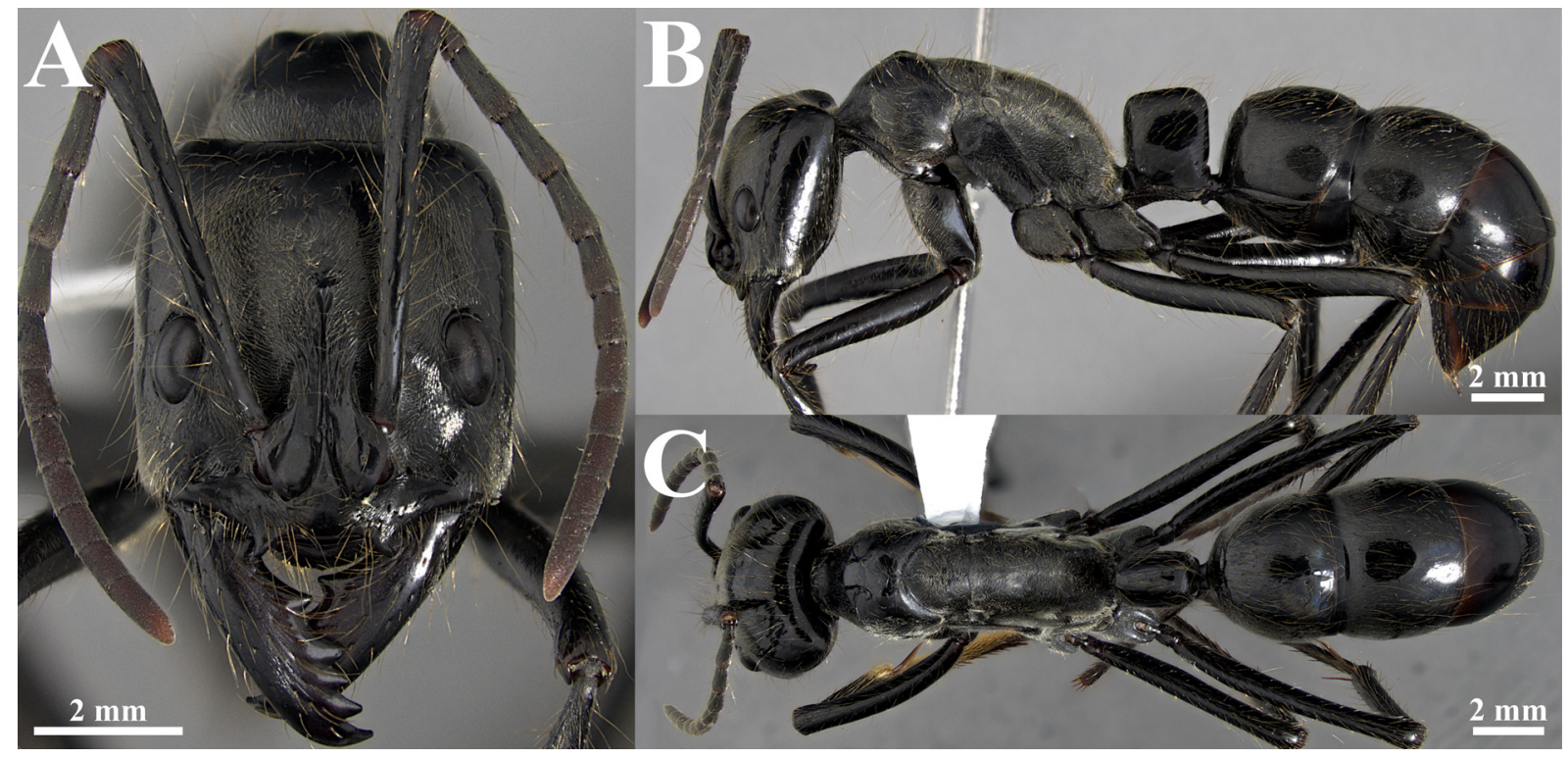

Fig. 23. Dinoponera mutica Emery, 1901, ఛ (specimen from Juara, Mato Grosso, Brazil; DZUP 549809). A. Full-face view. B. Full body in lateral view. C. Full body in dorsal view. 
Mesosoma. Dorsal margin of pronotum in lateral view convex, usually with pronounced dorsoposterior swelling; anteroventral corner of pronotum forming obtuse angle, never toothed. Pronotal dorsum smooth, with bluish iridescence. Metapleural-propodeal suture well-marked, straight to slightly sinuous.

Metasoma. Petiolar node in lateral view elongate $(\mathrm{DPI}<0.8)$; anterodorsal corner at same level or slightly lower than posterodorsal corner; anterior, dorsal and posterior margins straight; antero and posterodorsal corners forming blunt angle. Node lateral face smooth with bluish iridescence. Node anterior posterior and lateral margins in dorsal view broadly convex. Abdominal tergite III smooth with bluish iridescence; punctulae denser laterally than dorsally; covered by flexuous, brownish, decumbent to suberect hairs on all surfaces; brownish appressed pubescence sparse on dorsum, denser laterally.

\section{Male \\ Unknown.}

\section{Remarks}

Dinoponera mutica may resemble the sympatric D. nicinha sp. nov. The most useful diagnostic traits are the golden pilosity, the sparse pubescence on the dorsum of abdominal tergite III and the petiolar node in lateral view with its convex dorsal margin in D. nicinha sp. nov. Dinoponera grandis may also occur in sympatry, but has DPI $>0.8$, while $D$. mutica usually has DPI $<0.8$. Besides that, D. mutica has no visible microsculpturing on abdominal tergite III, unlike $D$. grandis. The petiolar node of D. mutica in lateral view can present an anterodorsal angle slightly lower than the posterodorsal angle, sometimes resembling $D$. lucida. However, $D$. lucida has an anteroventral pronotal tooth and strigulae on the cephalic ventral surface. Dinoponera quadriceps and D. gigantea are different on account of their predominantly microareolate and opaque integument.

\section{Biology}

Little is known about the habits of D. mutica. Although apparently occurring in sympatry with D. grandis, a species more common in savanna environments, Meurer et al. (2015) suggested that $D$. mutica may be restricted to forest environments.

Distribution (Fig. 28B)

This species is distributed in the midwest and part of northern Brazil, as well as Bolivia and Paraguay. The northernmost record is in Jacareacanga, Pará, Brazil, and the southernmost Brazilian record is in Camapuã, Mato Grosso do Sul.

$$
\begin{gathered}
\text { Dinoponera nicinha sp. nov. } \\
\text { urn:lsid:zoobank.org:act:4BCDB67F-8944-4BE4-A613-BCC4AB018C27 }
\end{gathered}
$$

Figs 24, 29B

\section{Diagnosis}

\section{Female}

Anteroventral corner of pronotum in lateral view forming obtuse angle. Petiolar node in lateral view with convex dorsal margin, anterodorsal corner at same level as posterodorsal corner. Abdominal tergite III smooth and with bluish iridescence, covered with sparse golden pubescence. Body covered by golden hairs.

\section{Etymology}

This species epithet is a matrinym in memory of Nilce de Souza Guimarães, locally known as Nicinha. She was an environmental and human rights activist that took to task consortiums that constructed 
hydroelectric dams and displaced entire villages to new sites with dismal living conditions. She lived in Rondônia State, near the type locality, and was murdered in 2016.

\section{Material examined}

\section{Holotype}

BRAZIL - Rondônia • 1 ఫ̛; Porto Velho, Área Abunã; 9³8'03.3" S, 65²6'23.9" W; 17-27 Jul. 2013; G.R. Mazão and R.S. Probst leg.; DZUP 549810.

\section{Paratypes $(25$ ఫఢ)}

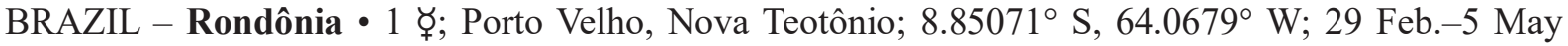
2016; TPI Network exped.; 105 Forest, 10T T06; MZSP 65802 • 1 ६; same collection data as for preceding; MZSP 65803 • 1 ఛ; same collection data as for preceding; MZSP $65804 \bullet 1$ ६; same locality as for preceding; $8.86987^{\circ} \mathrm{S}, 64.0546^{\circ} \mathrm{W}$; 29 Feb.-5 May 2016; TPI Network exped.; 117 Forest, 11C T04; MPEG HHY03034650 • 1 ఫ్; same collection data as for preceding; MPEG HHY03034651 • 1 ఫ; same collection data as for preceding; MPEG HHY03034652 • 1 ఫ; same locality as for preceding; $8.85071^{\circ} \mathrm{S}, 64.0679^{\circ} \mathrm{W} ; 29$ Feb.-5 May 2016; TPI Network exped.; 105 Forest, 10T T05; CASENT 0887850; INPA • 1 ఢ; same collection data as for preceding; CASENT 0887851; INPA • 1 ఈ ; same locality as for preceding; $8.87762^{\circ} \mathrm{S}, 64.0623^{\circ} \mathrm{W} ; 29 \mathrm{Feb} .-5$ May 2016; TPI Network exped.; 115 Forest, 9C T05; CASENT 0887852; CASC • 1 ф ; same collection data as for preceding; CASENT 0887853; CASC • 1 ६̧; same collection data as for preceding; CASENT 0887854; CASC $\bullet 1$ ६; same locality as for preceding; 29 Feb.-5 May 2016; TPI Network exped.; 115 Forest, 9C T04; CASENT 0887855; MCZC • 1 ఫ; same collection data as for preceding; CASENT 0887856; MCZC • 1 ६; same collection data as for preceding; CASENT 0887857; MCZC • 1 ఢ̧; same locality as for preceding; $8.86987^{\circ} \mathrm{S}, 64.0546^{\circ} \mathrm{W}$; 29 Feb.-5 May 2016; TPI Network exped.; 117 Forest, 11C T05; DZUP 550208 • 1 ६;; same collection data as for preceding; DZUP 550209 • 1 ६̧; same collection data as for preceding; DZUP $550210 \bullet$ 1 ఫ; same locality as for preceding; $8.85071^{\circ} \mathrm{S}, 64.0679^{\circ} \mathrm{W} ; 29 \mathrm{Feb} .-5$ May 2016 ; TPI Network exped.; 105 Forest, 10T T08; DZUP 550211 • 1 ६; same collection data as for preceding; DZUP 550212 •

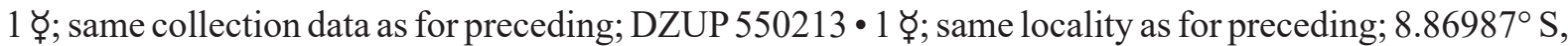
64.0546 ${ }^{\circ}$ W; 29 Feb.-5 May 2016; TPI Network exped.; 117 Forest, 11C PPT08; CASENT 0887848; DZUP • 1 ६; same collection data as for preceding; CASENT 0887849; DZUP • 1 ६ ; same locality as for preceding; $8.86432^{\circ} \mathrm{S}, 64.063^{\circ} \mathrm{W} ; 29 \mathrm{Feb} .-5$ May 2016; TPI Network exped.; 131 Forest, 9T T08; DZUP 550215 • 1 ६; same collection data as for preceding; DZUP 550216 • 1 ६; same locality as for preceding; $8.86987^{\circ} \mathrm{S}, 64.0546^{\circ} \mathrm{W}$; 29 Feb.-5 May 2016; TPI Network exped.; 117 Forest, 11C T03; DZUP 550214.

\section{Non-type specimens $(24$ ఫఢ)}

BRAZIL - Amazonas - 5 ఫ̧ఫ; Lábrea, Ramal Apaeral, km 09 sítio São Raimundo; $7^{\circ} 19^{\prime} 10^{\prime \prime}$ S, 6440'07" W; Jun. 2006; F.F. Xavier F. leg.; coleta manual; INPA • 1 ఫ; Humaitá, Galego; 12 Apr. 1975; V.P. da Silva leg.; 11944; MZSP • 2 ర్ఛర్; Manaus, Uypiranga, Rio Negro, 14 km from Manaus; alt. 81 m; Oct. 1941; August Rabaut leg.; MZSP. - Rondônia • 1 ఫ̧; Ariquemes, Rio Ji-Paraná; 944' S, $61^{\circ} 52^{\prime}$ W; 28 Oct. 1986; J.A. Rafael leg.; arm. Malaise; INPA • 3 ఫఢర్; Nova Colina; 30 Oct.-4 Nov. 1984; Polonoroeste exped.; MZSP • 10 ఫఢఝ;; Porto Velho; 845'43" S, 6354'14" W; 21 May 2011; Carmo et al. leg.; pitfall; INPA • 1 ఢ; Guaporé; 1 Nov. 1954; F. Pereira, Werner Dente and M. Alvarenga leg.; MZSP • 1 ఫ; Rio Madeira, M. Teotônio; 15 Oct. 2011; F.D. Santana leg.; \#5696; CPDC.

\section{Description}

Female

Measurements. Holotype: HL 5.73; HW 5.6; MDL 4.53; SL 5.54; MSL 8; HFL 7.8; HBL 6.5; PL 2.35; PH 3.3; PW 1.7; ATS 7.76; BL 28.38 (mm); CI 0.97; SI 1.03; DPI 0.62. Non-types ( $=10)$ : HL 5.48-6.64; HW 5.54-5.96; MDL 4.47-5.04; SL 5.98-6.64; MSL 8.2-9.2; HFL 7.92-8.8; HBL 6.4-7.5; 
PL 2.38-2.63; PH 3.32-3.42; PW 1.59-1.89; ATS 7.6-9.2; BL 28.86-32.51 (mm); CI 0.89-0.98; SI 1.05-1.13; DPI 0.63-0.72.

HEAD. Malar area with weak longitudinal to oblique striae that do not reach anterior eye margin. Gena smooth, with bluish iridescence; usually without rugulae. Golden appressed pubescence present between eye and frontal lobe, extending posteriorly to frons. Frons smooth, with bluish iridescence; with flexuous, golden, decumbent to suberect hairs, longer than scape diameter; pubescence densest laterally. Occipital corner smooth and with bluish iridescence. Antennal scape weakly microareolate and silky; antenna with decumbent to suberect hairs, except for 5-6 apical segments. Ventral surface of head mostly smooth, with bluish iridescence; longitudinal strigulae present on anterolateral cephalic margin, including hypostomal tooth. Labrum without median longitudinal sulcus, transverse rugulae absent. Mandibular dorsum weakly longitudinally strigulate on inner base, sculpture gradually fading apicad.

Mesosoma. Dorsal margin of pronotum in lateral view convex, dorsoposterior swelling sometimes very pronounced, anteroventral corner of pronotum forming obtuse angle, never toothed. Pronotal dorsum smooth, with bluish iridescence. Metapleural-propodeal suture well-marked and straight.

Metasoma. Petiolar node in lateral view elongate (DPI $<0.8)$, antero- and posterodorsal corners at same level, anterior and posterior margins broadly convex, dorsal margin convex, antero- and posterodorsal corners rounded. Node lateral face smooth, with bluish iridescence. Node lateral margin in dorsal view broadly convex, anterior and posterior margins convex. Abdominal tergite III mostly smooth, with bluish iridescence; laterally and dorsally with evenly distributed punctulae; densely covered by golden, flexuous, suberect hairs and sparse pubescence evenly distributed on dorsal and lateral surfaces.

Male

Unknown.

\section{Remarks}

The main difference between D. nicinha sp. nov. and other species of Dinoponera is in the shape of the petiolar node. This character has proven to be useful for separating species in this genus, as its shape is

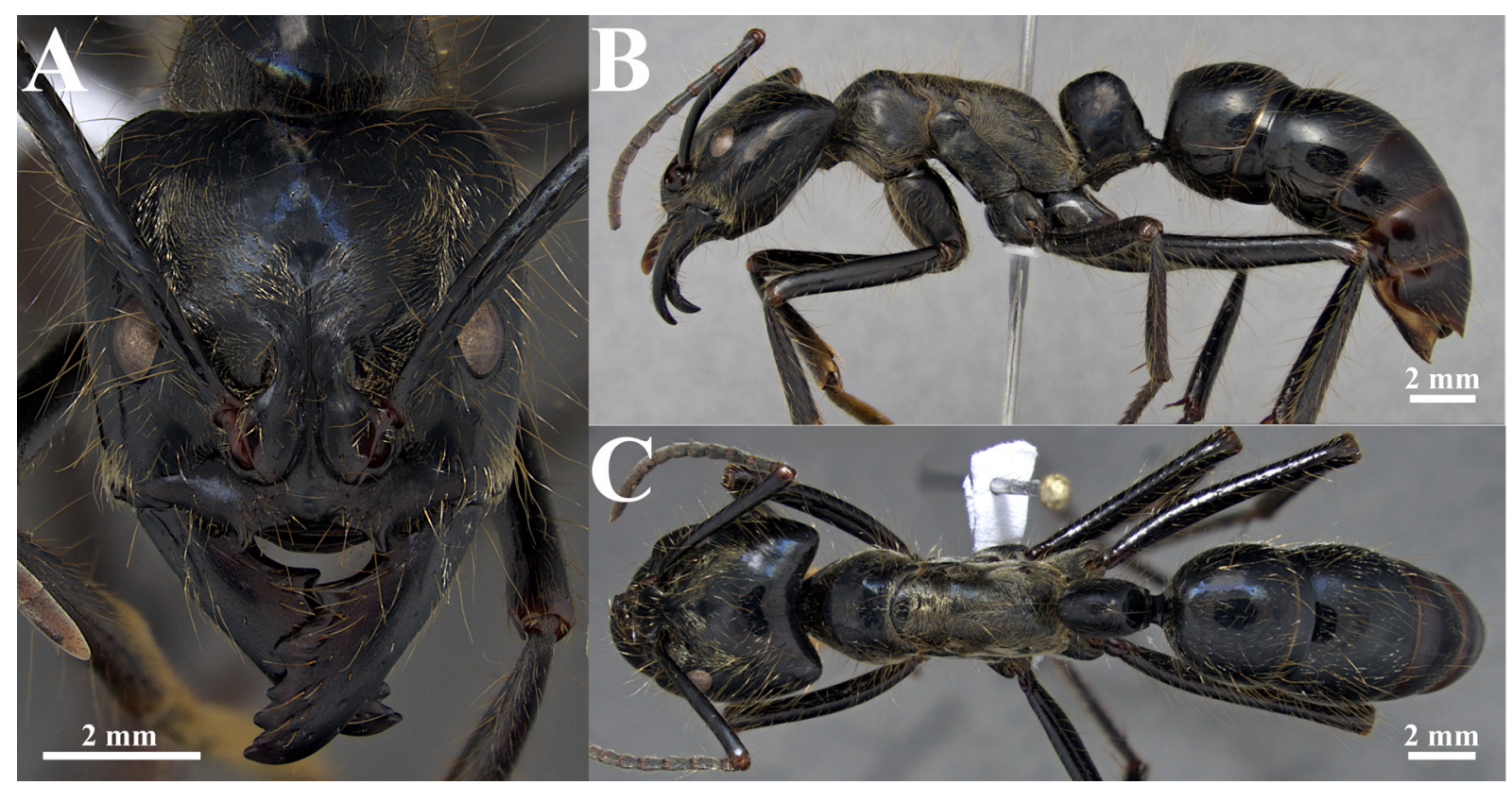

Fig. 24. Dinoponera nicinha sp. nov., holotype, ఫ̛ (Porto Velho, Rondônia, Brazil; DZUP 549810). A. Full-face view. B. Full body in lateral view. C. Full body in dorsal view. 
generally constant within the species. Specimens of this species were found in collections identified as $D$. longipes, but besides the node shape they can also be separated by the ratio of the length of the hind basitarsus to the head width, which in D. longipes is greater (always $>1.3$ in D. longipes and $<1.3$ in D. nicinha sp. nov.). Dinoponera nicinha sp. nov. can also be confused with the sympatric D. mutica, but the pilosity is not golden in D. mutica and abdominal tergite III has dense pubescence on its side (sparse in Dinoponera nicinha sp. nov.). The node in D. mutica has the anterior and dorsal margins in lateral view meeting at a blunt angle, slightly lower than the posterodorsal angle. Dinoponera nicinha sp. nov. has rounded antero- and posterodorsal node angles, both at the same level.

\section{Biology}

Dinoponera nicinha sp. nov. occurs in forest environments with high rainfall and dense coverage of medium to large trees, with a maximum of six months of drought during the year (IBGE 2012). Its natural history is unknown, except for the fact that most specimens were collected in pitfall soil traps.

\section{Distribution (Fig. 29B)}

Dinoponera nicinha sp. nov. is only known from the Brazilian states of Amazonas and Rondônia. The northernmost record is Manaus, Amazonas, and the southernmost record is in Ji-Paraná, Rondônia.

Dinoponera quadriceps Kempf, 1971

Figs 25-26, 29B

Dinoponera quadriceps Kempf, 1971: 380, figs 5, 13-16 (ఫ).

Dinoponera opaca Kempf, 1971: 379 (ఫ).

Dinoponera quadriceps - Mann 1916: 409. - Borgmeier 1937: 226 (male description). - Lenhart, Dash \& Mackay 2013: 149, figs 4b, g, 1, 5a, 6a, 10a, 11a, 12b (redescription, key, male genitals). Tozetto \& Lattke 2020: 5, figs 2-3, 6 (male genitals).

Dinoponera opaca - Kempf 1975: 344 (junior synonym of D. quadriceps).

Non Dinoponera grandis mutica quadriceps - Santschi 1921: 84 (invalid name).

Non Dinoponera grandis mutica opaca - Santschi 1921: 84 (invalid name).

\section{Diagnosis}

\section{Female}

Malar area without striae or with weak longitudinal to oblique striae that do not reach anterior eye margin. Ventral head surface without strigulae. Head with short to inconspicuous pubescence. Anteroventral corner of pronotum in lateral view forms an obtuse angle. Abdominal tergite III microareolate and opaque, with sparse pubescence on dorsum.

\section{Male}

Antenna with long suberect to erect hairs, clearly longer than maximum scape diameter. Mesoscutum without notaulus. Gastral tergites without long hairs. In lateral view, dorsal margin of basal ring broadly concave to straight.

\section{Material examined}

Non-type specimens (200 ఫॄర, $17 \precsim \widehat{\jmath})$

BRAZIL - Bahia • 1 ఫ̛; Aramari, ex Distrito de Alagoinhas; MZSP • 1 ఫ̛; Banzaê; 10³4'37" S, 38³6'54" W; Mar. 2009; M.D. Dantas leg.; 01; CPDC • 1 ఫ̛; Barragem de Anagé [Amajés]; 19 Oct. 1996; Argôro Santos leg.; 5126; CPDC • 1 ఢ̧; Barreiras, Serra do Mimo; 5 Aug. 2010; S. Souza and B. Santos leg.; \#5657; CPDC • 1 ६̧; Bendegó, próx. Canudos; 19-22 Nov. 1965; Exp. DZ Fapesp leg.; 
MZSP • 2 ఫ̧ఫ; Lapa [Bom Jesus da Lapa]; 1 Dec. 1948; Gonçalves leg.; MZSP • 1 ఫ;; Bonfim; 6 Dec. 1948; C.R. Gonçalves leg.; "Let OT Borgmeier set 1953"; MZSP • 7 ఫ̛ర్; Buritirama; 22 Mar. 1958; E. Dente leg.; MZSP • 1 ఫ; Caatinga do Moura; 24 Jan. 1980; M.T.U. Rodrigues leg.; MZSP • 1 ఛ; same locality as for preceding; 24-29 Jan. 1980; P.E. Vanzolini leg.; MZSP • 2 ఫॄఫ; Caculé; Jul. 1961; S. Laroca leg.; DZUP• 1 ఫ; Caetité; Nov. 2009; Jaqueline leg.; 8593; CPDC • 1 ఢ̧; Camisão; 8 Apr. 1905; E. Bondas leg.; n 3401 Coll Borgmeier; MZSP • 1 ६̧; Campo Formoso; 20 Apr. 1974; R.L. Araújo leg.; n5534; MZSP • 1 ఫ; same locality as for preceding; Jun. 1995; C. Moura leg.; 4940; CPDC •

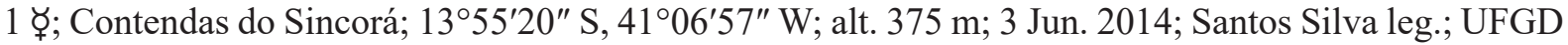

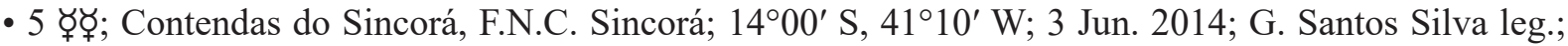
DZUP • 2 ర̧ఫ; Cruz das Almas; 1 Apr. 1988; C.A.L. Carvalho leg.; 704188 (2/2) ME 014; MZSP • 2 ఫॄఢ; Feira de Santana; 23 Feb. 1993; J. Ricardo leg.; 4611; CPDC • 1 ఫ; same locality as for preceding; 19 Jun. 2006; J.J. Resende leg.; 11, ninho 1 F07; CPDC • 1 ఫ;; Feira de Santana, UEFS; 30 Nov. 1993; I.M.F. Soares leg.; 4899; CPDC • 1 ф̧; Guanambi, EAFG; Apr. 1997; A.J.S. Argolo leg.; CPDC • 3 ఫॄర; Ibiraba; 1 Mar. 1989; Pedro Rocha leg.; "noite, ninho pé arbusto"; MZSP • 1 ఫ్; Ibotirama; 21 Jul. 1969; W. Silva leg.; MZSP • 1 ఫ్; Igaporã; 9 Nov. 2011; J.A. Jesus leg.; CPDC • 1 ఫ;; Itaberaba; 19 Aug. 2008; Antônio Alves leg.; CPDC • 1 ఫ̛; Itaberaba, Amparo Br28; 16 May 1965; R. Grantsan leg.; MZSP • 4 ర̧ષ్; Itaberaba, Faz. Riacho do Uruçu 1; 5 Dec. 1990; C.R.F. Brandão, J.L.M. Diniz and O.S. Oliveira leg.; 9 pm; MZSP • 3 ఫॄఫ; Itaberaba, Faz. Riacho do Uruçu; 1 Dec. 1990; S.T.P. Amarante

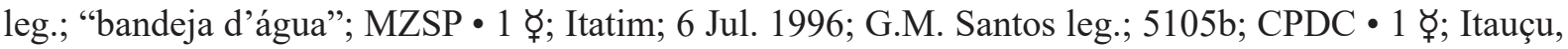
FLONA Contendas do Sincorá; 9 Sep. 2005; Daniela and Péricles leg.; TR pt 14; CPDC • 1 ఫ̛; Jandaíra, Costa Azul; 11 ${ }^{\circ} 56^{\prime} 58^{\prime \prime}$ S, 37³6'34" W; 6 Oct. 2010; M.L.O. Travassos leg.; H1430; CPDC • 1 ఫ్; Juazeiro; 11 Jul. 1989; M. Cristiano leg.; CPDC • 7 ఫॄఢ; Lagoa Itaparica; 8 Oct. 1990; Jorge L.M. Diniz leg.; coleção Diniz; DZUP • 1 ఫ; Marcionílio Souza; 24 Jul. 1993; N.S. Laca leg.; 4664; CPDC • 1 ○ૈ; Manoel Vitorino; 26-27 Jan. 2006; R.R. Hora leg.; CPDC • 1 ६; Milagres; 1254'54.2" S, 39 51'27.9" W; 22-26 Oct. 2010; M.A. Ulyssea, A.M. Medina and E.M. Campos leg.; T1F 3H1; MZSP - 1 ६; same collection data as for preceding; T2F 2H5; MZSP • 1 ६; same collection data as for preceding; T3F 4H4; MZSP • 1 ఫ̧; same collection data as for preceding; 23-25 Oct. 2010; M.A. Ulysséia leg.; MuBio-CE Hym 507; UFGD • 1 ఫ̛; Milagres, Br 116 km 561, caatinga arbórea; 1252'12" S, 39¹1'31" W; 4 May 2009; J.J. Resende leg.; DZUP • 1 ६̧; Monte Santo; 19 Jul. 1995; Cardoso leg.; 4945A; CPDC • 1 ఫ; Morro do Chapéu; 25 Mar. 1990; J. Roseira leg.; \#278; CPDC • 2 ఫॄఫ; Morro do Cruzeiro; 31 Jan. 1993; André leg.; 4610; CPDC • 1 ఫ;; Mucugê; 6 Jul. 2009; Thomas Strwtzel leg.; UFSC • 1 ६; Paulo Afonso, APA Serra Branca; 19 Mar. 2009; Layla Marques leg.; \#5596a; DZUP •

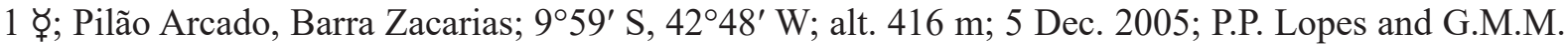
Santos leg.; CPDC • 1 ఫ్; same locality as for preceding; 3 Oct. 2006; J.J. Resende leg.; ninho 1 F30, 08; CPDC • 1 ఢ̧; Poções, Faz. São João; 9 feb. 1964; Eduardo leg.; CPDC • 1 ఢ̧; Rio Real; 27 Jun. 1994; Carmo leg.; 4859F; CPDC • 1 ఫ̛; Rui Barbosa; 16 Nov. 2012; Juliana Alves leg.; CPDC・ 1 ఫ; Sambaíba; 24 Aug. 1993; C. Ivan leg.; 4512; CPDC - 1 đ̇; same locality as for preceding; Mar. 2001; D.C. Nascimento leg.; CPDC • 1 ఫ६; S [Santa] Rosa; 18 Jul. 1995; Cardoso leg.; 4944; CPDC • 1 ఫ; Santa

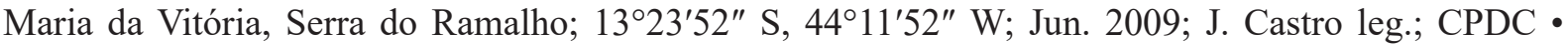
2 ఫఢఫ; Sr do Bonfim [Senhor do Bom Fim]; 20 Jul. 1974; S. Laroca leg.; DZUP • 1 ఫ; Serra da Jiboia;

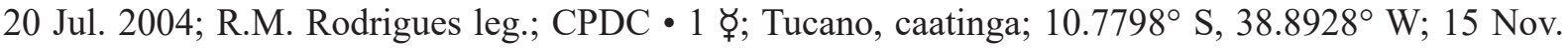
2010; E.M. Campos, A.M. Medina, P.L. Paixão and P.L.O. Rebouças leg.; MZSP • 2 ఫॄ孔; Vila Nova; 1 Feb. 1908; E. Gazbe leg.; MZSP. - Ceará • 1 ఫ;; Araripe; 10 Nov. 1975; R.L. Araújo leg.; MZSP •

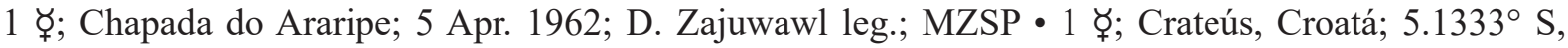

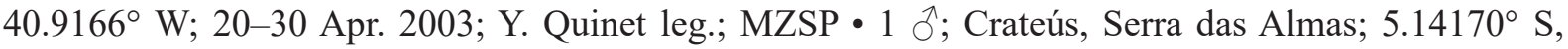
40.91620 W; 19 May 2014; G. Melo and B. Rosa leg.; DZUP • 1 Oे$^{\top}$; same locality as for preceding; 19-20 May 2014; G. Melo and B.B. Rosa leg.; Mini-luminosa; DZUP 549801 • 1 गे; same collection data as for preceding; DZUP 548847 • 6 ఫॄర్;; Fazenda Malhada Arcoverde; Jul. 1974; MZSP • 1 ఫ; Fortaleza; 343'01" S, 38³2'34" W; Sep. 2008; Y. Quinet leg.; 04; CPDC • 1 ఫ; Maranguape, Serra de Maranguape; 14 Nov. 2003; A.A. Tavares leg.; MZSP • 1 ६; same locality as for preceding; 
$3.8809^{\circ} \mathrm{S}, 38.6958^{\circ} \mathrm{W}$; alt. 100 m; 16. Oct. 2017; Y.P. Quinet leg.; manual; DZUP • 1 ఛ; Pacatuba; 10 May 2016; G. Melo and B. Rosa leg.; DZUP • 1 ఫ̧; Tianguá; 18 Dec. 1948; C.R. Gonçalves leg.; MZSP. - Distrito Federal • 1 đ̃; Brasília; Sep. 1972; N. Simões leg.; MZSP. - Minas Gerais •

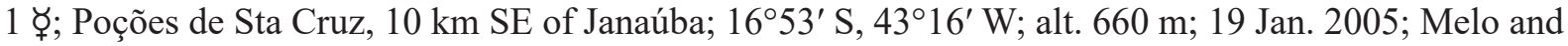
Costa leg.; DZUP • 1 ६̧; Viçosa, UFV; 30 Oct. 1975; J. Freire leg.; CPDC. - Paraíba • 1 ६; Areia; 1 Jul. 1955; Pe. Pereira leg.; MZSP • 1 ఢ;; Barra do Rio Mamanguape, Rio Tinto; 10 Jan. 2018; Marília Costa leg.; DZUP • 1 ఛ; Brandão [Caldas Brandão]; 22 Sep. 1955; Aristóteles Silva leg.; MZSP • 1 ఛ̧; Estrela Dalva, S [São] Sebastião do Umbuzeiro; 24 Aug. 1954; A. Silva leg.; MZSP • 1 ఫ;; Fazenda Almas; 20 Dec. 2006; J. Paulo leg.; pitfall A5; CPDC • 1 ఫ̧; forest near Areia; alt. 630 m; 24 Jan. 1981; Robert Davidson leg.; primary forest, sweeping day; MPEG • 1 ६̧; João Pessoa; 28 Nov. 2008; Linsmara Nunes leg.; CPDC • 1 ६̧; same locality as for preceding; 23 Jan. 1988; M. Kammers and I.L. Oliveira leg.; MZSP • 1 ఫ; same locality as for preceding; 4 Nov. 1955; C.A. Gonçalves leg.; MZSP • 2 ఫఢఫ; same locality as for preceding; 9 Sep. 2002; A. Vasconcelos leg.; CPDC $\bullet 1{ }^{\lambda}$; same collection data as for preceding; CPDC • 1 ६ ; same locality as for preceding; $7^{\circ} 7^{\prime} 9.2^{\prime \prime} \mathrm{S}, 34^{\circ} 50^{\prime} 41.67^{\prime \prime} \mathrm{W}$; alt. $41 \mathrm{~m}$; 4 Sep. 2014; J.M. Churata S. leg.; DZUP • 1 ६̧; João Pessoa, UFPB; 2-5 Apr. 1995; M.F.S. Santos leg.; 4921; CPDC • 1 ఢ̧; João Pessoa, Cabo Branco; 18 Jul. 1993; N. Rabet leg.; CPDC • 1 ఢ̧; João Pessoa, forest of Gargau; alt. 45 m; 22 Jan. 1981; R. Davidson leg.; primary forest, sweeping day; MPEG • 5 ఫॄ;; Mamanguape; 1 Jul. 1957; Dep. Zoologia exped.; MZSP • 1 ఫ; Mata do campus UFPB; 24 Apr. 1977; V.Py Daniel leg.; INPA • 1 ఫ; same collection data as for preceding; Dec. 1976; INPA • 1 §ै; Matureia, Pico do Jabre; $7.25250^{\circ}$ S, $37.38472^{\circ}$ W; 19 Feb. 2018; A. Ferreira leg.; "armadilha de luz"; DZUP •

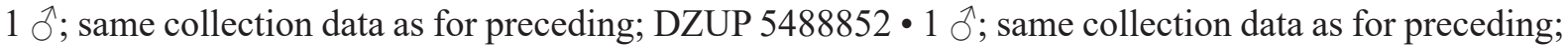
DZUP 5488853 • 2 ర̧ఠ్; Olivedos; 20 Aug. 1954; Aristóteles Silva leg.; MZSP • 1 ఢ̧; Rebio Sema 3; 2 Jul.

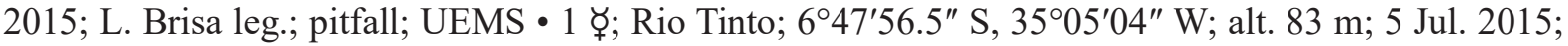
R. Silvestre leg.; pinça; UFGD • 2 ઠ̧ષ్; São José Cordeiros, Faz. Almas; 2 May 2003; A. Vasconcelos leg.; CPDC • 1 ఢ̧; São José da Mata, Sítio São Miguel; 12 Apr. 1997; A.D. Brescovit leg.; at night; MZSP

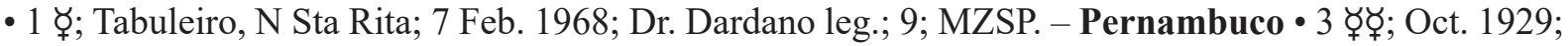
Pickel leg.; MZSP • 1 ఢ̧; Afrânio; alt. 500 m; 16 May 2007; J.A. Rafael and F.F. Xavier F. leg.; light; INPA • 1 ६; Araripina; 2 Jan. 1973; R. Montenegro leg.; \#324, 8430; MZSP • 2 ఫర్; Arcoverde; 17 Jul. 1974; R.L. Araújo leg.; MZSP • 1 ఫ; Brejão, Faz. Matary, R Maranhão; 24 Apr. 1974; 932; MZSP • 1 ఫ; same collection data as for preceding; coleção Diniz; DZUP • 6 రోర్ఘ; Carnaubeira; 20 May 1971; ABC MZUSP exped.; MZSP • 13 రోఫ్; Floresta, Faz. Campos Bons; 20-27 Jun. 1971; ABC MZUSP exped.; MZSP • 3 ఫఢ ; Garanhuns; 13 Jan. 1967; F.B. Galinda leg.; DZUP • 1 ф;; same locality as for preceding; 29 Oct. 1938; A. Silva leg.; 5314; MZSP • 1 ఫ; Itambé; 13 Feb. 1976; C.J. Rosetto leg.; 931; DZUP • 1 ఫ; Olinda; Reichensperger leg.; 34; MZSP • 1 ६̧; Parque Nacional do Catimbau; $8^{\circ} 30^{\prime} 40.561^{\prime \prime}$ S, 37¹6'37.133" W; 27 Dec. 2017; Katherine B. Haedo leg., R27; DZUP • 1 ६; same locality as for preceding; $8^{\circ} 32^{\prime} 48.38^{\prime \prime} \mathrm{S}, 37^{\circ} 15^{\prime} 21.74^{\prime \prime} \mathrm{W}$; alt. $938 \mathrm{~m}$; 27 Dec. 2017; Katherine B. Haedo

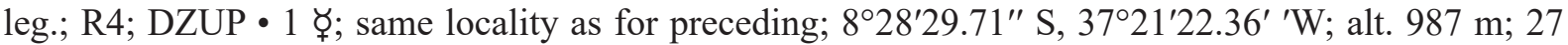
Dec. 2017; Katherine B. Haedo leg.; R23; DZUP • 1 ६̧; same locality as for preceding; 8³1'32.41" S, 37¹4'57.62" W; alt. 910 m; 27 Dec. 2017; Katherine B. Haedo leg.; R45; DZUP• 1 ఫ్; Pesqueira; 5 Aug. 1928; B. Pickel leg.; MZSP • 1 ६̧; Petrolina; 18 Jul. 1974; R.L. Araújo leg.; MZSP • 1 ఫ;; Recife; 21 Apr. 1905; L. Lima Castro leg.; 2376; MZSP • 1 ఫ; Salgueiro; 17 Jul. 1974; P.L. Araújo leg.; MZUSP 5502 • 1 ఫ్; same collection data as for preceding; MZSP. - Piauí - 1 ఫ;; Bom Jesus; 9²8'52.3" S,

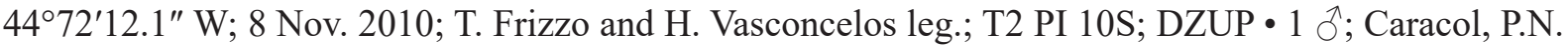
da Serra das Confusões; $9.22637^{\circ}$ S, $43.46331^{\circ}$ W; 3-7 Mar. 2016; R.M. Feitosa, G.P. Camacho and M.F.O. Martins leg.; DZUP 549804 • 1 ô; Colônia do Piauí; 27 Mar.-1 Apr. 1994; Boussard leg.; CPDC

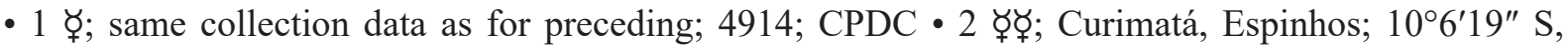
44¹3'08" W; 20 Apr. 2000; M.P.D. Santos leg.; coleta manual; MPEG • 1 ఫ; Faz. Sta. Paz; 19 Jun. 1992; Argolo leg.; 4635; CPDC • 1 ఫ̛; Ribeirão Gonçalves, Est. Ecol. Uruçuí-Una, cerrado; 10 Dec. 1980; A.I. Almeida leg.; MZSP • 1 ఛ̧; São Raimundo Nonato, P.N. Serra da Capivara, Zabelê; 12 Apr. 2011; A.C.A. leg.; pitfall; MZSP. - Rio Grande do Norte • 1 ఢ̧; FLONA de Nísia; Jun. 2017; Dina leg.; UFRN • 1 ६;; 
same locality as for preceding; 15 Sep. 2005; R.R. Hora leg.; 5457; CPDC • 1 ఫ; Natal; 24 May 2008; Pitfall F4; CPDC • 1 ఛ; Natal, Campus Central UFRN; Jun. 2014-Jan. 2016; Dina leg.; "4 ninhos"; UFRN • 1 ఫ; same collection data as for preceding; DZUP 549811 • 3 ồ; Campus Central UFRN, Jul. 2012-Jan. 2016, Dina leg., "4 ninhos"; DZUP • 1 đ̂; same collection data as for preceding; DZUP 548850 • 1 \%; same collection data as for preceding; DZUP 548851 • 1 ६; Natal, Lagoa de Jenipabu; Oct. 2010; R. Silvestre leg.; CPDC • 1 ఫ;; Parnamirim, Mata do Jiqui; Oct. 2009; Dina leg.; UFRN. - Sergipe • 1 ఫ̛; Estância; 15 Jun. 1994; J. Jardim leg.; CPDC・ 1 ఫ̧; Itabaianinha, Mata Verde; 15 Dec. 1991; B. Santos leg.; 4492; CPDC • 1 ६; Pirambu, Pov. Aguilhada, restinga; 1041'37" S, 3650'37" W; 8 Jun. 2017; D.S. Mesquita and team leg.; pitfall; MPEG • 1 ఢ̧; Poço Redondo, Angico, alto sertão; $9^{\circ} 41^{\prime}$ S, $38^{\circ} 31^{\prime}$ W; Jun. 2008; F.S. Nascimento leg.; MZSP • 1 ఢ̧; São Cristóvão; $11^{\circ} 00^{\prime} 54^{\prime \prime}$ S, 37²1'21" W; 16 Apr. 2009; J.O. Dantas leg.; "ninho 2, 12"; CPDC • 1 ఫ్; Serra de Itabaiana; Mar. 2008; T.J. leg.; CPDC. - Tocantins • 1 ఫ̧; Jalapão, 19 Nov. 2012; H.L. Vasconcelos and T. Frizzo leg.; 405, T49-19S; UFU • 1 ६; same locality as for preceding; 409, T49-17S; DZUP・ 1 ६; same locality as for preceding; 409, T50-11S; DZUP• 1 ६̧; same locality as for preceding; 452, T51-2S; DZUP.

\section{Redescription}

\section{Female}

Measurements. Non-types $(\mathrm{n}=32)$ : HL 4.95-5.76; HW 4.9-5.73; MDL 3.9-4.66; SL 4.95-5.73; MSL 7.52-8.47; HFL 6.78-7.71; HBL 5.84-6.48; PL 2.15-2.59; PH 2.85-3.35; PW 1.45-1.95; ATS 7.048.4; BL 25.71-29.39 (mm); CI 0.93-1.04; SI 0.96-1.09; DPI 0.64-0.81.

HEAD. Malar area without striae or with weak longitudinal to oblique striae that do not reach anterior eye margin. Gena microareolate and opaque, usually without rugulae. Brownish, appressed and very short pubescence present between eye and frontal lobe, extending posteriorly to frons. Frons microareolate, opaque to silky; with very sparse brownish, flexuous, suberect to erect hairs, longer than scape width; pubescence densest laterally. Occipital corner microareolate and opaque (sometimes silky). Antennal scape microareolate and silky; long, suberect hairs usually present on antennal segments 1-3. Ventral surface of head microareolate, generally without strigulae, sometimes present only on anterolateral margin and extending to hypostomal tooth. Labrum without median longitudinal sulcus; very shallow

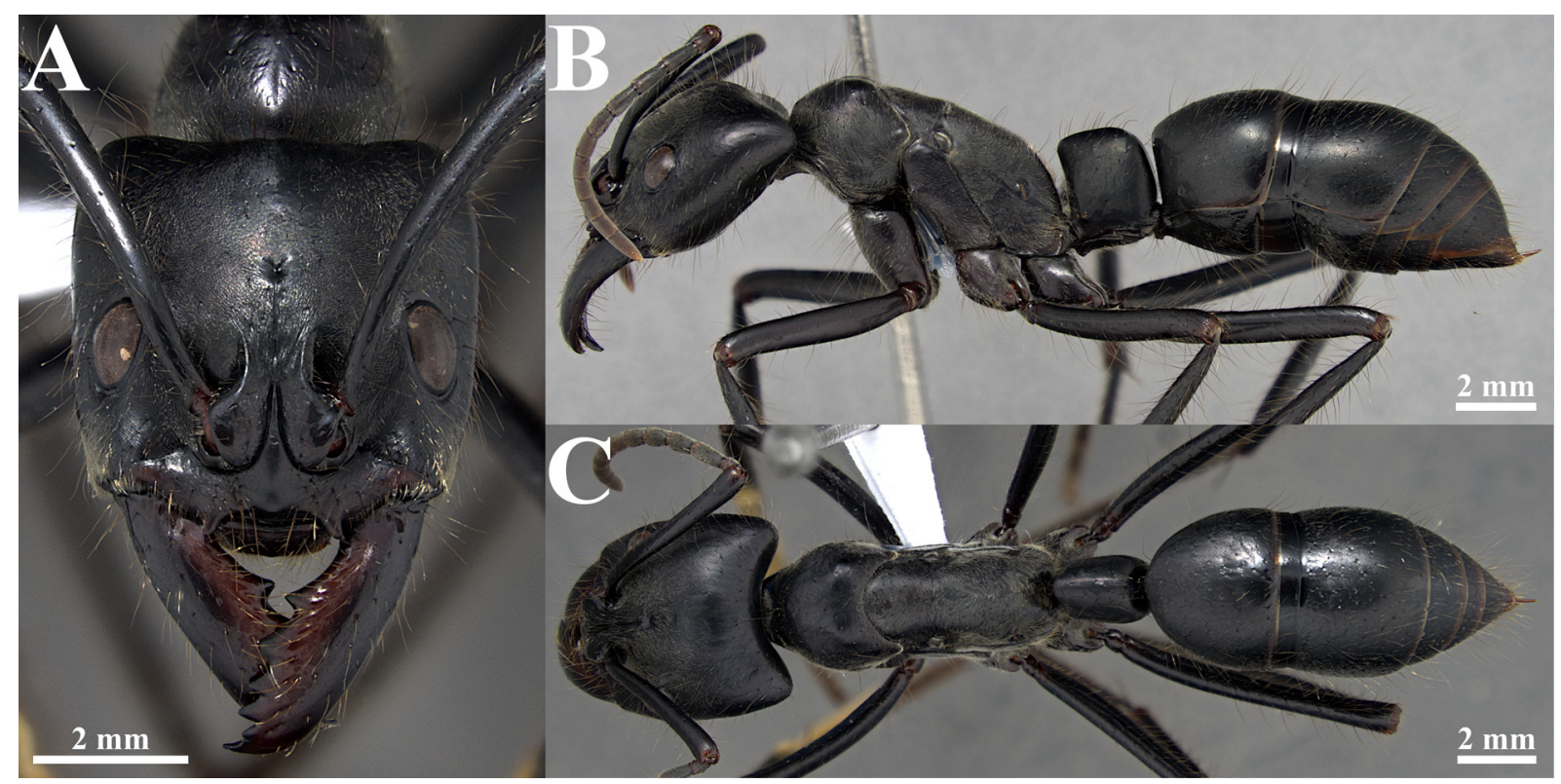

Fig. 25. Dinoponera quadriceps Kempf, 1971, ఫఢ (specimen from Natal, Rio Grande do Norte, Brazil; DZUP 549811). A. Full-face view. B. Full body in lateral view. C. Full body in dorsal view. 
transverse rugulae sometimes present. Mandibular dorsum weakly longitudinally strigulate on inner base, sculpture gradually fading apicad.

Mesosoma. Dorsal margin of pronotum in lateral view broadly convex, with no pronounced dorsoposterior swelling; anteroventral corner of pronotum forms obtuse angle. Pronotal dorsum weakly microareolate, opaque to silky. Metapleural-propodeal suture well-marked and usually straight.

Metasoma. Petiolar node in lateral view elongate (usually DPI $<0.8$ ); anterodorsal corner usually higher than posterodorsal corner; anterior margin slightly concave to straight, forming blunt angle with dorsal margin; dorsal and posterior margins broadly convex and forming rounded angle. Node lateral face microareolate and usually opaque, rarely silky. Node anterior margin in dorsal view strongly convex, posterior margin broadly convex to straight, lateral margins broadly convex and converging anterodorsally. Abdominal tergite III microareolate and opaque; punctulae in variable density, usually denser laterally than dorsally; covered by brownish, flexuous, suberect hairs on entire surface; appressed pubescence usually sparse on dorsum, denser laterally.

\section{Male}

Measurements. Non-types ( $\mathrm{n}=5$ ): HL 2.13-2.32; HW1 2.56-2.84; MDL 0.52-0.58; SL 0.87-0.97; EL 1.5-1.58; MOD 0.53-0.58; LOD 0.51-0.57; MSL 6.75-7.16; HFL 5.5-6; PL1 1.8-1.9; PH 1.44-1.54; PW 1.17-1.27; ASL 4.35-4.75; BL1 15.56-16.53 (mm); CI1 1.13-1.24; SEI 1.59-1.77; SI1 0.33-0.36.

HEAD. Frontal carina usually forming short longitudinal swelling. Lateral ocellus clearly surpassing posterior head margin in full-face view. Head punctulate, weakly microareolate and with silky sheen; with yellowish decumbent pubescence and scarce long suberect to erect hairs, longer than ocellus height in full-face view. Antenna with appressed pubescence and long suberect to erect hairs clearly longer than maximum scape diameter; third to fourth most apical antennomeres without hairs. Ventral surface of head punctulate and slightly microareolate; with subopaque to silky sheen.

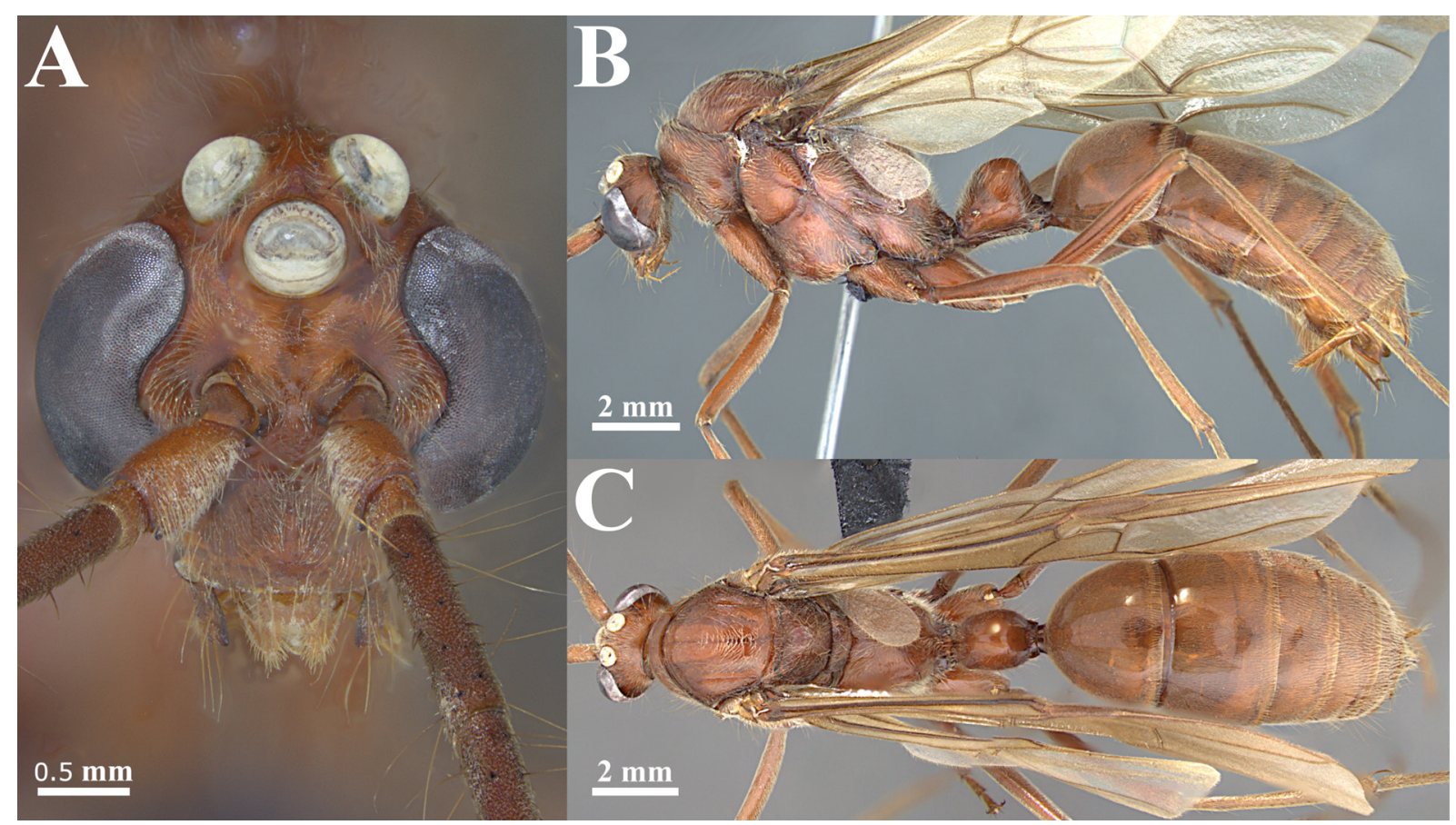

Fig. 26. Dinoponera quadriceps Kempf, 1971, ð̊ (specimen from Caracol, Piauí, Brazil; DZUP 549804). A. Full-face view. B. Full body in lateral view. C. Full body in dorsal view. 
Mesosoma. Mesoscutum without notaulus. Mesopleural sulcus punctate or slightly scrobiculate. Scutoscutellar sulcus scrobiculate. Mesoscutellum longitudinally strigulate laterally. Metapleuralpropodeal suture with same microsculpture as rest of integument. Mesosoma mostly slightly microareolate and with silky sheen, becoming coarsely punctate on declivitous surface of propodeum; with decumbent to suberect pubescence and suberect hairs, distance between each hair usually greater than half its length. Legs densely covered by decumbent pubescence; coxae with suberect long hairs, greater than femur diameter. Protibial apex with at least one stout seta.

Metasoma. Petiolar node microareolate and shining; densely covered by decumbent to suberect pubescence and sparse suberect hairs. Abdominal tergite VIII spiniform. Gaster very slightly microareolate and shining; tergites densely covered by appressed to decumbent pubescence, without long hairs.

GeNiTALIA. Basal ring in dorsal view with slightly concave lateral margins, anteriorly slightly narrower than posteriorly; fenestra rounded to slightly transversally directed; median invagination U-shaped; dorsal margin in lateral view broadly concave to straight; anteroventral process subquadrate. Gonostylus narrow and sharp. Dorsal margin of volsella in lateral view anteriorly straight and posteriorly concave; anteroventral corner with two anterior teeth; posteroventral margin strongly concave and forming sharp triangular posterior lobe; digitus volsellaris with posterior margin straight or with a slight concavity. In lateral view, penisvalva with continuous dorsal posterior margins, ending in a subacute apex; ventral margin even and serrated, with slight concavity; anteroventral corner sharply pointed.

Color. Body mostly chestnut brown.

\section{Remarks}

Females of Dinoponera quadriceps have a robust set of characters that usually permit easy separation from those of other species of the genus. However, D. quadriceps and D. gigantea, geographically close species, can sometimes cause confusion. The main characters dividing the two species are: (1) in D. quadriceps the anteroventral pronotal margin forms an obtuse angle, but in D. gigantea it is toothed or forms an acute angle; (2) the metapleural-propodeal suture in D. quadriceps is well-marked and straight, but in D. gigantea it is weaker and sinuous; (3) the cephalic venter is mostly strigulate in $D$. gigantea but in D. quadriceps the strigulae are absent or sometimes present just anterolaterally; (4) the dorsal region of abdominal tergite III in $D$. quadriceps is sparsely punctulate, but densely so in D. gigantea; and (5) the anterodorsal corner of the petiolar node is higher in D. quadriceps than in $D$ gigantea. Some specimens of $D$. quadriceps can present one or two D. gigantea characters, and viceversa, so the use of all these characters affords the most reliable identifications. It is worth noting that the difficult cases are more common among specimens from Maranhão and Tocantins, as in D. gigantea. Notwithstanding these complications, we consider the aforementioned set of diagnostic characters to provide stronger support for maintaining D. quadriceps and D gigantea as separate species than for synonymizing them. The alternative of describing a new species from Tocantins and Maranhão is not possible because the characters seem to vary randomly. Determining the degree of expression of each character is also important. Species differences are frequently a degree of difference one from another, as in the case of the anteroventral pronotal corner in D. quadriceps, which may be strongly angular but not toothed or forming an acute angle.

A specimen from Itabaianinha (Sergipe) has a short and robust peciolar node (DPI $>0.8$ ), characteristic of $D$. grandis. However, these two species differ in the absence of: (1) the pronotal anteroventral tooth; (2) striae in the malar area and (3) strigulae on the ventral head surface in D. quadriceps. The other species of Dinoponera can be easily distinguished by having abdominal tergite III smooth and shining. 
It was not possible to examine the holotype of $D$. opaca. It is kept as a junior synonym of $D$. quadriceps, on account of the examination of the holotype by C. Baroni Urbani in 1974 at the request of W. Kempf (1975: 344). Dr Baroni Urbani found that the type agreed with the description of D. quadriceps. Lenhart et al. (2013) examined the type and found total coincidence with D. quadriceps. The Rio de Janeiro record for D. opaca is undoubtedly a labelling error, as there are no other records of Dinoponera for Rio de Janeiro, a heavily collected area for ants, and if there were any Dinoponera, the expected species would either be D. lucida or D. australis.

Males of D. quadriceps are different from those of D. lucida, D. longipes, Dinoponera morphospecies 1 and $D$. grandis by having hairs on the antennae that are clearly longer than the scape diameter and the gonostylus narrow, with a sharp apex. As mentioned before, males of D. gigantea and D. quadriceps are similar in many characters, but the former is longer, more pilose and has a visible notaulus on the mesoscutum.

\section{Biology}

The species occurs mainly in arid or savanna areas with the temperature of the coldest month greater than $18{ }^{\circ} \mathrm{C}$ and the precipitation of the driest month less than $60 \mathrm{~mm}$ (Alvares et al. 2013). Nests are usually built in the ground, near roots and often in direct contact with termite mounds (Araujo et al. 1990; Paiva \& Brandão 1995). However, Vasconcellos et al. (2004) found nests more than $3 \mathrm{~m}$ from trees in a remnant of Atlantic Forest, indicating nesting habits may vary with the environment. Each nest can have two to ten entrances surrounded by branches and some loose earth (Araujo et al. 1990; Paiva \& Brandão 1995). Nest depth varies from 10 to $120 \mathrm{~cm}$ and the number of chambers can reach 16 (Araujo et al. 1990; Paiva \& Brandão 1995; Vasconcellos et al. 2004). Assis et al. (2017) recorded D. quadriceps reusing nests of Atta sexdens (Linnaeus, 1758), which are deep enough to ensure protection against hot and dry weather. The density of nests varies from 15 to 40 per hectare (Vasconcellos et al. 2004).

The size of the colony can vary from 12 to 141 workers (Paiva \& Brandão 1995; Monnin \& Peeters 1997, 1998; Vasconcellos et al. 2004; Nascimento et al. 2012; Asher et al. 2013). Vasconcellos et al. (2004) found males almost every month of the year, suggesting male production is not seasonal.

Their diet is omnivorous, with a preference for arthropods found dead on the soil (Araújo \& Rodrigues 2006). Foraging is solitary and occurs during the day, avoiding the hottest hours (Medeiros et al. 2012). The size of food items varies, but regardless of its weight there is no recruitment of other workers (Araújo \& Rodrigues 2006). Before finding food, the worker is usually slow and meanders about its usual route, moving up to $35 \mathrm{~m}$ from the nest. Foraging tends to be faster during the return trip and follows a relatively straight line (Araújo \& Rodrigues 2006; Azevedo et al. 2014). Araújo \& Rodrigues (2006) suggested that spatial orientation during foraging may follow chemical and visual cues.

Medeiros \& Araújo (2014) divided the life cycle of the colony into stages. The first stage is monodomic, with the ants occupying a single nest. Subsequently the colony becomes polydomic, until gradually the ants stop visiting the parental nest and the colonies become isolated, completing the fission. The newly separated colonies go through a period of territorial conflict that results in the extinction or migration of the old colony (Medeiros \& Araújo 2014). Vasconcellos et al. (2004) also pointed out that intraspecific territorial competition may be one of the main factors responsible for the spatial arrangement of nests.

Colonies of D. quadriceps are predominantly monogynous (Monnin \& Peeters 1997, 1998, 1999), though Araujo et al. (1990) found colonies with more than one gamergate. The dynamics that determine the hierarchy of dominance in this species is well studied, mainly by Monnin \& Peeters (1999). Hierarchical position is determined by age and agonistic interactions involving mainly the ants with high status in the colony (Monnin \& Peeters 1999). Newly emerged workers usually replace older ones in the highest 
positions of the hierarchy. Agonistic interactions are usually related to the stability of monogyny in the colony, and can be performed by the gamergate itself, inhibiting other workers (Monnin \& Peeters 1999). After copulation, gamergates chew away the end of the male abdomen, which remains trapped in the female genitalia, preventing further copulation (Monnin \& Peeters 1998).

\section{Distribution (Fig. 29B)}

Dinoponera quadriceps is endemic to northeastern Brazil, occurring predominantly in the Caatinga. The northernmost record is in Fortaleza, Ceará and the southernmost record is in Viçosa, Minas Gerais. However, Viçosa is more than $500 \mathrm{~km}$ away from the next southernmost record (Janaúba, Minas Gerais), leaving doubts as to the reliability of the former record. Another unexpected record is from Brasília, which is also more than $500 \mathrm{~km}$ distant from any other record. These records may reflect a wider distribution in a recent past (both date from the 1970s) or just labeling errors. Lenhart et al. (2013) cited records of D. quadriceps in the cities of Santarém and Óbidos, as well as along the Tapajós River, all in the state of Pará. However, we found no records of this species within at least $1000 \mathrm{~km}$ of that region. This discrepancy may be due to either wrong labeling or differences in the criteria used for species identification in each study. The latter is most probably the case, given the similarity between D. quadriceps and D. gigantea.

\section{Dinoponera morphospecies 1}

Figs 27, 28B

\section{Preliminary considerations}

The morphology of this single male is described because it is significantly different from that of all other known males of Dinoponera. However, the lack of an associated female does not allow us to identify this specimen. This male may belong to either one of the sympatric species, D. mutica or D. nicinha sp. nov., both of which do not have described males. Given the present impossibility of associating this specimen with an available name, we present it here with the intention of increasing our knowledge about Dinoponera males, but avoiding a wrong association. We also feel compelled to present it due to the recent significantly increased rate of deforestation and bush fires that have ravaged vast swathes of potential distribution range for Dinoponera, including the species represented by this male. In view of this calamity, it is not unreasonable to expect dwindling opportunities to collect additional specimens of Dinoponera in many parts of the Brazilian Amazon. This male is evidence of the wonderful biodiversity that is literally turning into ashes before our very eyes, and we have no certainty that more specimens will come to light.

\section{Diagnosis}

Male

Antenna with thick and stiff decumbent hairs, as long as or slightly longer than maximum scape diameter. Abdominal tergite VIII spiniform. Penisvalva ending in a rounded apex, without a ventral lobe. Anteroventral corner of penisvalva in lateral view with long and very sharp spine.

\section{Material examined}

BRAZIL - Rondônia - 1 đ̧; Porto Velho, Rio Madeira, Area Mutum, Ahe Jirau; 9³5'29.5" S, 6502'57.6" W; 7-20 Feb. 2013; F. Fernandes leg.; malaise, MZSP 62285.

\section{Description}

Male

MeAsurements ( $\mathrm{n}=1$ ). HL 2.23; HW1 2.68; MDL 0.57; SL 0.88; EL 1.47; MOD 0.45; LOD 0.43; MSL 6.91; HFL 5.41; PL1 1.82; PH 1.5; PW 1.25; ASL 4.45; BL1 15.99 (mm); CI1 1.19; SEI 1.64; SI1 0.33. 
HEAD. Frontal carina forming short longitudinal swelling. Lateral ocellus clearly surpassing posterior head margin in dorsal view. Head punctulate, weakly microareolate and shining; with yellowish suberect pubescence and long decumbent to suberect hairs, longer than ocellus height in dorsal view. Antenna with appressed pubescence and thick, stiff decumbent hairs as long as or slightly longer than maximum scape diameter. Ventral surface of head punctulate and slightly microareolate with silky sheen.

Mesosoma. Pronotum with weak transverse rugulae on posterior margin, mesoscutum without notaulus. Mesopleural sulcus slightly scrobiculate. Scutoscutellar sulcus smooth. Mesoscutellum longitudinally strigulate laterally. Metapleural-propodeal suture slightly scrobiculate. Mesosoma mostly smooth and shining, becoming coarsely punctate on declivitous surface of propodeum; with decumbent to suberect pubescence and suberect hairs; distance between each hair usually less than half its length. Legs densely covered by suberect pubescence; also with long suberect hairs, longer than femur diameter. Protibial apex without a stout seta.

Metasoma. Petiolar node smooth and shining; densely covered by decumbent pubescence and abundant suberect hairs. Abdominal tergite VIII spiniform. Gaster mostly smooth and shining; tergites densely covered by appresed to decumbent pubescence and sparse suberect hairs.

GeNitALIA. Basal ring in dorsal view with slightly concave lateral margins, anteriorly much narrower than posteriorly; maximum diameter of fenestra longitudinally directed, median invagination $\mathrm{V}$-shaped; dorsal margin of ring in lateral view anteriorly concave, anteroventral process subquadrate. Gonostylus broad and rounded. Dorsal margin of volsella in lateral view straight; anteroventral corner rounded; posteroventral margin strongly concave and forming a posterior triangular lobe; digitus volsellaris with posterior margin with a slight concavity. In lateral view, penisvalva with continuous dorsal and posterior margins, ending in rounded apex; ventral margin even and serrated, concave; anteroventral corner with long, very sharp spine.

CoLOR. Body mostly brown, with head and gaster apex slightly clear.

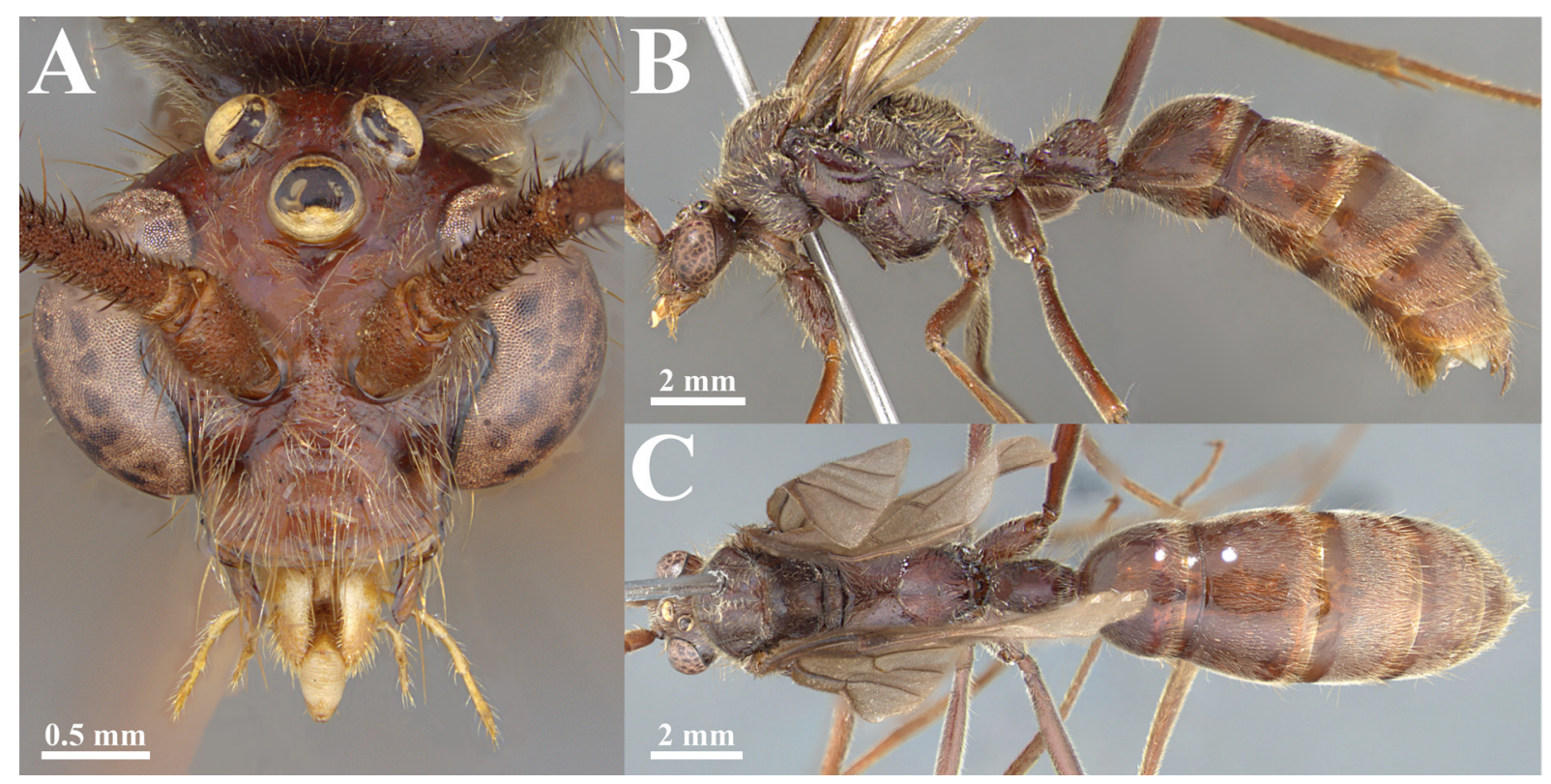

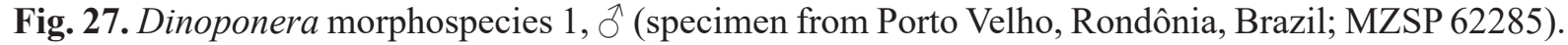
A. Full-face view. B. Full body in lateral view. C. Full body in dorsal view. 


\section{Remarks}

Dinoponera morphospecies 1 is different mainly because of the shape of the anteroventral corner of the penisvalva, which ends in a long, sharp spine. It also differs from D. gigantea and D. quadriceps by the antennal hairs, which are shorter and thicker. An additional character that distinguishes this male from $D$. lucida and the $D$. grandis is the concavity of the basal ring in lateral view, much weaker in Dinoponera morphospecies 1 . In D. longipes the penisvalva is wedge-shaped, not rounded, in lateral view, and the spine is shorter (observations made from the illustrations and description in Lenhart et al. 2013). Hopefully, additional specimens will be collected in the future, permitting the association of this male with its conspecific females. This could be done directly by collecting nest series of both sexes of the same species, or indirectly by collecting those of another species, making apparent which species it does not belong to.

\section{Biology}

Unknown.

Distribution (Fig. 28B)

This morphospecies is only known from Porto Velho, Rondônia, Brazil.

\section{Discussion}

We have redescribed all known species of Dinoponera and described a new species using the largest amount yet available of specimens for a study of this group, particularly from Brazilian institutional collections. Due to the large size of these ants, a trait that would make them attractive for even generalist insect collections, we expected to find more of these ants in collections. Especially surprising and worrying is the paucity of recent collecting events for several of these species.

It was possible to note that males are morphologically more variable than females. In $D$. grandis, males seem to be discreetly variable, in sharp contrast with the continuous variability of females. This offers the hope of permitting less challenging identifications than when using the females, but in practice this is cold comfort as males are harder to come by, and the apparent greater discreteness of male characters may be an artefact of the few males examined.

While we believe that we have been able to significantly improve the alpha taxonomy of these species, there is still much to be done. The application of molecular methods could give us valuable insights into the phylogenetic relationships amongst the different lineages and provide additional evidence for taxonomic decisions. During the course of this study we unsuccessfully tried to extract and amplify DNA from several specimens. Given the paucity of museum specimens, particularly from recent collecting events, we advocate for field work specifically targeting the known populations and searching localities where some populations may still remain; this is especially urgent for D. grandis. The long history of deforestation, fragmentation and conversion of natural landscapes into agricultural landscapes has probably complicated matters even further, both for the survival of these ants and the opportunities for studying them. Particularly worrying is the dramatic increase in bush fires in recent times. Even though one species, D. lucida, figures in the Brazilian Red list of endangered species (ICMBio 2018), it is possible that other species and populations, such as D. hispida, are arguably in even more dire straits.

\section{Acknowledgements}

We would like to thank all those responsible for specimen loans or donations, and support: Jacques Delabie, Fernando Fernández, Bolívar Rafael Garcete-Barrett, Rogério R. Silva, Lívia Pires do Prado, Rogério Silvestre, Carlos Roberto Ferreira Brandão, Mônica Ulyssea, Hélida Ferreira da Cunha, Daniel 


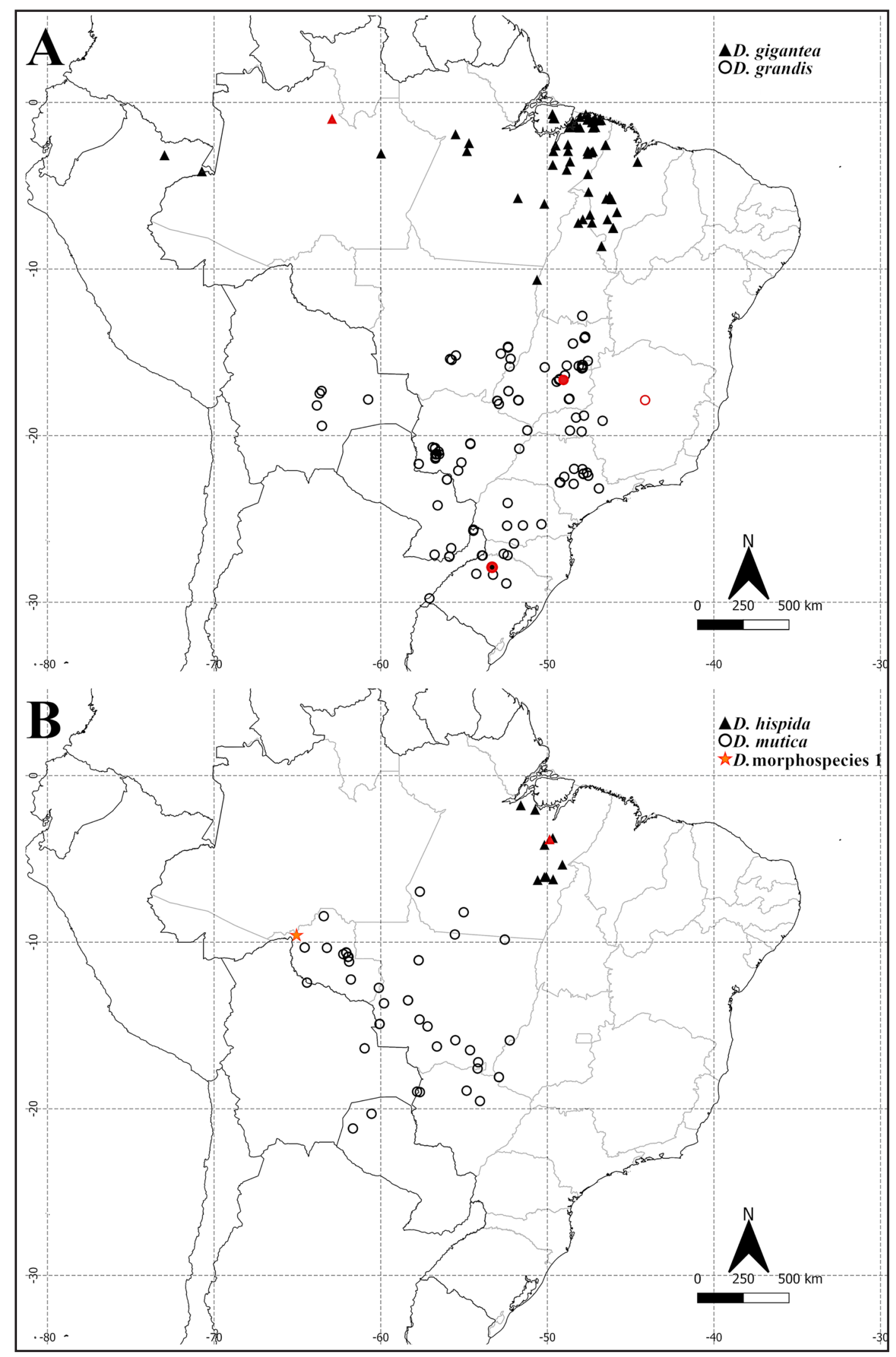

Fig. 28. Distribution maps for species of Dinoponera Roger, 1861. Red symbols indicate type specimens examined here. A. D. gigantea (Perty, 1833) and D. grandis Guérin-Méneville, 1838. B. D. hispida Lenhart, Dash \& Mackay, 2013, D. mutica Emery, 1901 and Dinoponera morphospecies 1. 


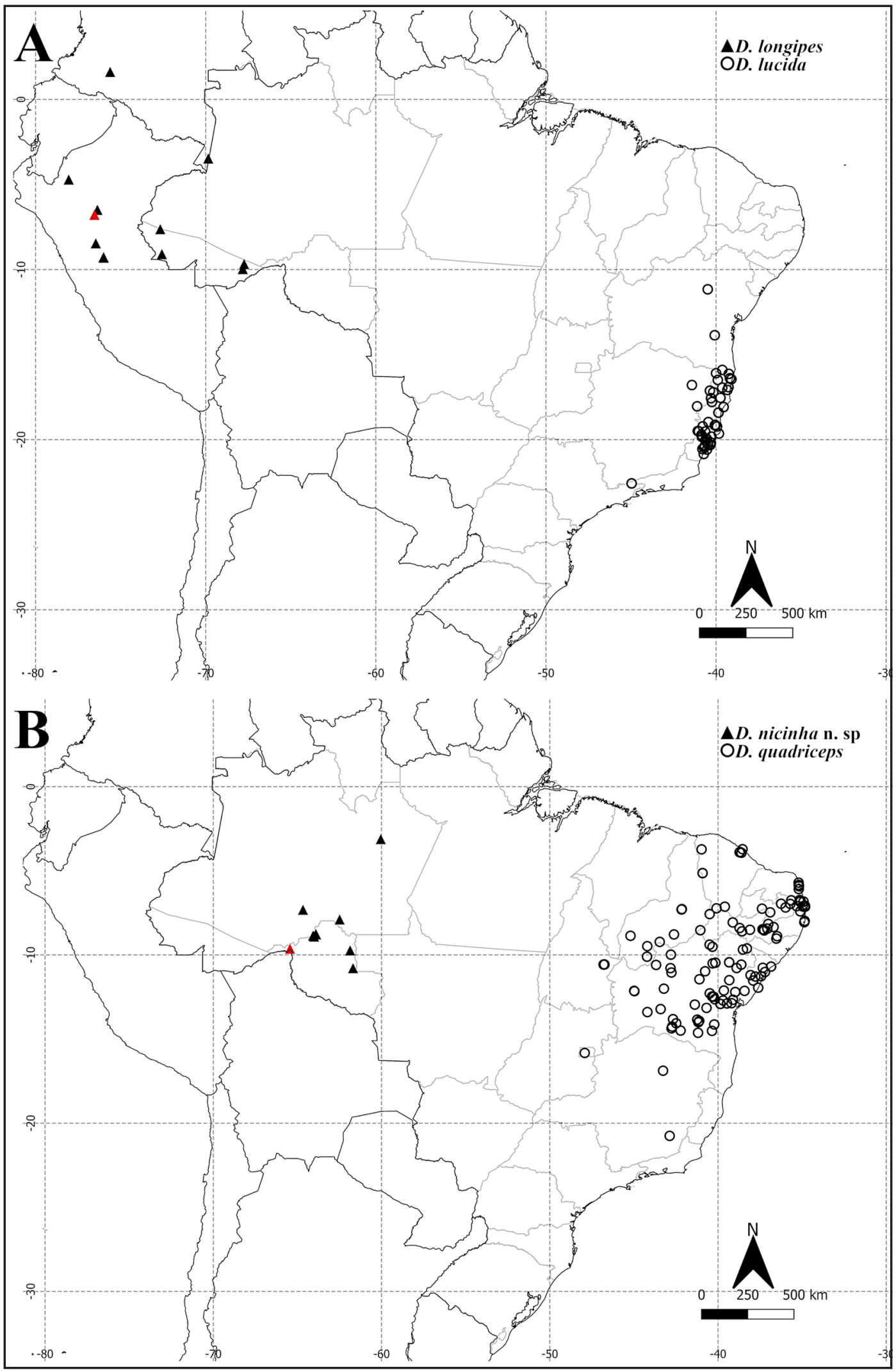

Fig. 29. Distribution maps for species of Dinoponera Roger, 1861. Red symbols indicate type specimens examined here. A. D. longipes Emery, 1901 and D. lucida Emery, 1901. B. D. nicinha sp. nov. and D. quadriceps Kempf, 1971. 
Burckhardt, William Fernando Antonialli Junior, Stefan Schmidt, Marcelo Teixeira Tavares, Priscila Hanisch, Iracenir Andrade dos Santos, Luciana Regina Podgaiski, Arrilton Araújo, Benedito Cortês Lopes, José Henrique Schoereder, Heraldo Vasconcellos, Gustavo Graciolli, Mariah Tibcherani, Itanna Fernandes and Marília Costa. We also thank Flavia Esteves and Alexandre Ferreira for imaging specimens, Leonardo Tozetto for helping with dissections, and Rodrigo Feitosa, Monica Ulyssea, Itanna Fernandes and Gabriel Melo for critical reviews of the first version of this manuscript. To Marcio Pie and André Olivotto we are grateful for all their support in our attempts to include molecular data in this study. Finally, we thank the Conselho Nacional de Desenvolvimento Científico e Tecnológico (CNPq) for the financial support that made this study possible. We also thank the reviewers for their valuable suggestions.

\section{References}

Alonso L.E. 2012. A preliminary survey of the ants of the Kwamalasamutu region, SW Suriname. In: O'Shea B.J., Alonso L.E. \& Larsen T.H. (eds) A Rapid Biological Assessment of the Kwamalasamutu Region, Southwestern Suriname: 110-117. Conservation International, Arlington, VA.

Alonso L.E. \& Helms J.A. 2013. A rapid assessment of the ants of the Grensgebergte and Kasikasima regions of southeastern Suriname. In: Alonso L.E. \& Larsen T.H. (eds) A Rapid Biological Assessment of the Upper Palumeu River Watershed (Grensgebergte and Kasikasima) of Southeastern Suriname: 109-118. Conservation International, Arlington, VA.

Alvares C.A., Stape J.L., Sentelhas P.C., Gonçalves J.L. de M. \& Sparovek G. 2013. Köppen's climate classification map for Brazil. Meteorologische Zeitschrift 22 (6): 711-728.

https://doi.org/10.1127/0941-2948/2013/0507

Araújo A. \& Rodrigues Z. 2006. Foraging behavior of the queenless ant Dinoponera quadriceps Santschi (Hymenoptera: Formicidae). Neotropical Entomology 35 (2): 159-164.

https://doi.org/10.1590/S1519-566X2006000200002

Araujo C.Z.D., Lachaud J.P. \& Fresneau D. 1990. Le système reproductif chez une ponérine sans reine: Dinoponera quadriceps Santschi. Behavioural Processes 22: 101-111.

https://doi.org/10.1016/0376-6357(90)90011-4

Asher C.L., Nascimento F.S., Sumner S. \& Hughes W.O.H. 2013. Division of labour and risk taking in the dinosaur ant, Dinoponera quadriceps (Hymenoptera: Formicidae). Myrmecological News 18: $121-129$.

Assis D.S., Morris S. \& Nascimento F.S. 2017. "Empty spaces 'where' we are living for" - first record of Dinoponera quadriceps reusing nests of Atta sexdens. Sociobiology 64 (1): 130-132.

https://doi.org/10.13102/sociobiology.v64i1.1251

Azevedo D.L.O., Medeiros J.C. \& Araújo A. 2014. Adjustments in the time, distance and direction of foraging in Dinoponera quadriceps workers. Journal of Insect Behavior 27: 177-191.

https://doi.org/10.1007/s10905-013-9412-6

Bequaert J. 1926. The date of publication of the Hymenoptera and Diptera described by Guérin in Duperrey's 'Voyage de La Coquille'. Entomologische Mitteilungen 15: 186-195.

Bolton B. 1994. Identification Guide to the Ant Genera of the World. Harvard University Press, Cambridge, MA.

Borgmeier T. 1937. Formigas novas ou pouco conhecidas da América do Sul e Central, principalmente do Brasil (Hym. Formicidae). Arquivos do Instituto de Biologia Vegetal 3 (2): 217-255. 
Boudinot B.E. 2013. The male genitalia of ants: musculature, homology, and functional morphology (Hymenoptera, Aculeata, Formicidae). Journal of Hymenoptera Research 30: 29-49.

https://doi.org/10.3897/JHR.30.3535

Boudinot B.E. 2015. Contributions to the knowledge of Formicidae (Hymenoptera, Aculeata): a new diagnosis of the family, the first global male-based key to subfamilies, and a treatment of early branching lineages. European Journal of Taxonomy 120: 1-62. https://doi.org/10.5852/ejt.2015.120

Buys S.C., Cassaro R. \& Salomon D. 2010. Biological observations on Kapala Cameron 1884 (Hymenoptera Eucharitidae) in parasitic association with Dinoponera lucida Emery 1901 (Hymenoptera Formicidae) in Brazil. Tropical Zoology 23: 29-34.

Campanili M. \& Schaffer W.B. 2010. Mata Atlântica: Manual de Adequação ambiental. MMA/SBF, Brasília.

Diller E. 1990. Die von Spix und Martius 1817-1820 in Brasilien gesammelten und von J.A.M. Perty 1833 bearbeiteten Hymenopteren in der Zoologischen Staatssammlung München. Spixiana 13 (1): 6181.

Emery C. 1901. Notes sur les sous-familles des Dorylines et Ponérines (famille des Formicides). Annales de la Société entomologique de Belgique 45: 32-54.

Escárraga M.E., Lattke J.E. \& Azevedo C.O. 2017. Discovery of the Dinoponera lucida male (Hymenoptera, Formicidae), a threatened giant ant from the Atlantic rain forest. Zootaxa 4347 (1): 128-136. https://doi.org/10.11646/zootaxa.4347.1.7

Fourcassié V. \& Oliveira P.S. 2002. Foraging ecology of the giant Amazonian ant Dinoponera gigantea (Hymenoptera, Formicidae, Ponerinae): activity schedule, diet and spatial foraging patterns. Journal of Natural History 36: 2211-2227. https://doi.org/10.1080/00222930110097149

Fourcassié V., Henriques A. \& Fontella C. 1999. Route fidelity and spatial orientation in the ant Dinoponera gigantea (Hymenoptera, Formicidae) in a primary forest: a preliminary study. Sociobiology 34 (3): 505-524.

Franco W., Ladino N., Delabie J.H.C., Dejean A., Orivel J., Fichaux M., Groc S., Leponce M. \& Feitosa R.M. 2019. First checklist of the ants (Hymenoptera: Formicidae) of French Guiana. Zootaxa 4674 (5): 509-543. https://doi.org/10.11646/zootaxa.4674.5.2

Groc S., Delabie J.H.C., Fernández F., Leponce M., Orivel J., Silvestre R., Vasconcelos H.L. \& Dejean A. 2014. Leaf-litter ant communities (Hymenoptera: Formicidae) in a pristine Guianese rain-forest: stable functional structure versus high species turnover. Myrmecological News 19: 43-51.

Guérin-Méneville F.E. 1838. Première division. Crustacés, arachnides et insectes. In: Duperrey L.I. (ed.) Voyage autour du Monde, exécuté par Ordre du Roi, sur la Corvette de sa Majesté, La Coquille, pendant les Années 1822, 1823, 1824 et 1825: 9-320. Arthus Bertrand, Paris.

Harris R.A. 1979. A glossary of surface sculpturing. Occasional Papers in Entomology 28: 1-31.

Haskins C.P. \& Zahl P.A. 1971. The reproductive pattern of Dinoponera grandis Roger (Hymenoptera, Ponerinae) with notes on the ethology of the species. Psyche 78 (1-2): 1-11.

Helms J.A., Alonso L.E. \& Isaacs S. 2016. Ants of the South Rupununi region, Guyana. In: Alonso L.E., Persaud J. \& Williams A. (eds) Biodiversity Assessment Survey of the South Rupununi Savannah Guyana: 135-147. BAT Survey Report No. 1. WWF-Guianas, Guyana Office, Georgetown, Guyana.

Hölldobler B. \& Wilson E.O. 1990. The Ants. Belknap Press of Harvard University Press, Cambridge, MA. 
IBGE - Instituto Brasileiro de Geografia e Estatística. 2012. Manual técnico da vegetação Brasileira. Instituto Brasileiro de Geografia e Estatística, Rio de Janeiro.

IBGE - Instituto Brasileiro de Geografia e Estatística. 2019. Biomas e Sistema Costeiro-Marinho do Brasil - 1:250 000. Instituto Brasileiro de Geografia e Estatística, Rio de Janeiro. Available from https://www.ibge.gov.br/geociencias/informacoes-ambientais/estudos-ambientais/15842-biomas. html? $=\& \mathrm{t}=$ downloads [accessed 17 Aug. 2020].

ICMBio - Instituto Chico Mendes de Conservação da Biodiversidade. 2018. Livro Vermelho da Fauna Brasileira Ameaçada de Extinção. ICMBio, Brasília.

Keller R.A. 2011. A phylogenetic analysis of ant morphology (Hymenoptera: Formicidae) with special reference to the poneromorph subfamilies. Bulletin of the American Museum of Natural History 355: 1-90. https://doi.org/10.1206/355.1

Kempf W.W. 1971. A preliminary review of the ponerine ant genus Dinoponera Roger (Hymenoptera: Formicidae). Studia Entomologica 14: 369-394.

Kempf W.W. 1975. Miscellaneous studies on Neotropical ants. VI. (Hymenoptera, Formicidae). Studia Entomologica 18: 341-380.

Lapolla J.S., Suman T., Sosa-Calvo J. \& Schultz T.R. 2007. Leaf litter ant diversity in Guyana. Biodiversity and Conservation 16 (2): 491-510. https://doi.org/10.1007/s10531-005-6229-4

Lattke J.E. 2011. Revision of the New World species of the genus Leptogenys Roger (Insecta: Hymenoptera: Formicidae: Ponerinae). Arthropod Systematics \& Phylogeny 69 (3): 127-264.

Lenhart P.A., Dash S.T. \& Mackay W.P. 2013. A revision of the giant Amazonian ants of the genus Dinoponera (Hymenoptera, Formicidae). Journal of Hymenoptera Research 31: 119-164. https://doi.org/10.3897/jhr.31.4335

Mann W. 1916. The Stanford Expedition to Brazil, 1911, John C. Branner, Director. The ants of Brazil. Bulletin of the Museum of Comparative Zoology 60 (11): 399-490.

Medeiros J. \& Araújo A. 2014. Workers' extra-nest behavioral changes during colony fission in Dinoponera quadriceps (Santschi). Neotropical Entomology 43 (2): 115-121.

https://doi.org/10.1007/s13744-013-0193-6

Medeiros J., Araújo A., Araújo H.F.P., Queiroz J.P.C. \& Vasconcellos A. 2012. Seasonal activity of Dinoponera quadriceps Santschi(Formicidae, Ponerinae) in the semi-arid Caatinga of northeastern Brazil. Revista brasileira de Entomologia 56 (1): 81-85. https://doi.org/10.1590/S0085-56262012000100013

Meurer E., Battirola L.D., Delabie J.H.C. \& Marques M.I. 2015. Influence of the vegetation mosaic on ant (Formicidae: Hymenoptera) distributions in the northern Brazilian Pantanal. Sociobiology 62 (3): 382-388. https://doi.org/10.13102/sociobiology.v62i3.359

Monnin T. \& Peeters C. 1997. Cannibalism of subordinates' eggs in the monogynous queenless ant Dinoponera quadriceps. Naturwissenschaften 84: 499-502. https://doi.org/10.1007/s001140050433

Monnin T. \& Peeters C. 1998. Monogyny and regulation of worker mating in the queenless ant Dinoponera quadriceps. Animal Behaviour 55: 299-306. https://doi.org/10.1006/anbe.1997.0601

Monnin T. \& Peeters C. 1999. Dominance hierarchy and reproductive conflicts among subordinates in a monogynous queenless ant. Behavioral Ecology 10 (3): 323-332.

https://doi.org/10.1093/beheco/10.3.323

Monnin T., Ratnieks F.L.W. \& Brandão C.R.F. 2003. Reproductive conflict in animal societies: hierarchy length increases with colony size in queenless ponerine ants. Behavioral Ecology and Sociobiology 54: 71-79. https://doi.org/10.1007/s00265-003-0600-9 
Morgan R.C. 1993. Natural history notes and husbandry of the peruvian giant ant Dinoponera longipes (Hymenoptera: Formicidae). In: Sonoran Arthropod Studies (ed.) Proceedings of Invertebrates in Captivity Conference. Sonoran Arthropod Studies, Tuscon, AZ.

Available from: http://archive.vn/LMubG\#selection-25.34-25.60 [accessed 25 Jul. 2020].

Nascimento F.S., Souza D.I.S.A., Tannure-Nascimento I.C. \& Dantas J.O. 2012. Social facilitation and food partitioning in the queenless ant Dinoponera quadriceps (Hymenoptera: Formicidae). Journal of Natural History 46 (31-32): 1959-1967. https://doi.org/10.1080/00222933.2012.700333

Paiva R.V.S. \& Brandão C.R.F. 1995. Nests, worker population, and reproductive status of workers, in the giant queenless ponerine ant Dinoponera Roger (Hymenoptera Formicidae). Ethology Ecology \& Evolution 7: 297-312. https://doi.org/10.1080/08927014.1995.9522938

Peeters C. 1991. The occurrence of sexual reproduction among ant workers. Biological Journal of the Linnean Society 44: 141-152. https://doi.org/10.1111/j.1095-8312.1991.tb00612.x

Peeters C. \& Crewe R. 1984. Insemination controls the reproductive division of labour in a ponerine ant. Naturwissenschaften 71 (1): 50-51. https://doi.org/10.1007/BF00365989

Peixoto A.V., Campiolo S., Lemes T.N., Delabie J.H.C. \& Hora R.R. 2008. Comportamento e estrutura reprodutiva da formiga Dinoponera lucida Emery (Hymenoptera, Formicidae). Revista brasileira de Entomologia 52 (1): 88-94. https://doi.org/10.1590/S0085-56262008000100016

Peixoto A.V., Campiolo S. \& Delabie J.H.C. 2010. Basic ecological information about the threatened ant, Dinoponera lucida Emery (Hymenoptera: Formicidae: Ponerinae), aiming its effective long-term conservation. In: Tepper G.H. (ed.) Species Diversity and Extinction: 183-213. Nova Science Publishers, Inc., Hauppauge, NY.

Perty M. 1833. Delectus animalium articulatorum, quae in itinere per Brasiliam annis MDCCCXVIIMDCCCXX jussu et auspiciis Maximiliani Josephi I. Bavariae regis augustissimi peracto, collegerunt Dr. J.B. Spix et Dr. C.F.Ph. de Martius. Fasc. 3. Published by the author, Monachii [= Munich].

Roger J. 1861. Die Ponera-artigen Ameisen (Schluss). Berliner Entomologische Zeitschrift 5: 1-54.

Santos I.S., Delabie J.H.C., Silva J.G., Costa M.A., Barros L.A.C., Pompolo S.G. \& Mariano C.S.F. 2012. Karyotype differentiation among four Dinoponera (Formicidae: Ponerinae) species. The Florida Entomologist 95 (3): 737-742. https://doi.org/10.1653/024.095.0324

Santschi F. 1921. Ponerinae, Dorylinae et quelques autres formicides néotropiques. Bulletin de la Société vaudoise des Sciences naturelles 54 (200): 81-103.

Santschi F. 1928. Sur quelques nouvelles fourmis du Brésil (Hym. Form.). Deutsche Entomologische Zeitschrift 1928: 414-416.

Schmidt C. 2013. Molecular phylogenetics of ponerine ants (Hymenoptera: Formicidae: Ponerinae). Zootaxa 3647 (2): 201-250. https://doi.org/10.11646/zootaxa.3647.2.1

Schmidt C.A. \& Shattuck S.O. 2014. The higher classification of the ant subfamily Ponerinae (Hymenoptera: Formicinae), with a review of ponerine ecology and behavior. Zootaxa 3817 (1): 1-242. https://doi.org/10.11646/zootaxa.3817.1.1

Smith C.R., Suarez A.V., Tsutsui N.D., Wittman S.E., Edmonds B., Freauff A. \& Tillberg C.V. 2011. Nutritional asymmetries are related to division of labor in a queenless ant. PLoS One 6 (8): 1-5. https://doi.org/10.1371/journal.pone.0024011

Tillberg C.V, Edmonds B., Freauff A., Hanisch P.E., Paris C., Smith C.R., Tsutsui N.D., Wills B.D., Wittman S.E. \& Suarez A.V. 2014. Foraging ecology of the tropical giant hunting ant Dinoponera australis (Hymenoptera : Formicidae ) - evaluating mechanisms for high abundance. Biotropica 46 (2): 229-237. https://doi.org/10.1111/btp.12097 
Tozetto L. \& Lattke J.E. 2020. Revealing male genital morphology in the giant ant genus Dinoponera with geometric morphometrics. Arthropod Structure and Development 57: 1-12.

https://doi.org/10.1016/j.asd.2020.100943

Vasconcellos A., Santana G.G. \& Souza A.K. 2004. Nest spacing and architecture, and swarming of males of Dinoponera quadriceps (Hymenoptera, Formicidae) in a remnant of the Atlantic Forest in Northeast Brazil. Brazilian Journal of Biology 64 (2): 357-362.

https://doi.org/10.1590/S1519-69842004000200022

Wheeler W.M. 1916. Ants collected in British Guiana by the expedition of the American Museum of Natural History during 1911. Bulletin of the American Museum of Natural History 35: 1-14.

Wheeler W.M. 1918. Ants collected in British Guiana by Mr. C. William Beebe. Journal of the New York Entomological Society 26 (1): 23-28.

Wilson E.O. 1955. A monographic revision of the ant genus Lasius. Bulletin of the Museum of Comparative Zoology at Harvard College 113: 1-201.

Wilson E. O. 2003. Pheidole in the New World. A Dominant, Hyperdiverse Ant Genus. Harvard University Press, Cambridge, MA.

Manuscript received: 28 February 2021

Manuscript accepted: 14 October 2021

Published on: 21 December 2021

Topic editor: Nesrine Akkari

Section editor: Gavin Broad

Desk editor: Danny Eibye-Jacobsen

Printed versions of all papers are also deposited in the libraries of the institutes that are members of the EJT consortium: Muséum national d'histoire naturelle, Paris, France; Meise Botanic Garden, Belgium; Royal Museum for Central Africa, Tervuren, Belgium; Royal Belgian Institute of Natural Sciences, Brussels, Belgium; Natural History Museum of Denmark, Copenhagen, Denmark; Naturalis Biodiversity Center, Leiden, the Netherlands; Museo Nacional de Ciencias Naturales-CSIC, Madrid, Spain; Real Jardín Botánico de Madrid CSIC, Spain; Zoological Research Museum Alexander Koenig, Bonn, Germany; National Museum, Prague, Czech Republic. 